\title{
Exploring the Role of the Rock and Water Programme in the Improvement of Māori and Pasifika Boys' Engagement
}

\author{
with School.
}

Andrew McMillan

300153975

A thesis submitted in fulfillment of the requirement of the Degree of Masters of Education 


\begin{abstract}
The aim of this study is to explore boys' achievement within a New Zealand secondary school. More specifically the focus of this research has been to look at the impact that an intervention programme - Rock and Water, has in improving boys' engagement within a school.
\end{abstract}

This study has explored how school engagement is defined and how it has an effect on boys. This research looked at how the school experience differs for Māori and Pasifika boys. Using secondary sources of data, this study examined how education fits within society as a form of social control and has attempted to position the school experience within containment theory. Factors considered were the dynamics within these programmes and the role teachers' play in improving engagement.

This research has specifically identified how intervention programmes might be used as a tool with schools pedagogy to raise Māori and Pasifika boys' participation and engagement with school.

A qualitative methodology was employed for this research, focusing on one New Zealand College. Primary sources of data were student questionnaires and individual student interviews. Questionnaires and interviews were also carried out with two of the teachers/facilitators delivering the programme.

This study found that student engagement was improved as a consequence of their participation in the Rock and Water programme. For Māori boys, the opportunity to have fun and to connect with their peers was significant and identified by the participants in this study. For Pasifika boys, the results were mixed, those participating enjoyed it and said that it improved their engagement with school, the reasons behind why were not revealed in significant detail for this group. The pedagogies incorporated in the intervention programme (Rock and Water) had similarity with those advocated as part of Te Kōtahitanga. The weaving of Maori tikanga such as Ako, Manaakitanga and cultural performance helped in 
creating an environment whereby the boys participating were valued as being culturally located.

For the teacher/facilitators, the initial aim of participating in the Rock and Water programme was to introduce an intervention that addressed issues of behaviour management. However as the programme grew in popularity and a space was created within the curriculum, the teacher/facilitators commented on the changing dynamic within the group. An identity based around shared values and experiences in the group was evolving. Over time this was utilised to promote participants into tuākana roles. Similarly, the embedding of the Rock and Water into the school curriculum led to it becoming part of the schools kaupapa or vision.

Future challenges based on this study are to examine in greater detail the impact that the programme has in improving academic outcomes for Māori and Pasifika boys. The link between improved engagement and achievement is implied in participant responses, but quantitative data was not produced or explored due to the methodology chosen. 


\section{Acknowledgements}

I would like to acknowledge and thank my wife Shona and my son Angus for their support and Aroha during my study.

To the students and teachers that participated in this study completing questionnaires and taking part in interviews. Thank you for your time, insight and honesty.

I would like to thank those who have supported the work on boys' education at Mana. To Scott McIntosh, Simon Stott, Jeff Chapman and Todd Parata, Ka Pai. YNWA

I would like to thank my research supervisor, Dr Cherie Chu for her wisdom, support and advice. I could not have completed this without her guidance.

Rock and Water Whakatauki

Te toka tūmoana,

Ka tū, ka tū, ka tū.

Ahakoa i āwhātia mai te rangi

Whakapākākātia i te whitinga o te rā,

Te toka tūmoana,

Ka tū, ka tū, ka tū.

The rock stands in the sea,

Stands, stands, stands.

Although the weather may be stormy

And the rock may be roasted by the sun,

The rock stands in the sea,

Stands, stands, stands.

Source: Ngapuhi 


\section{Table of Contents}

Abstract

Pg. 2

Acknowledgements

Pg. 4

Table of contents

Pg. 5

Glossary of Terms

Pg. 9

Chapter One: Research problem and rationale

Pg.10

Introduction

Pg.10

The Research Problem

Pg.14

Research aim and Questions

Pg.17

Aim

Pg. 17

Research Questions

Pg.17

Chapter Two: Literature Review

Pg. 18

Introduction

Pg.18

Gaps in the Literature

Pg.18

What is Meant by Engagement

Pg.22

The Affective Dimension

Pg.22

The Behavioural Dimension

Pg.23

The Cognitive Dimension

Pg.23

Social Control Theory

Pg.25

Outer Containment

Pg.26

Achievement Trends for Boys.

Pg.29 
What is being done to influence student engagement for students from

indigenous backgrounds, Māori and Pasifika boys in New Zealand? Pg.31

$\begin{array}{ll}\text { How is student engagement measured? } & \text { Pg.36 }\end{array}$

$\begin{array}{ll}\text { Student Achievement in New Zealand } & \text { Pg.39 }\end{array}$

$\begin{array}{ll}\text { Summary } & \text { Pg.47 }\end{array}$

$\begin{array}{ll}\text { Chapter Three: Methodology } & \text { Pg. } 48\end{array}$

$\begin{array}{ll}\text { Introduction } & \text { Pg.48 }\end{array}$

$\begin{array}{ll}\text { The Research Paradigm } & \text { Pg.48 }\end{array}$

$\begin{array}{ll}\text { Research Method } & \text { Pg.50 }\end{array}$

$\begin{array}{ll}\text { Data Collection } & \text { Pg.53 }\end{array}$

$\begin{array}{ll}\text { Research Timeline } & \text { Pg.54 }\end{array}$

$\begin{array}{ll}\text { The Questionnaire } & \text { Pg.55 }\end{array}$

$\begin{array}{ll}\text { In Depth Interviews with the Students } & \text { Pg.56 }\end{array}$

$\begin{array}{ll}\text { In Depth Interviews with Teachers/Facilitators } & \text { Pg.58 }\end{array}$

$\begin{array}{ll}\text { Data Analysis } & \text { Pg.58 }\end{array}$

$\begin{array}{ll}\text { Challenges for the Study } & \text { Pg.59 }\end{array}$

Chapter Four: Description of the Rock and Water Programme Pg. 61

$\begin{array}{ll}\text { Sessions } & \text { Pg.62 }\end{array}$

$\begin{array}{ll}\text { Rock and Water salute } & \text { Pg.63 }\end{array}$

$\begin{array}{ll}\text { The Rock and Water Attitude } & \text { Pg.63 }\end{array}$

Rock and Water Themes $\quad$ Pg. 64

$\begin{array}{ll}\text { Chapter Five: Findings } & \text { Pg. } 67\end{array}$ 
Student Responses

Pg.67

School engagement

Pg.68

Participation in School

Pg.72

Teacher/Facilitator Responses

Pg.76

Interview Findings

Pg.82

Engagement

Pg.83

Relationships

Pg.84

Connectedness

Pg.86

Fun

Pg.87

Trust

Pg.88

Ako: Shared or Reciprocal Learning

Pg.89

Te Kōtahitanga

Pg.90

Contextual Learning

Pg.91

Manhood

Pg.92

Role Modelling

Pg.93

Chapter Six: Discussion of Findings

Pg.95

Chapter Seven: Conclusions and Recommendations

Pg.107

References

Pg.117

Appendix 2: Interview questions (students)

Pg.126

Appendix 2a: Facilitator A, semi structured interview questions

$\operatorname{Pg} .127$

Appendix 2b: Facilitator B, semi structured interview questions

Pg.129 


\section{Glossary of Terms}

\section{Te Kōtahitanga}

"A collaborative response towards a commonly held vision, goal, purpose or outcome". In the context of this study "teachers and students separately and collaboratively promote, monitor and reflect on outcomes that in turn lead to improvements in educational outcomes for Māori students”.

Bishop, Berryman, Cavanagh \& Teddy (2007, p. 30)

\section{Manaakitanga}

Caring for the individual, caring for the group. The task of "building and nurturing a supportive and loving environment for all students where students can be themselves".

Bishop, Berryman, Cavanagh \& Teddy (2007, p. 28)

Ako

The concept of ako describes a teaching learning relationship, where the educator is also learning from the student. Ako is grounded in the principal or reciprocity and also recognises that the learner and whanau cannot be separated.

Ka Hikitia (2008, P.20)

\section{Tikanga}

Rule, plan method; custom, habit; anything normal or usual.

http://www.waitangi-tribunal.govt.nz/reports 


\title{
Kaupapa
}

"A collective vision". Bringing to the "centre and privileging indigenous values, attitudes and practices".

\author{
Tuhiwai-Smith (1999, p. 125)
}

\section{Tuākana tēina}

The tuākana tēina relationship, an integral part of traditional māori society, provides the model for buddy systems. An older or more expert tuākana helps and guides a younger or less expert tēina.

\section{$\underline{\text { http://tereomaori.tki.org.nz }}$}

\section{Taonga}

Gift, heirloom or treasure, any thing highly prized. 


\section{Chapter One: Research Problem and Rationale}

\section{Introduction}

Chapter one introduces the rationale and aims of this study. It outlines why the study is beneficial for the education of Māori and Pasifika boys. When using the term Pasifika in this research I am using the following definition:-

"Pasifika is a collective term used to refer to people of pacific heritage or ancestry who have migrated or been born in Aotearoa New Zealand. Pasifika include recent migrants or first, second and subsequent generations of New Zealand born Pasifika men, women and children of single or mixed heritages. They identify themselves with their indigenous Pacific countries of origin because of family and cultural connections with Samoa, Cook Islands, Tonga, Niue, Tokelau, Fiji, Solomon Islands, Tuvalu and other Pacific countries. Pasifika people are not homogenous and Pasifika does not refer to a single ethnicity, nationality, gender, language or culture." (Education Review Office, 2012, p. 6)

This research attempts to explore some of the issues surrounding Māori and Pasifika boys' engagement with school and suggest ways that this might be addressed. This study locates its research in a New Zealand context and looks at how a specific intervention may add to the body of knowledge around this issue.

My interest in this as a research topic relates to the school in which I work, the community in which I live and a desire to improve the opportunities for boys. The passion I have for boys' education has been driven by my involvement in raising the achievement of boys at the school in which I work. I started working here in 2003. At the time the school was suffering from a falling role, high truancy (internal and external), poor academic results and a negative perception in the local area. I chose to research Māori and Pasifika boys as they represent the largest ethnic groups within the school. Whilst they each have different identities, cultures and histories, I chose to look at how factors within the Rock and Water programme would impact on this group of students. There was also a practical consideration in that the 
majority of boys taking part in the programme identified themselves as being of Māori and Pasifika.

As a new migrant and new member of staff, I saw an opportunity to initiate a series of programmes that might help the students at the school, especially the boys. Working alongside a member of the Board of Trustees, we informally interviewed boys at the school as to their interests outside the school. Many of the boys were interested in outdoor pursuits such as fishing, diving, and hunting. From this we devised a programme where we would take a group of at risk boys in the outdoors and mentor them, teaching them skills that would help in their pursuits (fishing, diving and hunting skills). Over a period of time we expanded the focus of the programme to anger management and role modelling. This had an impact on behaviour management at the school and soon we had competition amongst the boys for places on our trips. At this point we reflected upon our successes and decided to incorporate an academic component. Participants could gain either junior college or NCEA level one credits for the activities either from the Physical Education (PE) curriculum or through the use of reflective journals English credits. It was at this point that I was allowed to go to the Boys' Education Conference in Melbourne in 2005.

Whilst at the conference I took part in a work shop on the Rock and Water programme delivered by Freek Ykema. The evidence from Australia and the Boys in Schools Action group at Newcastle (NSW) University suggested that this was having an impact there. I believed that this programme could be used at the school in which I teach. Upon my return I proposed it to the senior management but hit a road block related to funding.

The school in which I teach is in a low socio economic area with a high proportion of beneficiaries. Work opportunities are predominantly in the service sector. Work for many is part time, casual or nonexistent. This has led to the school being categorized as decile $2 \mathrm{a}$ (a decile is a $10 \%$ grouping.). A school's decile rating indicates the extent to which it draws its students from low socio-economic communities. Decile 1 schools are the $10 \%$ of schools with the highest proportion of students from low socio-economic communities, whereas decile 10 schools are the $10 \%$ of schools with the lowest proportion of these students. A 
decile does not indicate the overall socio-economic mix of the students attending a school or measure the standard of education delivered at a school. The indicator is based on census data for households with school-aged children in each school's catchment area (Ministry Of Education, 2012).

Upon hitting this financial road block, we had to think laterally. We decided to prevail with the initiative and tried to enlist other teaching staff and members of the community. They gave of their time and resources freely. The programme grew in size and popularity. As the finances of the school improved I was eventually allowed to undertake Rock and Water training.

Over the following years' new avenues of funding were sought. The school, with the help of the guidance team; gained funding from the Ministry of Youth Development to the point that five other staff members were trained up. These facilitators come from a variety of backgrounds in the school (Guidance, PE, Truancy and Science). Some have moved on and we currently have two facilitators in the school (myself and a female member of staff).

The training of a female facilitator is significant as the decision to start a girls group has been brought about as a consequence of the impact of the programme with boys. At the time of writing this thesis, the school has two classes operating for boys, one at Year 9 and one at Year 10. As a result of the programme running for a series of years, there are a number of senior boys who have been trained and can be used as tuākana teinna (these students have passed through the programme).

From relatively humble beginnings, the initiative is embedded in the school and forms one corner of a triangle of interventions aimed at improving the engagement and achievement of the boys at the school. The other two corners are the outdoor experiences, which have continued and attract a different group of boys and this year the introduction of the Duke of Edinburgh's Hillary award. I have always believed that while the Rock and Water programme is effective, it has been lacking a rationale from an academic stance. Therefore 
this study has looked at where Rock and Water sits within an educational pedagogy and what are the benefits of utilising it to improve the engagement of Māori and Pasifika boys.

\section{The Research Problem}

Over the last 40 years, a significant debate has been taking place within education over differences between male and female achievement in education. Boys have lagged behind girls in academic achievement in a number of developed countries (New Zealand, the United Kingdom, Australia, and the United States) and as a result there has been an increased focus on the achievement of boys. This focus is as much about perception as it is about the reality.

Boys' achievement and the possible causes, ignites passions in people and is a source of debate and speculation. To place the issue within a historical context, the issue of boys and their underachievement has been around for some time but has come to the fore since the mid 1990's. In 1996 the Office for Standards in Education (OFSTED) in the United Kingdom published The Gender Divide: Performance Differences Between Boys and Girls at School, focusing primarily on the increased visibility of boys lower exam scores than girls at General Certificate of Secondary Education. In New Zealand the Education Review Office (ERO) produced a publication on the Achievement of Boys in 1999. Since then a number of other reports have been published around this issue achievement (Federal Government of Australia 2002, Office for Standards in Education 2000, (OFSTED, 2003), (OFSTED, 2008)).

In 2007, The Ministry for Education published Education Counts reporting on student engagement in New Zealand schools. Using stand-down data as one of the indices of engagement, their research found that

“...72\% of stand-downs that occurred in 2007 were from male students, resulting in male students having an age-standardised stand-down rate 2.4 times that of female students." 
They also concluded that

"This difference between the genders has remained relatively constant over the last eight years" Ministry of Education (2007b, p. 7).

This evidence of a disparity between the engagement of our boys and girls within New Zealand schools needs further research Education Review Office (2007).

In 2008, the Education Review Office published a report entitled "Boys' Education: Good Practice in Secondary schools'. Findings were made from this report that stated that a particular group of boys were generally at risk. The report stated that

"boys from lower socio-economic backgrounds, and Māori and Pacific boys, are among the lowest performing groups of students in New Zealand" (Education Review Office, 2008, p. 5).

When data on school leavers was collated in 2006, Māori and Pasifika males were more likely to leave school with little or no formal qualification than their peers.

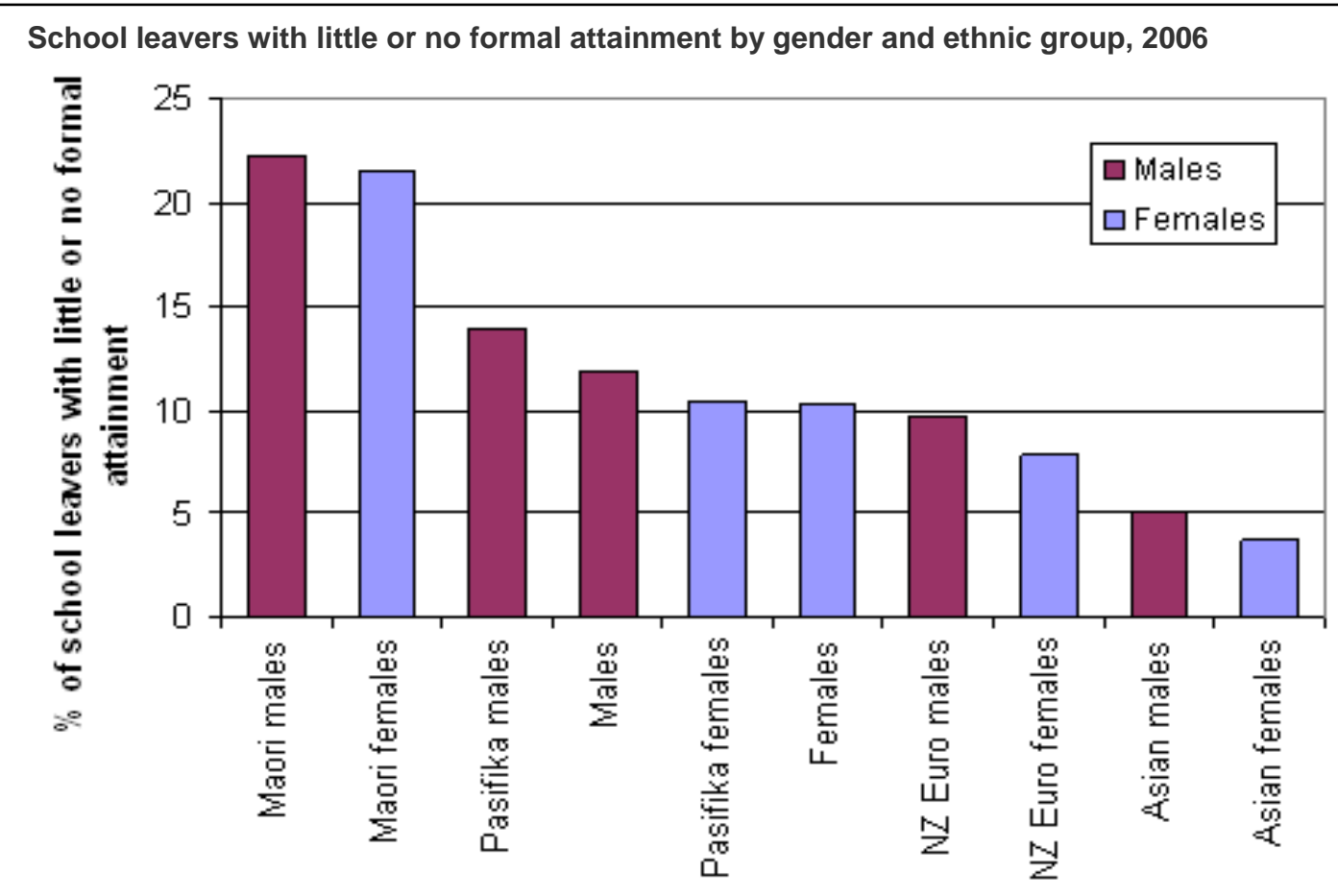

Source: (Ministry of Education, 2007a, p. 41) 
From the data presented in this chart, evidence can be found to support the idea that regardless of ethnicity, boys are more likely to leave school with little or no formal qualifications. Māori and Pasifika boys are most at risk. The challenge was to look at the reasons or factors behind these facts.

In 2001, Alton-Lee and Praat looked at the causes of differences in achievement between genders in New Zealand schools. They concluded that there were a number of competing factors as to the causes, with ethnicity and social class significant in explaining differences in achievement. The aim of this study is to look at differences in achievement for boys and take engagement as a causal factor. With that as a starting point, this study will look at the factors that affect achievement when ethnicity and gender collide.

The issue of Māori and Pasifika boys' engagement with school and their subsequent achievement is significant, in that I look at the effectiveness of an intervention employed at the school to address boys' engagement.

The theoretical framework for this research was based around that of phenomenology (Edmund Husserl 1859-1932). In explaining boys' engagement with high school, I examine their life worlds within the education system. I examine how their involvement with Rock and Water affects their experience of school. In the context of the school Socio-economic lass is similar for all students (I work in a decile two school) and the ethnicity of the school is predominately Māori (65\%)with Pasifika(27\%) the next major group and Pakeha (8\%) students a minority group within the school. 


\title{
Research aim and Questions
}

\begin{abstract}
Aim
The aim of this research is to provide teachers and facilitators with strategies to improve the engagement of Māori and Pasifika boys with school. This study investigates some of the reasons behind boys' disengagement and provides evidence from the Rock and Water programme of ways to work collaboratively with these students.
\end{abstract}

\section{Research Questions}

The main question of this study is:

How does the Rock and Water programme improve the engagement of Māori and Pasifika boys with school?

In exploring this question the following themes are examined

1. What is meant by engagement?

2. What are the trends for boys in the developed world?

3. What is being done to address boys' dis-engagement with school?

4. Where are specialist boys programmes positioned within this debate?

5. How is this affecting boys' from indigenous backgrounds, Māori and Pasifika boys in New Zealand?

6. Is there a sub text to the issue of boys' engagement and boys' programmes? 


\section{Chapter Two: Literature Review}

\section{Introduction}

This literature review will look at how the issue of boys' engagement with school has become 'contested space' in education. That is to suggest that a "space where cultures clash and grapple with each other in context of highly asymmetrical relations of power, such as colonialism, slavery or the aftermath as they are lived out in many parts of the world today" (Pratt, 1991, p. 34) The concept of engagement is also discussed. It examines whether there is a wider societal role being undertaken by schools and will look at how schools are addressing the needs of Māori and Pasifika boys.

\section{Gaps in the Literature}

There have been many studies about the impact of intervention programmes for boys overseas in the United States, United Kingdom, and Australia. However, there are no comparable studies in New Zealand. Instead in New Zealand, studies have been carried out to look at differences in achievement between genders (Alton-Lee \& Praat, 2000) and look at the factors influencing the development of boys (Lashlie, 2004). Evans (2011) examined the factors affecting the achievement of Pacific island students. But very little is known about the impact of intervention programmes and how these improve student engagement.

In the United States, intervention programmes for boys have been used to create a space in which issues of identity and belonging are addressed. One such intervention is described by Hall (1991, p. 13) who outlines how in 1984, a group known as Simba Wachanga (young lions) was set up in Cleveland Ohio. This intervention was as an attempt to improve the engagement of young African American males with school.

Hall argued that in traditional African society "Education was a social process, as opposed to the "west's focus on individualization". He seemed to suggest that for young African American males, school was alienating them and that the development of a group identity might have an effect on those young men. 
This might be considered romanticism and based on a utopian gaze, but the attempt to locate issues of boys' engagement with school and society within a cultural context should not be dismissed. The intervention of Simba Wachanga, worked on removing the boys from classes and working with them on issues of manhood, belonging, masculinity and identity. This is an example of one of many interventions in the United States aimed at improving the engagement of boys from different ethnicities with school. It illustrates an approach that tries to recognize the boys as culturally located individuals within a mono cultural process of education. It also recognises the impact that gender plays within in the engagement debate.

In Australia, there has been an attempt to position the issue of boys' engagement with school within a wider debate based around the construction of the curriculum. Newcastle University's (New South Wales) 'boys in schools' programme has been the focus for initiatives and interventions aimed at exploring the 'way' boys learn as well as how specific programmes can be used to improve engagement. Browne \& Fletcher (1995, p. 4) looked at the role of relationships within boys education. They found that as boys grow older the influence of their parents diminishes and the influence of peers and wider societal forces increases. They argued that the role of the school is significant in that they are the "shaping grounds". Within these shaping grounds "constructions of masculinity are shaped and reinforced daily" (Pg. 225). They suggest that two important influences on boys' behaviour are successful role models in school and the dominant cultural forms of masculinity in society. Using a model to demonstrate the social construction of masculinity (see Figure 1. Page 17), they argued that schools can be agents of change through intervention points. This research argues that the intervention used in this context, the Rock and Water programme can be seen as the vehicle of change. 


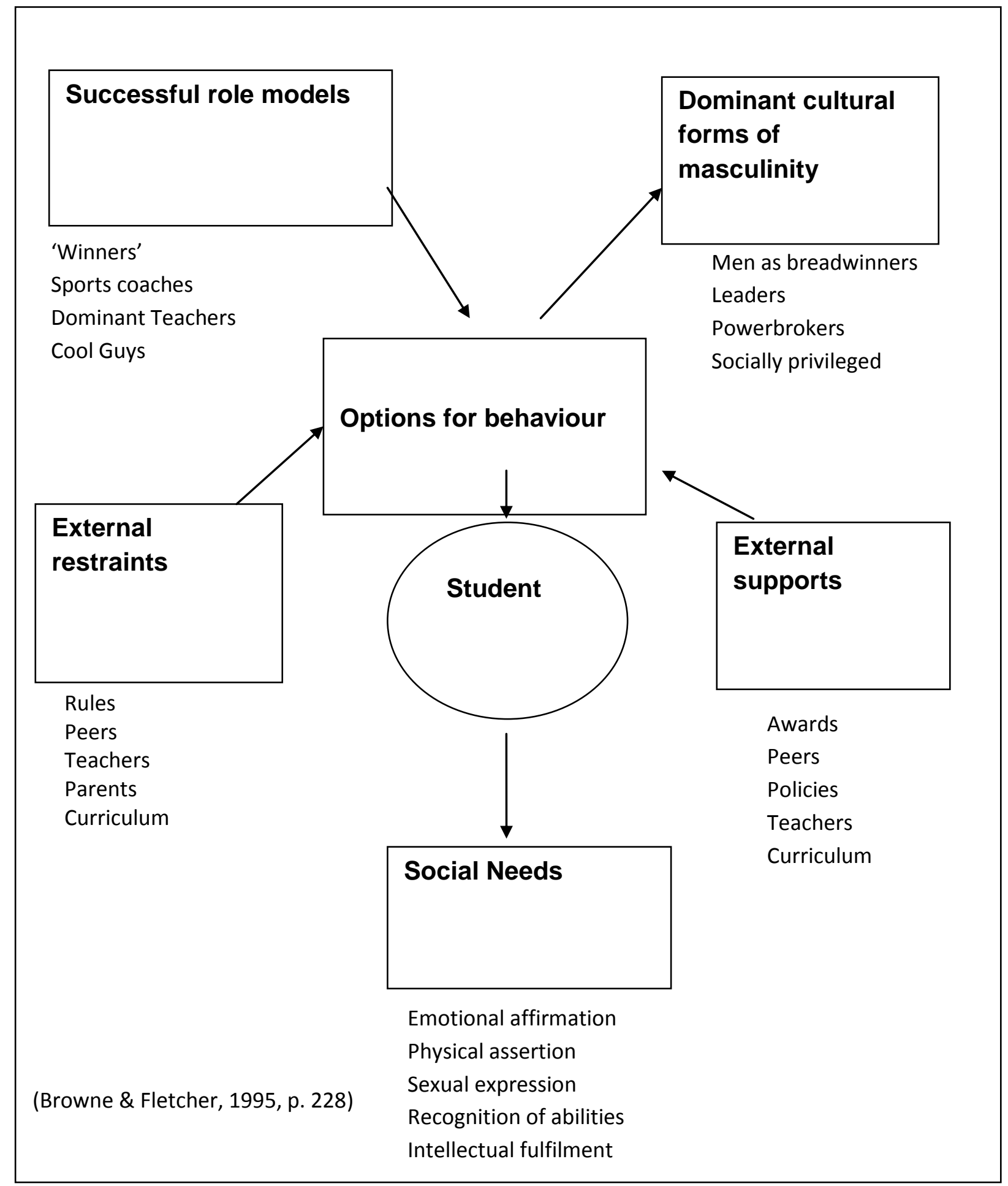

Figure 1 
Browne \& Fletcher (1995, p. 223) have suggested that

"Boys reassess when they have experienced alternative ways of getting their needs met. Suitable opportunities for boys to develop such awareness can come through schools running small group programs for boys".

This viewpoint is not without criticism and one concern they suggest is that parents and teachers need to address the way masculinity is shaped in schools.

Zoe Gill takes up this point with her critique of state sponsored studies into boys' perceived underachievement. Gill argues that the debate should focus on the issue of 'hegemonic masculinity' in society. Her assertion is that "differences between boys and girls need to be located in a social context" Gill (2005, p. 107). The suggestion here being that Australian society has been constructed in such a way that there is a gender order and that the 'patriarchal dividend' disadvantages boys and girls. Her argument suggests that the debate around boys' engagement and achievement is in part "fuelled largely by concerns articulated within the "mythopoetic men's movement' or recuperative masculinity politics" (Pg.107).

It is suggested by Gill (2005) that the reasons for these concerns being the gains made by the feminist movement of the latter $20^{\text {th }}$ century. She argues that this has led to claims that men and boys are the "new victims". One way in which the issue of masculinity within the Australian education system is being addressed as a response to the perception of boys as 'victims' is the call for changes to the sex discrimination act in an attempt to encourage more male role models in Australian schools (Gill, 2005).

From the evidence provided above, the issue of boys' engagement with school is being approached from a number of different ideological and philosophical positions. Before this study can critique these positions, the notion of engagement and how it impacts on Māori and Pasifika boys in education should be examined. My study provides a vehicle for this. A review of existing thought will be examined and this review will attempt to uncover a variety of themes. 


\section{What is Meant by Engagement?}

In exploring the issue of engagement, the term can be value laden. In the context of education, it could be argued when defining engagement, it is referring to

"The extent to which students identify and value schooling outcomes, and participate in academic and non-academic activities.” OECD/PISA (2000, Pg. 8).

This definition usually “comprises a psychological component pertaining to students' sense of belonging at school and acceptance of school values, and a behavioural component pertaining to participation in school activities" (Finn, 1989, 1993; Finn and Rock, 1997; Goodenow, 1993; Goodenow and Grady, 1993; Voelkl, 1995, 1996, 1997; Wehlage et al., 1989).

The psychological component emphasizes students" "sense of belonging or attachment to school, which has to do with feelings of being accepted and valued by their peers, and by others at their school” OECD/PISA (2000, Pg. 8).

In delving deeper into engagement as a construct, Jimerson, Campos \& Greif (2003) argue that student engagement has three dimensions, affective dimensions, behavioural dimensions and cognitive dimensions.

\section{The Affective Dimension}

This relates to the role of students' affect in schools and classrooms. This dimension is also referred to emotional engagement by Yonezawa, Jones \& Joselowsky (2009) and concerns the extent to which students feel connected to the school and have a sense of belonging. This dimension covers aspects such as interest, boredom, happiness, sadness and anxiety (Fredericks, Blumenfeld, \& Paris, 2004).

One argument put forward in this thesis is that programmes that increase school connectedness can increase school engagement and achievement. Blum \& Libbey (2004, p. 232) argue in support of this by stating that "Increased school connectedness correlated with educational motivation, classroom engagement and better attendance, which in turn were 
linked to higher academic achievement".

\section{The Behavioural Dimension}

This dimension looks at observable actions or performance, defining engagement as positive actions or conduct, perseverance and participation in school or extra- curricular related activities such as sports teams or school clubs, student performance such as grades, homework completed or achievement in assessments. It also defined the 'avoidance of unruly behaviour' as an indicator of engagement (Yonezawa, et al., 2009).

\section{The Cognitive Dimension}

The cognitive dimension includes students' perceptions and beliefs related to self, school, teachers of peers (Jimerson, et al., 2003). This dimension refers to the investment that students put into learning and mastering concepts, knowledge and skills. Students achieve through their construction of meaning and their production of knowledge. Accordingly they use inquiry to construct meaning and produce discourse, products and performances that have meaning beyond the school (Newmann \& Wehlage, 1993). This last criterion has validity when looking at the place of programmes such as Rock and Water within and outside the school environment.

These elements are not mutually exclusive and overlap one another. The level to which a student participates in each of the elements will provide an indicator of their level of school engagement. Yonezawa, et al $(2009$, p. 8) argue that research to date has evolved from a 'unidimensional' approach, seeing each dimension or component in isolation towards a 'multidimensional' approach, looking at how each dimension interrelates. The assertion here being that this will lead to more empirical data, supporting the claim that "improving student engagement improves students academic achievement" Yonezawa, et al (2009, p. 9).

In building a case for the effect that the Rock and Water programme has in improving Māori and Pasifika boys' engagement, I argue that the programme contains components from all three dimensions and that its primary impact is evident in the cognitive dimensions. Student engagement is however a multi faceted construct and requires anchoring with in a New 
Zealand context. One aspect that should be explored with regard to boys' engagement with school is that of belonging. This factor can be observed in all three dimensions.

The psychological aspect of engagement that students articulate as participants in education has been explored by Bishop, Berryman, Cavanagh \& Teddy (2007) and relates to the students sense of connectedness and their sense of belonging with the school. A critical component in this is their relationship with the teaching staff.

Bishop (2007) argues that as part of the Te Kōtahitanga initiative,

"Students who have good relationships with their teachers are able to thrive at school. Good relationships are based on teachers caring for them as culturally located individuals" Pg. 18.

That is to say that they are of their culture and that their culture and its practices are valued in the construction and production of knowledge. This could be seen as evidence of the multidimensional approach with an overlap between the affective, behavioural and cognitive dimension of Jimerson, et al's (2003) engagement model within a New Zealand context.

In examining the issues of engagement within middle schooling Gibbs \& Poskitt (2010) reported that seven factors were combined to influence student engagement. These factors have commonality with Jimerson's model. These factors are:-

- Connectedness/sense of belonging to school

- Sense of agency involvement, effort, commitment, and concentration

- Motivation and interest in learning

- $\quad$ Sense of self efficacy

- Orientation to achievement and performance

- Self-regulatory processes and skills

One model that can be used to explain student engagement with school is that of the 'participation- identification model (Finn, 1989). Finn's argument is that students have to 'bond' with school. They have to make a connection with the school whether it is for social, academic or cultural reasons. If this does not occur, the greater the likelihood the student will display problem behaviours and will leave the education system before graduation. 
In an examination of students' motivation to attend school, one can make the distinction between school as a place of academic endeavour and school as a place for social interaction. Firestone (1987, p. 288) argues that:

"Students identified two variables when attending school; the variables being commitment to learning and commitment to 'the place'. Students identified reasons for coming to school as an opportunity to be with their friends and where they find activities other than educational ones to keep them occupied".

If it is accepted that student's motivation to attend school may differ from that of educators, then one has to consider how a school forms part of the fabric of a wider society. What role do schools have as a form of social control over students, how does it exert influence over them emotionally, behaviourally and cognitively? If the school can be positioned within the wider society, then there can be an explanation of some of the reasons why students choose to disengage with school. To understand this fully, an understanding of social control theory has to be gained.

\section{Social Control Theory}

Social control theory is based around the idea that individuals conform to the rules and expectations of society based upon common perceptions. These ideas, formulated in the 1960's, have currency for this thesis. The origins of social control theory are within the criminal justice system and look at how individuals conform within a society. Social control theory also looks at the factors influencing delinquency in society. The ideas and factors in some aspects of social control theory have been applied to education to explain student disengagement and delinquency. Indeed the factors that influence boys in middle schools in New Zealand those of self efficacy and self regulation are two areas in which social control theory might apply.

One theory that has currency for the issue of student engagement is that of containment theory. This theory, advocated by Walter Reckless in 1961 argues that the individual in 
society is influenced by two forms of control or 'containment'. These are inner and outer containment.

Inner containment is constructed around the idea that an individuals positive image of self will develop within the family unit by the age of 12 . Inner containment is used as a way of “ regulating anti-social or deviant behaviour by negotiation of what is socially acceptable measured against the values of the family" Reckless (1961, p. 45).

The challenge is who defines what is acceptable and in a multicultural society? Values and attitudes will vary from family to family. The case is made here for the inclusion of a culturally located approach. In building a relationship with the student, knowing of their family and cultural background and not being judgmental of it is an example of this.

It can be suggested that the family in the post modern society of $21^{\text {st }}$ century has many influences leading to a hybridity. Schools in attempting to improve the engagement of students and especially Māori and Pasifika boys have to be aware and responsive to this. This is illustrated by the second layer of social control. It is at this point that Reckless' second form of control comes into effect, that of outer containment.

\section{Outer Containment}

Should the individual choose not to conform to the perception of normality and conformity within the family unit, then Reckless (1961, p. 45) argues that the second strand of outer containment comes into effect. This is the influence that families or peers have on the individual through counselling or talking. Reckless argues that the inner containment is to protect the individual from deviance and that the outer containment is to keep society and individuals in line using societal structures as a buffer. Participation in education would be an example of this buffer in action and disengagement from the education process an example of individual deviate from society and pass through the strand of outer containment. This disengagement takes many forms but truancy, non compliance and early leaving would 
be examples in a school context. Indeed Reckless (1961, p. 43) cites the membership of gangs and drug use as examples of this deviancy.

There are a number of factors that need to be accounted for when applying this idea. For inner containment to work, the individual has to have a favourable impression of themselves in comparison to other members of the family. Reckless argues that

"One must have very strong morals and ethics and must be goal orientated and focused". (Pg.45)

The assertion here is that these qualities will help the individual hold up under pressure from the outside world and handle frustration and adversity.

The strength of outer containment is that it provides scope for the individual to view themselves as part of a larger context. In comparison to themselves, the community or wider society is much larger. One of the strengths and weaknesses of outer containment is the extent to which individuals in wider society adopt roles and responsibilities.

In explaining the move towards delinquent or deviant behaviour, (Reckless, 1961) argues that individuals are influenced by pushes and pulls. These factors push or pull the individual towards non conformity or disengagement with society. Using gang membership as an example of non conformity and disengagement, the argument is that the push towards gang membership is the influence placed upon the individual to join by their peers. The pull factor is the chance to gain status and easy reward through deviant behaviour. Reckless also identifies family conflict, aggression in the household, boredom, racism and socio economic problems as push factors. In the context of student engagement, these push and pull factors are all valid reasons for student disengagement. These factors can be linked to the school as a hybrid space in which individuals have multiple identities and multiple roles and one can see that containment theory fits nicely into a rationale for student engagement or disengagement with school. In the context of the school in which I teach, students have to negotiate these hybrid spaces on a daily and in some instances hourly basis. The pushes and pulls of Reckless' model challenge the student and the school as the boys defines their identity to and in relation to 'others'. 
Joselowsky (2007, p. 257) argues that

"Many young people in high school are bored or have no opportunities for experiential learning or civic action (civic education, service learning or other approaches), and have limited opportunities for extracurricular activities. The challenge, then, is to create a vision of schools, especially middle and high schools, in which students' learning and growth is supported in the context of their lives and interests".

In supporting this statement, schools that seek to engage with students beyond the traditional classroom are relating to the life worlds of the students and the communities that they live in. Schools should be embedded within communities and reflect the communities' aspirations and needs, rather than being fortresses into which students are 'parachuted' for part of their day. The context in which schools conduct their practice is as important as the curriculum content that schools deliver.

Another factor of the psychological argument to student engagement centres on whether or not students value school success - do they believe that education will benefit them personally and economically? (Johnson et al., 2001). Students who do not feel they belong at school, or reject school values, are often referred to as alienated or disaffected. The participation component of engagement is characterised by factors such as school and class attendance, being prepared for class, completing homework, attending lessons, and being involved in extra-curricular sports or hobby clubs. One way in which one can delve deeper into this issue is to look at these differences based upon gender. It has been of some concern that the issue of academic gaps (as mentioned in Chapter One) between boys and girls has been taking place for some time in New Zealand. 


\section{Achievement Trends for Boys.}

The theme of gaps in academic performance between male and female students has been the source of much debate and speculation over the last 40 years. The issue of boys' underachievement has come to the fore since the mid 1990's. In 1996 the Office for Standards in Education (OFSTED) published The Gender Divide: Performance Differences between Boys and Girls at School. This report focused primarily on the increased visibility of boys lower exam scores than girls at General Certificate of Secondary Education. In New Zealand the Education Review Office (ERO) produced a publication on the Achievement of Boys in 1999. Since then a number of other reports have been published around this issue House of Representatives (2002), Office for Standards in Education (2003), Education Review Office (2007).

The finding of each of these reports was that boys are achieving at a lower rate than girls in the three countries identified (UK/NZ \& Australia). If college completion rates were chosen as indicative of this trend in New Zealand then the gap was as much as 27\% (OECD/PISA, 2006). From this information the issue of boys' academic achievement was becoming a source of some concern.

Theories abound as to the contributing factors of boys' achievement. In New Zealand, some suggested causes revolve around levels of literacy amongst students and of disengagement with school (Learning Policy Frameworks, Ministry of Education, December 2007). Taking the theme of disengagement from school as a significant factor, this thesis will be exploring the effectiveness of a specialist boys' programme at addressing boys' engagement with school.

If academic performance is chosen as an indicator of achievement, then gaps between boys and girls are evident. A factor in academic performance that could be used is that of literacy. Using literacy as an indicator of academic performance is one way of finding evidence to support this. In support of this statement, literacy, it can be argued, is a good indicator in that it provides a 'bridge' or 'gateway' to other subjects. Using New Zealand as a case study, "girls are more likely to gain the literacy requirement for National Certificate of Educational Achievement level 1and to gain English as a subject at all NCEA levels and 
scholarship' (Ministry of Education 2007). In NZ, the gap between boys and girls attaining NCEA level 1 in 2010 stands at 10\% nationally (New Zealand Qualifications Authority 2010).

Reports produced for the Education Review Office (2007) state that

"Gender gaps in reading are in favour of girls are present in New Zealand. There is also evidence that boys do less well in reading"

Education Review Office (2007, P.5).

This pattern is replicated in some of the other nations that reflect a similar education system to New Zealand, Australia, the United States and the United Kingdom for example.

In the UK ,the academic gap between boys and girls stood at 9.5 percentage points at Key Stage three (NZ equivalent Year 10) and 7 percentage points at Key stage four (NCEA Level 1) (Times Educational Supplement 2010). In explaining this, the UK education system is based upon student assessment at key points in their schooling. These correlate with transitions in the students' academic life. Key stage two is aligned with the end of primary education in NZ. Key stage three as the student leaves year ten and enters GCSE (NZ equivalent NCEA level 1) which is defined as key stage four. In terms of the statistics, the difference between boys and girls at the two key stages identified above is the equivalent to one full grade lower. GCSE is graded $\mathrm{A}^{*}$ to $\mathrm{G}$ with grade $\mathrm{C}$ being the benchmark for used by most secondary schools as a sign of success.

Literacy is not the only indicator of academic performance that could be is chosen. If college completion rates are used as an indicator, the gap between boys and girls is some $27 \%$ in NZ, the largest gap in the OECD (OECD/PISA, 2006).

It would appear that this pattern is being replicated in countries with similar education systems to New Zealand.In Australia, there is evidence to suggest that skewed subject choices and lower retention rates are ways in which boys academic underachievement is represented (Collins, Kenway, \& McLeod, 2000). 
In the USA the tone is one of 'rescuing' boys from a feminised curriculum (Gurian, 1998), arguing that the focus of research should be directed towards 'rescuing' boys and developing curricular that is sensitive to the needs of boys. In Europe there have been similar concerns to the issue although the tone is more measured with girls outperforming boys at baccalaureate in France, In Germany girls are repeating classes less often and in Belgium reports suggesting that amongst boys there is a culture that is less 'study orientated'. In Sweden the concern was that boys were less interested in democratic values and were "more attracted to anti-democratic ideals". Here the focus was less on academic performance and more on developing social competence and democratic understanding (Younger \& Warrington, 2005).

\section{What is being done to influence student engagement for students from indigenous backgrounds, Māori and Pasifika boys in New Zealand?}

In New Zealand the focus has shifted towards the experiences of Maori and Pasifika students within the schooling system. There have been a number of competing claims as to why students from Maori backgrounds do less well than their counterparts in the education system in New Zealand. Data suggests that Māori students achieve at a lower level than Pakeha students.

If the percentage of students leaving school without qualifications is used as an example, over the period 1991 - 2009 the figures stood at Europeans 31\%, Māori 58\% and Pasifika students 56\%. In 2001 the gap had narrowed a little with Europeans 25\%, Māori 43\% and Pasifika students making the largest net gain at 34\%. By 2009 the gap stood at Europeans 26\%, Māori 40\% and Pasifika students at 45\% (Statistics New Zealand Household Labour Force Survey).

In 1997, the Chapple Report concluded that the differences in achievement for Māori students compared with non-Māori students was because of their socio-economic status rather than ethnicity and there was therefore nothing significant about 'being Māori' that affected education success (Ministry Of Education, 2009a). 
This viewpoint would fit within an environmentally determining opinion that students are conditioned or shaped by their surroundings. One could argue that this provides some evidence for the arguments of Reckless (1961), in that for students to engage and achieve at a high(er) level, conditions need to improve within the backgrounds from which they originate. This argument is persuasive and positions the school as just one factor amongst many competing to improve the life chances of the individual. It could also be used as a convenient apology for the many hurdles that Māori students have to face within a dominant Pakeha culture. Some in education even suggesting " It's their background, what can we do?" (Ministry Of Education, 2009a). This viewpoint was challenged in 2007 when further analysis of the data in Chapple's report was undertaken. The conclusions here, using the original data was that "controlling for both socio-economic status and prior attainment reduces, but does not eliminate, significant differences between the four ethnic groups" (Ministry Of Education, 2009a).

In 2000, a report carried out for the Ministry of Education in New Zealand tried to explore some of the issues facing Māori and Pasifika student whilst looking at gender differences in the New Zealand school system. The report suggested:

"That schooling actively stratifies student achievement by gender, although gender disparities are the least marked of disparities by school decile level and ethnicity. Poorer performance is evident for students from low decile schools and Pacific girls and boys. Māori students', and in particular Māori boys', achievement is much lower than overall means" Alton-Lee \& Praat (2000, p. 6).

The assertion here is that the New Zealand Curriculum was one factor in explaining the differences between boys and girls and then within this gender divide, there were factors influencing Māori and Pasifika achievement. To explain further, Alton- Lee and Praat suggest that:

"Variations in patterns of relatively higher male or female achievement relate to the gendered nature of curriculum itself. Boys achieve more highly in social studies, for example, while girls achieve more highly in literacy. Literacy and Arts are positioned as feminine and Science is positioned as masculine. The undervaluing of the feminine 
in our culture is evident in the boys' resistance to feminine areas of curriculum, and in the heteronormative constraints that police boys' behaviour"' (2000, p. 6).

Technology education provides a site where traditionally gendered curriculum divisions are confounded" (Alton-Lee \& Praat, 2000). This statement provides an interesting point of contact with one of the criticisms of boy's only programmes in that they produce a 'masculinised curriculum' Martino \& Berrill (2003, p. 105). The suggestion here being that recent attempts to address the issue of boys achievement are nothing more than a reaction to the attempts in the early 1980's to address girls under achievement especially in the area of the sciences and mathematics (girls can do anything).

Whilst these claims have currency, it could be argued that societal changes have impacted upon boys to a greater level. The increase in non nuclear family structures for example, being one way in which boys (and girls to a lesser level) lack male role models. The danger here is reverting back to the findings of Chapple's 1997 report and suggesting that nothing can be done about it.

Alton Lee and Praat suggest that something can be done to address these gender differences and they point to the impact that teachers and education can have on the process. They suggest that:

"Education has been relegated to a low status position in our society, while also serving to stratify society, rather than to build diverse learning communities. The children of the middle classes are less likely to aspire to be primary teachers than once was the case. Unlike other countries, we consider our poorest qualified tertiary entrants to be the appropriate candidates for teaching — but not for law or medicine. It is timely that, as education has become re/positioned in economic theory as the potential powerhouse for building the knowledge society and a prosperous economy, then society should reflect upon the implications of the low status it has afforded the profession" (2000, p. 288).

Furthermore, the significance of the relationship between the student and the teacher was identified. Hattie (2003) suggested that teachers had a significant impact on a students 
engagement and achievement. His work looking at asTTle test scores suggested that there was no difference in achievement for Māori students in low and high decile schools. Hattie concluded from this data that it was not socio-economic differences that have the greatest effect on Māori student achievement. Instead, he suggested that:

"The evidence is pointing more to the relationships between teachers and Māori students as the major issue - it is a matter of cultural relationships not socio-economic resources', because these differences occur at all levels of socio-economic status" (Ministry Of Education, 2009a).

The implications for these findings mean that student achievement and student engagement can be shaped by the experience that students have when interacting with teachers and facilitators. As mentioned earlier in this thesis, schools environments fulfil many roles and the interactions that the individuals have whilst occupying this space is significant. Hattie suggests that when looking at student engagement we often look at the factors (variances) that surround the student and to use his metaphor we "try to find our wallet under a street light". He suggests that the variance or factor that has greatest impact is that of the teacher "the answer lies elsewhere, The answer lies elsewhere - it lies in the person who gently closes the classroom door and performs the teaching act -the person who puts into place the end effects of so many policies, who interprets these policies, and who is alone with students during their 15,000 hours of schooling." Hattie (2003, p. 3). The assertion here is that the relationship between teacher and student has a significant impact on student engagement and achievement. How the teacher negotiates the learning goals and direction of study with the student is shaped by their relationship. A power relationship exists but it has agency and can be negotiated or co constructed with the student dependent upon context.

In revisiting the impact that teachers have on student learning and engagement, the Ministry of Education commissioned Alton-Lee in 2003 to investigate what constitutes 'quality teaching'.

"Quality teaching is identified as a key influence on high quality outcomes for diverse students. The evidence reveals that up to $59 \%$ of variance in student performance is 
attributable to differences between teachers and classes, while up to almost $21 \%$, but generally less, is attributable to school level variables.

(2003, p. 5).

The suggestion is that diversity is the key to effecting improvement in student outcomes. The link is made that diversity relates to "Diversity encompasses many characteristics including ethnicity, socio-economic background, home language, gender, special needs, disability, and giftedness. Teaching needs to be responsive to diversity within ethnic groups, for example, diversity within Pakeha, Māori, Pasifika and Asian students. We also need to recognise the diversity within individual students influenced by intersections of gender, cultural heritage(s), socio-economic background, and talent.(Alton- Lee, 2003).

This approach would appear to be a seismic shift away from the ideas of the Chapple report of 1997, in that outside socio-economic factors influence student achievement and engagement. In this report, the stance is taken that any teacher equipped with a 'kete/basket' of quality teaching strategies (as outlined in this report) can significantly increase the achievement not only of some students but can raise the bar for all students. That for some the stigma of 'diversity' had been removed and now applied to all students. Thus it can be argued as a fundamental shift in educational strategy in New Zealand, where diversity is celebrated and planned for. The challenge for practioners is how to utilise this in a classroom of up to 30 students each with differing needs and abilities.

I digress, the BES quality teaching model can be embraced to improve student outcomes and one way in which this can be applied is in improving student engagement. For boys, there were some clear and achievable aspects to this; in divining what constitutes quality teaching one factor identified is that of "focusing on raising student achievement including social outcomes" Alton Lee (2003, p. 6).

A social outcome would be the engagement that boys have with their learning and with their school. Of the ten quality teaching characteristics outlined in the report, the third is the one that has most resonance for the Rock and Water programme. Effective links are created 
between school and other cultural contexts in which students are socialised, to facilitate learning.

Rock and Water works with students in a specific forum (the group) and within a specific context (ideas around male identity) to socialise boys to the expectation within the classroom and school environment. It does this by modelling, discussing and role playing specific situations that students may encounter or may initiate during their time in the school. The way in which these situations are discussed, negotiated, mediated and resolved in the group creates a social space for boys to shape and define their identity as males.

For a detailed description of the Rock and Water programme is provided in Pg 61.

If the relationship between the teacher and student is significant in improving engagement, how important then is the way that this relationship is fostered and nurtured? Increasingly in New Zealand this is being explored. The Ka Hikitia strategy (Ministry Of Education, 2009a) and the Te Kōtahitanga project (R. Bishop, Berryman, Tiakiwai, \& Richardson, 2003) are both aimed at introducing changes to the pedagogy of teachers to embrace the ways in which Māori students learn best.

In supporting these initiatives, the Rock and Water programme has relationships as the central focus. Respect for and towards different cultural practices or kaupapa are woven through all three programmes.

\section{How is student engagement measured?}

In this literature review engagement as a construct has been explored, but what are the objective indicators? Each year the Ministry of Education compiles data on student stand down and suspension rates. The annual report makes for interesting reading. They state "The majority of stand-downs occurred for students aged 13 to 15, accounting for $62.5 \%$ of all stand-downs. The peak was age 14 years, which had a rate of 84.1 students per 1,000 stand-downs." (Ministry Of Education, 2011). 
In the context of Rock and Water, the cohort of students involved range from Year's 9 to 11 (aged 14-16). This would be evidence that this programme is aimed at an at risk group.

Gender is a significant factor in student stand downs and suspensions with "Male students two-and-a-half times more likely to receive a stand-down, suspension or exclusion than their female counterparts" (Ministry Of Education, 2011). This is an increase from 2007 when male students were was only two times more likely to be stood down or suspended.(Ministry of Education, 2007b). If one look at the trend in stand down rates by ethnicity, Māori and Pasifika boys represent the largest group.

\begin{tabular}{|c|c|c|c|c|c|c|c|c|c|c|}
\hline \multirow{2}{*}{ Ethnic Group } & \multicolumn{10}{|l|}{ Years } \\
\hline & 2000 & 2001 & 2002 & 2003 & 2004 & 2005 & 2006 & 2007 & 2008 & 2009 \\
\hline Māori & 52.0 & 53.1 & 54.2 & 56.9 & 56.0 & 58.1 & 59.4 & 55.4 & 53.8 & 52.9 \\
\hline Pasifika & 32.1 & 31.9 & 35.6 & 36.4 & 36.5 & 41.1 & 44.8 & 37.4 & 33.7 & 35.4 \\
\hline Asian & 6.5 & 7.2 & 7.7 & 7.8 & 7.5 & 7.6 & 8.1 & 7.9 & 7.7 & 8.4 \\
\hline Other & 17.5 & 27.8 & 28.4 & 31.2 & 31.5 & 35.0 & 28.8 & 32.3 & 29.3 & 26.4 \\
\hline European/Pākehā & 19.3 & 18.3 & 18.1 & 20.0 & 20.4 & 21.5 & 22.0 & 20.9 & 20.7 & 20.2 \\
\hline Total & 26.0 & 25.9 & 26.4 & 28.3 & 28.5 & 30.3 & 31.2 & 29.2 & 28.4 & 28.2 \\
\hline
\end{tabular}

(Ministry Of Education, 2009b)

Schools are standing-down more Māori students than any other ethnic group. In 2009, the age-standardised stand-down rate for Māori students (52.9 students per 1,000) was 1.5 times higher than Pasifika (35.4 students per 1,000), and 2.6 times as high as European/Pākehā (20.2 students per 1,000). The stand-down rate for Asian students is the lowest of all ethnic groups. (Ministry Of Education, 2011). With echoes perhaps of the 1997 Chapple report, the 
tone is one of environmental determinism with the comment "There is a clear correlation between the socio-economic mix of the school the student attended and age-standardised stand-down rates. Schools in the lowest quintile (deciles 1 and 2) draw their students from communities with the highest degree of socio-economic disadvantage. Students from these schools are almost four times more likely to be stood-down from school than students in the highest quintile (deciles 9 and 10). On the face of it this source of data paints a bleak picture.

From this evidence Māori and Pasifika males are less likely to be engaged with school and are more likely to be stood down or suspended from school than their Pakeha or Asian counterparts. The evidence from this data being that if you live in a community that has a low socio economic status you are more likely to feature in stand down data. If a student is of Māori or Pasifika ethnicity the likelihood of being stood down in comparison to European or Asian students is higher. The reports produced annually by the Ministry of Education do highlight one positive aspect and that is that overall suspensions have reduced over the period " The incidence of suspensions has decreased by $16 \%$ over the last ten years, from an agestandardised rate of 7.9 students per 1,000 in 2000 , to 6.7 students per 1,000 in 2009 " (Ministry Of Education, 2011). This represents a shift away from suspensions as part of a behaviour management strategy. In the school that I teach, we have embraced restorative practices as part of our behaviour management a move away from a punitive approach.

However it is still a sobering fact that "Schools are suspending more Māori students than any other ethnic group. In 2009, the age-standardised suspension rate for Māori students (14.6 students per 1,000) was $82 \%$ higher than Pasifika (8.0 students per 1,000) and 3.6 times as high as European/Pākehā (4.1 students per 1,000). The suspension rate for Asian students is the lowest in New Zealand" (Ministry Of Education, 2011).

On the face of this evidence Maori and Pasifika boys are failing to engage with school if we use accepted definitions.

"The most important factor in student learning and personal development during college is student engagement, or the quality of effort students themselves devote to educationally purposeful activities that contribute directly to desired outcomes (Astin, 1993; Pascarella \& Terenzini, 1991). 
It is important to note the term here as there are a number of factors that influence student stand down and suspension rates, continual disobedience, violence and drugs are to name but three. How each school deals with these issues will vary dependent upon school policy. But it would be fair to suggest that a student involved in any of these activities is not engaged in fruitful and productive learning and thereby not engaged.

\section{Student Achievement in New Zealand}

The second criterion used in this thesis to gauge the level of engagement of Māori and Pasifika boys is that of achievement. Data provided by the Ministry of Education in New Zealand suggests that Māori and Pasifika boys are achieving at a lower level than their Pakeha or Asian contemporaries (Ministry of Education, Nov 2010a, Nov 2010b).

Breaking the data down into Māori boys first, the report states that "In 2009, 48 percent of year 11 Māori students gained an NCEA qualification at typical level or above. This compares to 69 percent of non-Māori” (Pg 2). This equates to a $21 \%$ gap between Maori and their contemporaries. If this gap between Pasifika students is compared to their peers the gap stands at $18 \%$ with a comparable $48 \%$ achieving as NCEA qualification but the overall achievement rate standing at $66 \%$. The discrepancy in the overall rate may be explaining by the inclusion of Māori students into the overall cohort. On the face of this data one can say that Pasifika students are doing better than their Māori counter parts. This disguises the fact that over half the Māori or Pasifika students taking NCEA level 1 at year 11 are not achieving (Ministry of Education, Nov 2010a, Nov 2010b).

When the data is broken down further and look at the difference between males and females a bleaker picture emerges. The percentage of Māori males achieving NCEA level 1 in 2009 stood at $45 \%$. The percentage of Pasifika males achieving was $42 \%$. In comparison to their peers by gender, $62 \%$ of non Pasifika males achieving NCEA level 1.

Further up the scale, NCEA levels a slight improvement in the picture of Māori and Pasifika male non achievement and engagement emerges with 50\% Māori males achieving NCEA 
level 2 in comparison to $64 \%$ of non Māori. At this point for Māori boys the gap falls to 14\% (Ministry Of Education, Nov 2010b). At NCEA level 3, the gap exposed at level one resumes with 29\% Māori boys achieving level 3 in comparison to 50\% of non Māori boys.

The overall trend for achievement for Māori boys over the year period (2007-2009) is upwards with Level 2 showing the greatest increase. However these rises are modest and should be placed within the context of the question "is the new Zealand schooling system delivering for Māori boys?" It is the assertion of this thesis that for significant numbers of boys the answer is no. The data for Pasifika boys shoes that at NCEA level $343 \%$ of Pasifika boys achieved level 2 compared to 64\% non Pasifika boys.

At Level 3 the figures stand at 24\% Pasifika boys gaining NCEA level 3 compared to $48 \%$ non-Pasifika. Whilst this data may hide the fact that a number of Pasifika may choose vocational pathways it is still staggering to think that over $75 \%$ of all Pasifika males entering year 13 fail to gain the level 3 qualification and almost 7 out of every 10 Māori boys in year 13 leave without gaining the qualification (Ministry of Education, Nov 2010a, Nov 2010b). Whist NCEA is a meritocracy and students gain the qualification based on the number of assessments achieved. It would be fair to suggest that for Māori and Pasifika boys that there are issues that need to be addressed.

At this point a case for an alternative viewing of the school experience for Māori and Pasifika boys needs to be made. A case is building that based on achievement of the NCEA qualifications framework in years 11, 12 and 13 or of stand downs and suspensions at Year's 9, 10 and 11, it is fair to say that boys, especially Māori and Pasifika boys are disproportionately or negatively represented. There are two other areas to explore when building this argument, those of college completion rates and then utilizing "Me and My schools" survey data.

College completion rates refer to the numbers of students completing Year 13 and leaving the state secondary school system. In New Zealand, " $84 \%$ of students remained at school to their 17th birthday. Retention rates have been gradually increasing since 2008. However, 
differences remain between girls and boys, and Māori and non-Māori’'(Ministry of Education, Aug 2011).

If we look at the data, a clearer picture emerges and one that shows some sign of optimism for Pasifika students. Pasifika students have the second highest retention rate of $87 \%$ and this may in some part be due to "...the importance that Pasifika families and communities place on their children staying in education"(Ministry of Education, Aug 2011). For Māori students the figure for retention is lowest. "In 2010, Māori students had the lowest proportion of students remaining at school to age 17 (70.3\%)" (Education, Aug 2011). Within both groups the trend is increasing (from 67\% in 2008 to $70.3 \%$ in 2010 for Māori students and from $85.4 \%$ to $87 \%$ for Pasifika students), for Māori students they still lag behind their peers. Overall, "Girls are more likely to stay at school till 17 than boys, $(86.1 \%$ compared to 81.4\%)" (Ministry of Education, Aug 2011) but there is no indication of the retention rates based on gender and ethnicity.

School decile is a contributing factor with higher decile schools able to retain a greater percentage of Māori and Pasifika students. 68\% of Māori students in decile 1 schools versus 84\% Māori retention in decile 5 schools. This correlates with data for retention of all students regardless of ethnicity and gender from $79 \%$ for decile 1 to $94.5 \%$ for decile 10 schools.

When retention in school is used as an indicator of student engagement, Māori boys fair worse than Pasifika boys, they are less likely to remain in school beyond the age of 17.

From the evidence provided so far Māori and Pasifika boys would be engaging with schools at a far lesser level than their Pakeha or Asian peers.

Each of the objective indicators used so far, stand down and suspension, NCEA achievement and retention (although Pasifika boys have a greater chance of staying at school) has shown that for Māori and Pasifika boys, school is somewhere where they have a higher change of being stood down or suspended will stand a lower chance of achieving and for Māori boys will leave before the age of 17. 
The impression gained from the data above would indicate that Māori and Pasifika students and more significantly boys achieve at lower rates than their peers. It could be argued that using these indices, centred on academic achievement; negates the validity and relevance of using a student centred approach to engagement. That is not the aim of this research. The data provided above provides and indication of the problem and the purpose of this research is to suggest how a student centred approach utilising rock and water can address this.

This does not paint a good image of the school experience for boys in New Zealand. One argument that could be put forward for Tangata Whenua and for colonised peoples such as those from the Pacific Islands is that the education system has been a construct of the coloniser.

Tuhiwai-Smith (1999, p. 64) argues that historically, the production of knowledge in education systems in colonized countries seeks to position the west as the centre of 'legitimate' knowledge thereby moving indigenous forms of knowing (worldview, cultural practice and belief system) to the margins. This is part of a strategy of constructing the colonized as an 'outsider' or 'other' to confirm the perceived superiority of the colonizer. She goes on to argue that

"School knowledge systems are linked by a comprehensive system of knowledge that links universities, scholarly societies with imperial views of culture". Schools have historically reproduced domesticated versions of knowledge for uncritical consumption" (1999, P.65).

From the data presented above, it is apparent that Maori and Pasifika boys are not fitting into this system well. Cotterell (2010, p. 223) argues that "educational practices have marginalised indigenous peoples around the globe". The argument here is that it has become something of an educational policy priority within New Zealand, Canada, Australia and the USA to close the educational gap between indigenous and non indigenous students. He also argues that there is a post colonial struggle currently going on within these four nations for the parents of indigenous children to regain control of their children's learning. 
In New Zealand this is evident with the growth and resurgence of Te Reo Māori (Māori language) in schools and the place that Kohanga Reo has in the current educational structure.

The implications for Māori and Pasifika boys are huge. Reflecting the diversity of students and catering for the diversity of educational and social needs that Māori and Pasifika boys have is one way in which the rock and water programme facilitates student engagement. A recognition of this diversity is not only a factor in catering to the needs of boys but also a key component on the quality teaching best evidence synthesis (Alton- Lee, 2003) .

The need for New Zealand to move away from a Eurocentric approach to education has led to "a demand to bring into modernity the voices and epistemologies of those whom Eurocentric colonialism sought to render invisible " Cotterell (2010, p. 224).

This argument is presented because initiatives developed in New Zealand have started addressing the need for a greater indigenous voice in the education system. I refer to the Te Kōtahitanga project and the Ka Hikitia project. Both of these initiatives have created a space in which the discourse around Māori and Pasifika engagement and achievement is being re visited. Rock and Water as a programme aimed at improving Māori and Pasifika boys' engagement with school would contribute to this debate.

To expand on this, Te Kōtahitanga (R. Bishop, et al., 2003) challenged the perception that Māori students were somehow pre disposed to fail based upon their socio-cultural backgrounds, it was a direct challenge to the Chapple report of 1993. This use of deficit theory appears as a common excuse for the poor educational outcomes of indigenous peoples in education. In a study of indigenous Australian students and successful strategies utilized to encourage them to stay in school, (Munns \& Parente, 2003) argue that retention rates for Aboriginal students in 1995 were 25\% compared with $75 \%$ for their non-indigenous peers. They argue that there has been a research focus on drop out and disaffection amongst indigenous peoples. The consequences of this has created a "conformist blindness' moving away from original research intentions, that was to look at strategies to encourage more students from minority background to remain in school. The suggestion here is that it is 
easier to be an apologist for wider societal factors as the cause of student disengagement than to look at engagement strategies.

In the New Zealand context, the deficit theory that relates either to the deficiencies of the participants or the need of the participants to change to 'improve' their experiences and chances within school emerged as an explanation/justification for Māori underachievement. Challenges to this stance have come about from (R. Bishop, et al., 2003) in the Te Kōtahitanga report, " they ignore Māori aspirations for the education of their children and also that they ignore the inherent power imbalances within the education system." R Bishop, et al (2003, p. 6). This would also appear to provide some justification for Cotterell (2010). Te Kōtahitanga recognised the role that teachers play in the process of education. It reflected on "the need for teachers to lift their expectations of student achievement and to make learning more challenging for their students" (R. Bishop, et al., 2003, p. 7).

In suggesting ways in which teacher could do this they suggest that "relating to" and "connecting with" students of other cultures without there being a means whereby teachers can understand, internalize and work towards changing the power imbalances of which they are a part”. (R. Bishop, et al., 2003).

Another concept that allows Rock and Water to engage Māori and Pasifika students is that of Manaakitanga/caring for the person.

"Effective teachers of Māori students demonstrate on a daily basis that they care for the students as culturally located human beings above all else. It was made clear to us that this was a fundamental prerequisite for teachers, a base on which all other characteristics rested. Therefore effective teachers:

- Treat students and whānau with respect leading to reciprocity

- Are compassionate

- Understand the world of the students as Māori and as teenagers

- Have a sense of humour

- Can be trusted - they keep confidences

- Are giving of themselves 
- Act in a just and fair manner)

- Are friendly and firm in relation to students

- Learn and ensure Māori names are pronounced properly

- Actions are culturally located

- Participate with students in a variety of ways

- Want to be in the classroom with the students. They are passionate about being with the students more than anything else

(R. Bishop, et al., 2003, p. 97).

Utilising these strategies is an integral part of the Rock and Water programme. In improving the engagement of Māori and Pasifika boys is about the integrating and incorporation of a range of strategies and pedagogies. An examination of the components that make Te Kōtahitanga successful as one tool in this 'kete' shows common ground between it and the Rock and Water programme.

Another strategy that has been introduced into which Rock and Water can be located is Ka Hikitia. The Ka Hikitia strategy has two components that have resonance with rock and water, those of "increasing the effectiveness of teaching and learning for and with Māori students in Years 9 and 10" (Ministry Of Education, 2009a) and "Sharpening actions and strategies to ensure that Māori students stay at school and are engaging in successful learning that leads to meaningful achievement" (Ministry Of Education, 2009a).

Raising the achievement and engagement of Pasifika boys has a similar theme, from the evidence above Pasifika boys are more likely to remain in the schooling system than their Māori peers but have low levels of achievement in comparison to Pakeha and Asian boys.

In a paper submitted as part of his Masters thesis, (Evans, 2011) suggested that one way in which Pasifika boys can be encouraged to achieve is through the use of group work that "kept them involved and active with the use of hands on activities" (2011, P.71). His research carried out with Pasifika boys at De La Salle College in Auckland found; in similarity with Bishops work around Te Kōtahitanga that 'Ako' or reciprocal learning was 
evident. He found that "Pacific boys enjoy sharing knowledge's and experiences within the classroom context and working together" Pg.72. He suggested that the

"Concept of togetherness is bound up within Pacific student's cultural identity and if teachers incorporate it in lessons then students appear to be more comfortable and more willing to participate and contribute" (2011, Pg.72).

It can be argued that this is one example where through an embracing of a collaborative learning strategy, Pasifika boys can be engaged behaviorally, cognitively and emotionally. In words that echo the philosophy of the Rock and Water programme, Evans found that the boys were more likely to engage and achieve if they were respected. In interviews with teachers at the college they said that "respect could be achieved by letting students voice opinions" Evans (2011, p. 72).

Rock and Water draws upon shared and individual experiences to discuss strategies for dealing with school and wider societal issues (identity, mana, bullying, violence). In his research with Pasifika boys, Evans (2011, p. 75) states that "students' engagement and learning is likely to be enhanced when the teacher takes the opportunity to use Pasifika literature, culture and experiences as part of their teaching processes.

(Hawk \& Hill, 2000) in their research suggested that one factor in how Pasifika boys could be engaged in a school context was through the development of community. They argue, with reference to Pacific cultural practice that this was considered 'the Pacific way'. The rationale here is that by creating a forum in which Pasifika boys can celebrate their culture, they would see how other cultures deal with situations. This would afford the boys a space to work together, enjoy the company of other boys and see the value in being a part of a community (Evans, 2011). 


\section{Summary}

In summary, from this literature review there are a number of factors to consider when looking at the role engagement plays in the educational experience for Māori and Pasifika boys. Issues of identity and masculinity are significant when examining the impact that the intervention has on the boys. When studying the level of engagement the boys have with school, an exploration of the relevance that the educational experience has in their wider lives outside of school was investigated.

Recognition of the role that culture plays within the lives of the boys had to be utilised. Indeed embracing and celebrating cultural practice is a central part of the intervention programme. This research looked at how cultural tradition and practice was woven through the programme. Practices from Te Kōtahitanga are evidence of this. It is clear from the literature review that improving the engagement of Māori and Pasifika boys with school is not a quick fix. There are a number of strategies that can be used. But the emphasis has to be on the role of relationships between the students and the teacher facilitators. Engagement cannot be improved through the imposition of an approach from above. This would suggest an 'othering' of the participants. The use of a strategy that works with the boys collaboratively rather than on the boys punitively is more likely to meet with success. Recognising the boys as culturally located and producing a pedagogy that is culturally responsive is more likely to meet with success based on the evidence found in this literature review. The importance of relationships has been identified in this literature review and it is significant that the boys form relationships with teacher facilitators of their gender and of their ethnicity. 


\section{Chapter 3: Methodology}

\section{Introduction}

In this chapter the research methodology is explored and the issue of the research paradigm examined. The research methods employed are also described and justified for the purposes of my study. The techniques used to gather and analyse data collected are described. Finally factors of the studies validity and relevance will be investigated.

Methodology refers to the "appropriateness of the techniques used to gather data" (Hart, 2010, p. 13). In the case of this research a qualitative methodology was employed. (Kaplan, 1973) argues that the choice of methodology will determine how the research is undertaken and what resources, processes and tools are used.

In choosing a qualitative approach for this research, a strategy based upon pragmatism is being used. Pragmatism as a philosophy relies upon the idea that what is important pertaining to knowledge is not abstractions, but what works in practice. According to pragmatism, the research design should be planned and conducted based upon what will best answer the research questions(s) (Johnson \& Christensen, 2008). This brings into play the ideological and philosophical debate regarding which methodological approach to use when conducting research.

\section{The Research Paradigm.}

A research paradigm is a perspective held by a community of researchers based upon shared assumptions, concepts, values and practices (Johnson \& Christensen, 2008). There are three major research paradigms in educational research - quantitative, qualitative and mixed methods. The primacy of each approach has waxed and waned over the years with either quantitative or qualitative having the upper hand. Until the early 1980's, quantitative was the generally accepted research paradigm in education but then a period known as the paradigm wars broke out. After this many researchers argued that their approach was the better than the other and that it was a case of either a quantitative or qualitative approach. This was known as the incompatibility thesis. By the 1990's though, pragmatism was breaking out with the opinion that both qualitative and quantitative research are important and should be mixed 
(Johnson \& Christensen, 2008). In the context of this research pragmatism is employed as a means of justifying a qualitative approach. The focus of the study, that of student engagement through a specialist intervention requires the researcher to identify a group of students from specific ethnic backgrounds participating in a school delivered programme.

As a researcher carrying out qualitative research it is important to develop a rapport and trusted relationship with the participants to be better explore their attitudes and opinions regarding a number of socially constructed issues (Guba \& Lincoln, 1989).

In this study, students were asked their opinions of school and what aspects of Rock and Water they valued. Further socially constructed values such as community and belonging were explored. This study has also looked at how issues of Māori Tikanga (practice) such as Ako (reciprocal or shared learning) were described and engaged with. Without a pragmatic approach using qualitative methodologies, participants may have found it difficult to articulate their position in relation to these concepts and ideas. Hence this meant that students could describe and explain in detail their attitudes and opinions as to the efficacy of the programme based around common shared values. The meaning of Ako for example was negotiated with the participants during questioning to ensure their responses were not misinterpreted.

A qualitative approach underpinned by pragmatism as its philosophy requires an approach to data collection that positions the researcher as central to the process. This approach relies upon the researcher as the "instrument of data collection" (Johnson \& Christensen, 2008). That is to say that rather than using a standardised instrument or measuring device such as a statistical model to quantify the results and to test against a hypothesis, this study depends my role as the inside researcher. As the researcher, I asked the questions, collected the data, recorded interviews and through this work made the interpretations from the results. The methods used and the interpretive techniques employed have to be rigorous to ensure the validity and integrity of the study.

This form of methodology is not without challenges and one that constantly stretches the researcher is the need to understand the research participants' viewpoints. The ultimate aim of the research process was to collect rich data from the participants' questionnaires and 
interviews. This required a certain amount 'empathetic understanding' from the researcher. Due to the direct and participatory contact that I had with the participants and my role as an insider research I had to empathise with the issues of being a Māori or Pasifika boy at college in the $21^{\text {st }}$ century. This approach was taken as a strategy to get the boys to open up on what the issues affecting their engagement were. This idea of understanding something from another person's view point originates from the sociologist Max Weber, a concept he termed it verstehen (Weber, 1968). Qualitative research is focused upon understanding the perspective of people and cultures from the viewpoint of the insider and involves direct personal and participatory contact. In the context of this research this was carried out using the questionnaire and interview methods.

\section{Research Method}

The intention of the research process was to examine at the culture amongst Māori and Pasifika boys and to examine how their attitudes towards school were influenced by a targeted educational programme. I also looked at how the teachers and facilitators involved in the programme engaged with the students, what their attitudes were about the effects the programme and their views on the impacts it had on the students' engagement in their school. A qualitative methodology was employed as the most pragmatic way of collecting data from the participants. Within this overall methodology an ethnographical approach was utilised.

Ethnography refers to the discovery and comprehensive description of the culture of a group of people (Johnson \& Christensen, 2008) Pg 401. The origins of this form of qualitative research rest within anthropology. However educational researchers have used this technique to study the cultural characteristics of small groups of people as they relate to educational issues. In this context, the cultural characteristics of Māori and Pasifika boys involved in Rock and Water and the teachers and facilitators involved in the programme, for example the use of a salute to start and end sessions or the informality of relationships between teacher/facilitators and students. These characteristics have been exhibited on a number of occasions but can be illustrated by the following example. Two of the facilitators have since left the school, but have returned on occasion to recognise the contribution of the group. At a recent porporaki (farewell) one of the facilitators returned to join with the Rock and Water group to acknowledge the contribution of the facilitator leaving. This shared experience 
demonstrates the willingness of all to participate in a shared event that had distinct cultural characteristics.

It was important to understand the cultures amongst the boys and to look at their shared beliefs - the specific cultural conventions or statements that they hold to be true or false (Johnson \& Christensen, 2008). It was significant in the context of this study to look at the groups shared values, what they felt good or bad about, desirable or undesirable about school and about the programme

In justifying this approach, one can examine the way that individuals become members of a culture or in this study, the culture of a school based programme. In chapter one, Reckless (1961) suggested that individuals participate or choose to opt out of society based upon a series of social controls. With an ethnographical approach to this research the process of socialisation is important. Individuals learn or are trained about the features of a culture. They chose, through inner and outer containment, to participate or reject the values, beliefs and norms of that culture, In the case of this study, participants (both students and teacher/facilitators) choose to engage with the Rock and Water programme on a number of levels and for differing reasons. But overall, the intention of the programme was to improve student engagement.

One of the strengths of this methodological approach is that the researcher becomes known to the participants and this leads them to open up to the researcher. The use of ethnography relies on an extended period of data collection and in the context of this research; this presents challenges and opportunities in the form of insider research.

Tuhiwai-Smith (1999, p. 137) argues that the role of the researcher in most contexts assumes that "the researcher is an outsider able to observe without being implicated in the scene". In the context of this study, my role as a researcher was shaped by the relationships that I had within the research setting - as a teacher, as part of the school whanau and as a facilitator of the programme. In other words I have to live with the consequences of the research process on a day by day basis for as long as I remain at the school. This could articulate itself as compliant or pleasing responses from the participants. The threat being that the participants may say what the researcher wants to hear. It was important to have checks into the validity 
of data collected. This was achieved using a process of triangulation or as Tuhiwai-Smith (1999) argues indulging in constant reflexivity, thinking critically about the data collection and interpretation process.

Another critique when carrying out research is that in this study my role shifted from insider to outsider dependent upon the individual taking part. I was an outsider when describing and discussing the context of what it meant to be a Māori or Pacific island boy studying at the school, an insider when discussing the programme. I was an outsider when interviewing the Māori facilitator about the importance of Māori tikanga (practice) within the programme, an insider when discussing the relevance of pedagogy to a teacher involved in the programme.

Responses from participants in this research were triangulated in the form of questionnaires, interviews, and follow up interviews. Participants' responses to initial questionnaires were transcribed and coded. These responses were then used as a basis for a deeper, more in depth interview. Triangulation was achieved when events or practices were verified and corroborated by other participants in the programme. Participants were given the chance to view transcripts as a form of participant review. The words of the participants had to speak for themselves. This approach relied upon good relationships with the participants. The researcher was playing a significant interpretive role within the process and this was based upon examining and exploring situations through the 'eyes of the participants' (Cohen, Manion, \& Morrison, 2000) .

Another challenge involved with insider research is that of ethnocentrism. The term refers to a researcher judging a culture or group of people according to the standards of one's own culture or background (Johnson \& Christensen, 2008) As a Pakeha adult studying Māori and Pasifika boys, it would have been a challenge to this research if I had attached a Eurocentric set of values to this work. I have worked within the community in which the study was set for nearly a decade. In the years prior to this I have spent an extensive amount of time away from my homeland living in and within indigenous cultures. I am from a working class, single parent background and have always respected the cultures within which I have lived. This has helping in developing the empathetic understanding necessary for this study. As outlined in chapter one, one challenge for the education of Māori and Pasifika boys in New Zealand is to move away from a Eurocentric or monocultural approach to 
education and to engage with ways that recognise the status of Māori and Pasifika communities in New Zealand society

One way in which a non judgmental stance when collecting data can be obtained is through the use of an emic and etic perspective (Johnson \& Christensen, 2008). This had relevance in this study as a balance has to be maintained between participants views on engagement with school and the wider view held by society.

Using the emic perspective, an understanding of the insider within the group could be explored. For example - what did respect as a concept mean to the boys? What did it look like to the boys, how was it articulated and how did the Rock and Water programme create a forum in which it was negotiated? Respect as a value has some agency and can be articulated in many different ways. This was emphasised in the responses from the Māori and Pasifika boys taking part in the study. Their use of specific terms or words in context related to respect. Applying these terms and words in an educational context allowed for the use of an etic perspective.

An etic perspective is referring to an external, social scientific view of reality. This allows the researcher to be objective and move beyond the perspectives of the students being studied and use social science concepts to describe the participants and their behaviour (Fetterman, 1998). In the context of this study an exploration of engagement and a look at the holistic nature of education facilitates this perspective. This is examined in greater detail in the findings and conclusions of this study.

\section{Data Collection}

The data was collected from 10 Māori and 3 Pasifika boys studying at Mana College. When asked to identify their ethnicity or iwi affiliations the boys identified the following: - Fijian, Samoan and Cook Island. For the Māori boys they had Iwi affiliations to :- Ngati Porou, Ngati Toa, Nga Puhi, Ngati Kahungunu, Ngati Maniapoto, Nga Tonu Te Atiawa They varied in age from year 9 (fourteen years old) through to year 12 (seventeen years old) and were invited to participate in the study. The criteria for participation were based upon their involvement in the rock and water programme. Some of the students had been involved with programme since its inception in the school in 2009; others had only been in the programme 
for one year. Two teacher and facilitators were invited to take part in the study; they were of Māori and Pakeha ethnicities and came from varied teaching backgrounds. One was active in the school as a tutor of kapa haka, his role within the school was as a member of the school guidance team dealing with issues of attendance, counselling and support. The other facilitator was a physical education teacher who was active around the school in developing a sense of community. This involved projects as diverse as painting, murals, running adventure based learning session and implementing a bicycle rack. He was a mature entrant into the school having previously been a police officer.

\section{Research Timeline}

In the first month of the data collection period I handed out and explained the information sheet. After gaining verbal permission to participate, I then gave information and consent forms to the student participants and their whānau/family. These took some time getting back in but by the end of the first months consent to participate had been gained.

During this period, I also approached the school principal and board of trustees to gain their permission to carry out the study. In the second month, I carried out questionnaires (see appendix 3) with the participants and collated the results. From the participants responses I constructed the semi structured interview questions (See appendix 2, 2A and 2B).

Interviews were carried out between the end of the second month and the middle of the third month of the data collection period. Student interviews were conducted either in a quiet office environment during the school day, on the marae or in the outdoors.

Interviews with teacher/facilitators were carried out outside of working hours at during weekday nights or at the weekend. These were conducted in the teacher/facilitators home or in my own home. Care was taken to provide hospitality and not to intrude into the customs and practices of the participants' home.

Interviews were digitally recorded and the data files uploaded into NVIVO 9 where they were transcribed and encoded. This was a time consuming exercise and took most of the remainder of the third month. Interviews were analysed and the findings written into this study as part of chapter four during the four month of data collection. 
On reflection follow up interviews were not carried out. The intention was to conduct these during the final stage of this study but time constraints and the movement of the teacher/facilitator participants away from the school meant that this was not possible.

Data was collected using three methods:-

- A questionnaire

- An in depth interview with students

- An in depth interview with Teachers/Facilitators

Using these three methods of data collection was significant as it allowed the voices of the participants to be heard. (Husen, 1997). That is to say that when analysing the responses as part of the finding sections, direct quotes from the participants can be used to inform about key themes such as identifying the factors that are important when looking at Māori and Pacific Island boys' engagement? Using each of these methods also afforded the opportunity to get an overall sense of the experiences and opinions of the participants (Evans, 2011). See appendix 2 for interview questions.

\section{The Questionnaire}

The questionnaire was an initial attempt at gaining information around the students' thoughts, feelings, attitudes and perceptions about the school environment and also the programme. This was also used as a tool for engaging the participants. The questionnaire gave the participants a chance to look at their participation in the programme and the school. It was an attempt to get them to think in a deeper manner about the impact that both environments had on them.

The questionnaire had a mix of open and closed questions and made use of a Likert scale for some questions. Participants filling in the questionnaire immediately took between 15 and 25 minutes to complete the questionnaire. Some participants chose to take the questionnaire home and then return after a few days. The questions used in the questionnaire are shown in the findings (Chapter 5). 
The purpose of the questionnaire was to provide initial data that could be expanded upon in the interviews. There are clear thoughts around the construction of questionnaires and (Johnson \& Christensen, 2008) provide a framework when considering the design of a questionnaire. Whilst questionnaires could be seen as the domain of quantitative studies, the use of one in this context was advantageous to introduce the focus of the study to the participants'. It involved carefully consideration of the literacy needs of the students. In the context that this research was carried out, student literacy was a significant factor. Questions were worded for ease of understanding. Likert scales were used to vary the style and type of questions asked. Space was provided for longer responses to some questions.

By using a mix of questions in the questionnaire, I was able to draw the participant into the research process. Closed questions were used to gain the confidence of the participant particularly those with low levels of literacy and then longer answers could be attempted or if the participant did not respond to the question this could be elaborated upon in the interview. Due to the insider nature of this research, the participants were known to the researcher and when questionnaires were collated, the interview questions were expanded or constructed in such a way as to get the interviewee to elaborate (see appendix 3)

\section{In Depth Interviews with the Students}

Following administration of the questionnaire, the next stage of the research involved interviewing the participants. The interviews varied in length from 15 minutes to 40 minutes. A common series of questions were used, but as the participant responded; clarification and elaboration was sought. A semi structured approach evolved as participants grew in confidence as the interview progressed (see appendix A for a list of questions). The advantage of the semi structured approach was the degree of informality with the participants. It was important to create an informal process in the interests of the students. . As Johnson \& Christensen (2008, p. 203) argue “ an interview is an inter-personal encounter. It is important that the interviewer establishes rapport with the person being interviewed. The interviewer should be friendly and open. At the same time, the interviewer must be impartial". This was difficult for me as the researcher due to the nature of insider knowledge - I had an established relationship with the participants through my role in the school and because of the students' perception of academic research. The research process had to be 
more than something that just happened to them. It is pertinent here to state the significance of Te Kōtahitanga as a concept. The term refers to the idea that 'we are all in this together'. Whilst Te Kōtahitanga is a Māori concept, (Evans, 2011) suggests that for Pasifika boys, a sense of community and shared involvement is significant in improving their achievement.

With Te Kōtahitanga in mind, interviews with Māori participants followed a kaupapa (an underlying philosophy) based upon important cultural values. They were:-

- Aroha ki te tangata (a respect for people)

- Kanohi kitea (the seen face, that is - present yourself to people face to face)

- Titiro, whakarongo ... korero (look, listen ... speak)

- Manaaki ki te tangata (share and host people, be generous)

- Kia tupato (be cautious)

- Kaua e takahia te mana o te tangata (do not trample over the mana of people)

- Kaua e mahaki (do not flaunt your knowledge, be humble).

(Te Awekotuku \& Maori, 1991)

This kaupapa for interviewing both students and facilitators was used as a way of recognising the important role that the participants played have in the research process. It also was a way of co-constructing a forum within which the data collection could take place. As a Pakeha man carrying out this research, these values are not unique to Māori, but do in fact have currency within my own culture. Employing these strategies was a form of best practice (Tuhiwai-Smith, 1999).

In Chapter One, the importance of these concepts for the engagement of Māori students was outlined. Ethically, as the researcher of this study, to appropriate the words and opinions of the participants without shared understanding and ownership would be wrong. Whilst I have been immersed into a school that has a high percentage of Māori children within it I cannot claim to be Māori. The similar argument is valid for the Pasifika participants. It is therefore important that participants have the opportunity to be fully involved in the research process. This involves consultation and permission from participants and whānau. After interviews 
and questionnaires have been collected and interpreted, the participants have the opportunity to see transcripts and if necessary to challenge what has been written.

\section{In Depth Interviews with Teachers/Facilitators}

These interviews tended to be longer in length and focused upon their responses to a questionnaire given out prior to the interview. The interview took a semi structured approach similar to that used with the students. The aim of the teacher/facilitator interviews was to look at the impact the programme had in improving the boys' engagement with school. The interview allowed for an exploration of the relationships that had been set up and were working within Rock and Water.

The interviews with the teacher/facilitators provided in depth information. They are used to consider the longer term impact of the programme and also to inform pedagogy as part of the findings section. Teachers were invited to take part based on their participation in the programme, in this respect it was purposive as the participants had already shown a commitment to the programme. Interview questions can be found in Appendix 2A \& B

\section{Data Analysis}

Once data had been collected from the participants, it was transcribed for analysis. The questionnaires were entered into NVIVO v9 as a source and nodes were generated. As the purpose of the data collection was to gain an impression of the life worlds of the students. NVIVO v9 was used as a tool to analyse the qualitative data provided by the participants. These nodes were used to identify themes from the source. The aim of this approach was to look at some of the recurring themes as deemed to be important by the participants. This was a challenge as the volume of data collected could become a type of data clutter that distracted from the main focus of the study. For the researcher, the search was on for evidence that supported the research questions outlined in the initial introduction. For example a theme that popped up regularity was that of brotherhood. The participants emphasised the importance of brotherhood to them and articulated how it related to their engagement with the school. This theme was then examined in more detail in the interview. 
Interviews were carried out over a two month period and involved each participant answering a series of open and closed questions about their attitudes to school, the things they valued, how important the rock and water programme was in engaging them and the significance of the relationships within the group. They also had the opportunity to expand upon responses to the questionnaire. The aim here is to generate deeper, rich data that would allow the participants to open up. Interviews were recorded using a voice recorder and then imported into NVIVO v9 as a source. They were transcribed, and then using the coding process, common topics were identified. Analysis of these themes and their relevance to research questions was undertaken and will be examined as part of the findings and conclusions section of this research.

One challenge for the research was the time involved interviewing, transcribing and then coding the responses of the participants. The volume of data generated was huge. The use of NVIVO as a tool to collate, code and interpret the data was invaluable.

\section{Challenges for the Study}

There are a number of challenges when choosing a qualitative methodology. There are unique challenges when some of the research participants are children and when they are of an ethnicity that is different to your own.

The prime focus of this research is Māori and Pasifika boys and the need to get consent from them and their families is significant. Loveridge (2010, p. 7) quoting work by (Suaalii \& Mavoa, 2001, p. 1) suggests that for Pasifika participants "the passing on of knowledge are articulated in terms of wider family and community, not within an individualistic framework". Clearly when gaining the consent for research from participants from Pacific Island communities, the need to inform the family about the nature of the research and its objective is important. Evans (2011, p. 31) also makes the point that as with Māori participants, an awareness and respect for Pasifika values is important:

- Being prepared to be negotiable, being flexible 
- Adaptation and compromise

- Oratory and verbal negotiation - the Pacific Way is spoken rather than written

- Kinship networks - literally thousands of people can claim kinship or affinity with any distinguished leader

- Universal Pacific notions of generosity with time, labour and property

- Pacific perceptions of 'time', leisure, dress, food and dancing

- The inseparable dynamics of church and culture

(Tupouniua, Crocombe, \& Slatter, 1975)

Another factor which must be taken into account when carrying out educational research involving young people is the need to listen carefully to their voices. This is to suggest that in a democracy young people have a right to be heard. The role of researcher can be to articulate this voice without appropriating it. In the context of this research, hearing the voices of the boys participating in the programme should be an empowering experience for them. This research should create a space in which their voices and their attitudes and opinions about the school experience are heard safely. 


\section{Chapter 4: The Rock and Water Programme}

The Rock and Water is a programme developed in the Netherlands by Freek Ykema. Its aim is to utilise a "psycho-physical method that does boys justice".(Ykema, 2000). It was developed primarily to challenge the portrayal of boys in a negative manner. At its core is the philosophy that boys are in a situation currently where they or an unknown or misunderstood in society. Ykema argues that " the stages in the development of a boy are given too little attention and consequently "they are not understood and respected" Ykema (2000, p. 12).

His approach was to develop a specific programme aimed at boys and delivered by educators and facilitators utilizing the perceived strengths of boys. The programme uses psychophysical didactics. The physical starting point is the basis for "teaching and learning mental and social skills" Ykema (2000, p. 13).

The programme recognises that boy's transition through developmental stages. It has been argued that the boys pass through three stages in their lives. Biddulph (2003, p. 7) argues that "from birth to six when a boy primarily belongs to his mother, from 6-14 when the boy driven by internal drives starts wanting to learn to be a man and from fourteen to adult when a boy needs inputs from male mentors". One could argue that this is a broad brush description and negates other factors as outlined by Reckless (1961) and negates the impact that whānau or family and peers have on the individual. But in the context of Rock and Water participation starts at Year 9 and continues through to Year 11. The relationships developed within the programme continue through until the boys leaves College As boys enter this stage they physically have lots of energy provided by a testosterone and hormonal surge as they enter puberty. The programme channels this energy through physical activity combined with short group discussions.

The focus of these group discussions is self reflection and collaborative learning. Rock and water has a number of building blocks to develop self control, self reflection and self confidence. These are woven together using four threads: 
- Grounding, centering and focusing

- The triangle of body awareness, emotional awareness and self awareness

- Communication

- The Rock and Water concept

(Ykema, 2000, p. 13)

The dynamic of the group is based around brotherhood and learning what it means to be a man. The group is made up of students who either self select to attend, are identified at the school induction phase in year 9, who are put forward by whānau or who join after recommendations from their peers. The group comprises of up to 20 students and 3 teacher/facilitators. Average numbers are around 12 students and 3 teacher/facilitators per session, with two groups running during the period of this research. This has expanded and grown to three groups (two male, one female) in 2012.

The structure of the sessions is that students are given permission to attend sessions out of class for one period a week on the condition they catch up on missed work.

In the context I teach, the programme is team taught by a range of facilitators who each bring their own 'kete' (or bag) of skills and experiences. Students attend for up to two years and can be brought into the programme in their senior years as tuākana tēina.

In exploring the role that Rock and Water plays in improving student engagement, there are a number of significant factors that come into play. The students have another opportunity to engage with their peers and the teaching staff in a different context to the classroom. The learning and teaching that takes place is reciprocal and fulfils one of the criteria of Te Kōtahitanga - that of 'Ako'. The programme recognises the diversity of individual students and celebrates that diversity.

\section{Sessions}

Sessions typically last 50 minutes and are broken into five episodes. The icebreaker phase is carried out at the start of the session. This involves students removing shoes and socks, 
watches, cell phones, wallets and personal items. Students then participate in a quick, high energy activity such as tag, rats, rabbits, rascals, sharks (a toned down version of bull rush, a game based around tagging/tackling opponents as they run from one safe area to another), bump. The aim of this activity is to burn of some excessive energy, to get the students working together and to introduce completion. The session then moves into a formal welcoming phase. Students and facilitators move into a large circle where the Rock and Water salute is given and the Rock and Water metaphors are articulated.

\section{Rock and Water salute}

The left hand is outstretched, then shaped into a fist and placed over heart. The interpretation of this is that the hand represents the rock - solid immoveable and is placed close to the things that matter in a person's life (whānau, friends, honour, mana).

The right hand is then outstretched and opened. The use of the open hand is to represent a welcoming or water attitude. This is the hand used in handshakes and the students are reminded that in pre industrial societies this was the hand used to hold weapons (metaphor: sword hand). This hand represent water and is open and then placed over the rock hand covering the heart. This recognises that the holder will use the water hand first will show friendship, trust and solidarity.

The participants then all bow inwards and utter the words 'respect' of 'whakaute'. This has a symbolic role; it refers to the values that will be embraced throughout the session. The use of a circle is significant in that it has no corners or top or bottom, all participants (students and facilitators) are included into the group. The use of the salute and bowing establish a boundary around and within that the session will run.

\section{The Rock and Water Attitude}

The programme has woven through it components that would be familiar to students of eastern philosophy. There is a significant martial arts component to the course. Central to 
this is the Rock and Water attitude. One challenge for the programme could be the potential for particular cultural hegemonies to dominate. For example as this is a programme that has it's origins in Europe, European or pakeha attitudes dominate. This is addressed through the use of Ako, in that sessions are co-constructed with students and Māori and Pasifika practice are woven through it and given equal space and time for expression and discussion.

The Rock element stands for strength and inflexibility. It is a recognition that for people there are situations and values that will be challenged and defended. Like the metaphor of a rock, these will involve an attitude that is solid and hard to change - not unchangeable but slow to change.

The Water element stands for flexibility and change. It is a recognition that individuals need to be quick to adapt to circumstances and flow around and within a situation. This is the attitude that students are encouraged to use first.

In Rock and Water, the use of metaphor and analogy is strong. Using the analogy method to explain roles in a conflict, we suggest that when two rocks collide (one or both break downdependent on material and get smaller), whereas when two bodies of water come together (e.g. streams in a tributary) and they get stronger and more powerful. We use this to illustrate an approach to conflict between boys, between boys and teachers, the suggestion being that if the boys project an attitude of water then the conflict will not occur or be resolved and they will gain from the experience.

Within Rock and Water there are many very effective learning tools combining to engage boys? The use of specific language reinforces positive attitudes about themselves and celebrates the attributes they have. It encourages belonging and participation. The use of the salute and the meeting circle support confidence without highlighting weaknesses.

\section{Rock and Water Themes}

Within the programme a number of themes are explored and discussed. The issue of balance and control are emphasised by the terms 'centred and grounded'. Students and encouraged to 
develop breathing exercises that emphasise the importance of breathing from the stomach and not from the chest.

'Grounding' is aimed at encouraging the students to take the time to feel the ground under their feet. To have a firm platform on which they can rely. The ultimate aim of these two activities is to address the fight or flight reaction inherent in all humans. The issue of centring and grounding is constantly re-enforced throughout the programme, all activities are based around this concept.

The majority of the activities in the programme are physical and involve completion of one form or another. Student sit in a circle prior to the start of each activity, the activity is introduced by either a teacher/facilitator or a tuākana or a student. The activity always begins with the salute to symbolise respect between participants. After the activity has been practiced by all participants, a reflective period is introduced. This takes the form of a discussion about the activity - what worked and what did not and then the discussion is widened to look at how the strategies used in the activity can be used in a wider context (in the classroom, in the school, at home or on the street). Sessions end with a plenary and a look forward. The plenary look $\mathrm{s}$ for opportunities for the participants to practice the skills introduced or explored in the session. All participants then salute out and disperse.

In conclusion, Rock and Water sessions are aimed at creating a shared sense of identity - that of brotherhood. Sessions have themes that focus on the notions of masculinity and the stages though which boys' transition on their 'journey' to manhood. In creating a forum in which these themes and issues can be negotiated, students have the opportunity to discuss and express their emotions, feelings, experiences and opinions. The format of the sessions encourages physical interaction. There is a recognition that the boys are going through physical change. The intention of the physical sessions is to provide an outlet for testosterone surges that the boys experience as part of changes to their bodies. Challenge and competition play a large part in the programme. Students take part in activities such as 'Chinese boxing' and 'Sticky hands' which are aimed at producing an environment in which competition is encouraged. After a physical activity comes the discussion. The intention 
being that the boys involved will open up about their experiences of situations and events and that the group will learn strategies that will help them manage situations they encounter within and out with the school environment. The boys in the programme are also taught exercises and strategies that will help them manage conflict across a variety of scales and in a number of contexts. The use of a centred and grounded approach teaches the boys to feel the ground under their feet and to listen to their breathing. The intent here is to allow the boys a brief period of inner reflection before embarking upon a response.

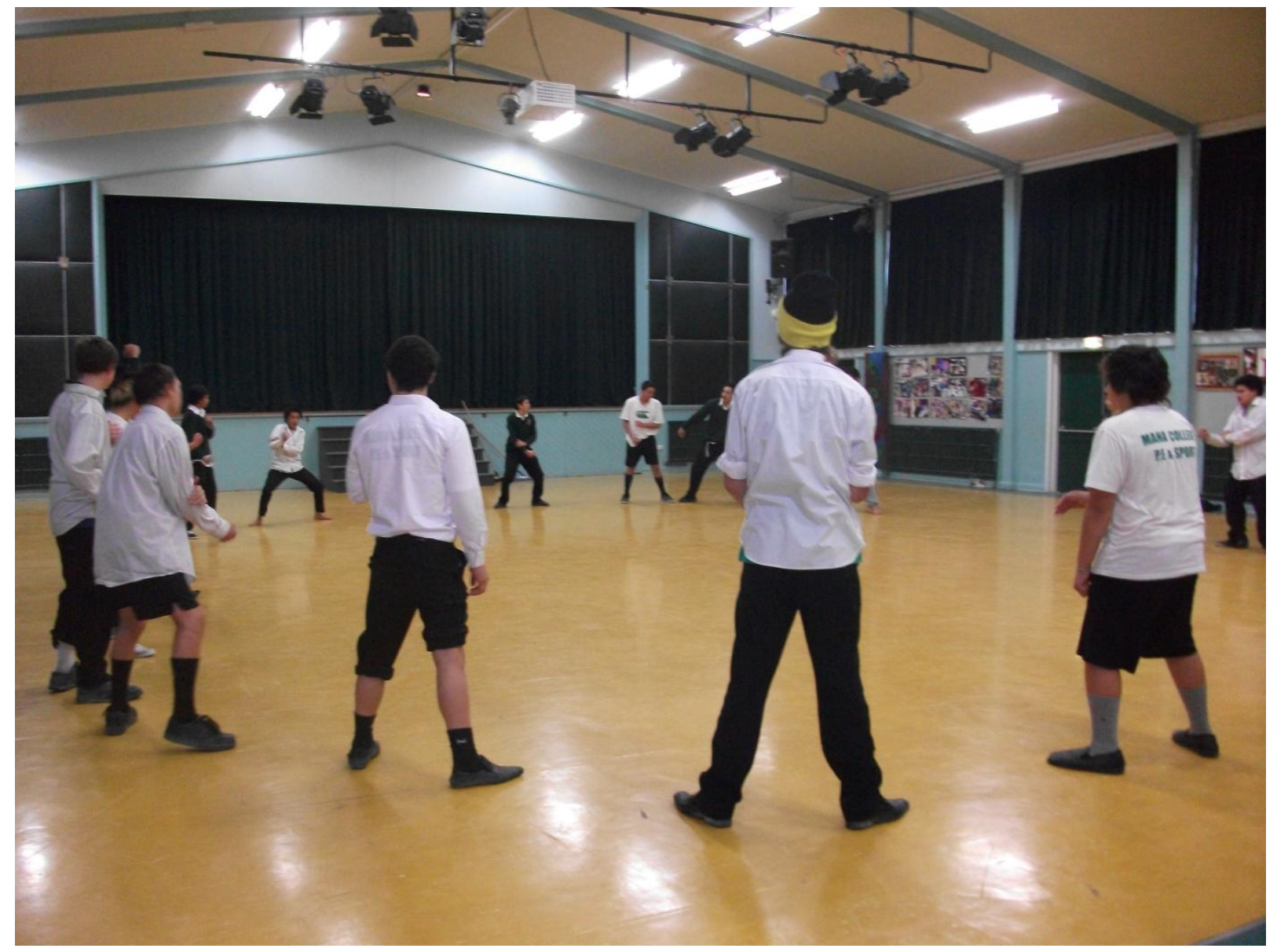

Students at start of session in a circle performing the opening salute 


\section{Chapter Five: Findings}

The questionnaires were the first method of data collection undertaken and the responses of students and teacher facilitators were used as the foundation for the in depth interviews that followed. Ten students and two teacher facilitators were approached to take part in the study. This was an opportunistic approach to data collection as the students and facilitators were engaged in the programme and were willing to participate.

The respondents were given consent and information sheets to sign and take home to discuss with their caregivers (in the case of the student participants). All participants were informed on how the information gathered would be used. After completion of the questionnaires, participants were invited to attend an in depth interview lasting approx one hour. It was the intention of this process to get rich data relating to the 'life worlds' of the students and teacher facilitators as to the effectiveness of the Rock and water programme in improving student engagement.

Once completed questionnaires were returned they were collated and coded. The use of coding allowed me to identify themes and issues and pick up on any patterns in the responses. The questionnaires were also used to break the ice with the participants, to get them thinking about the programme in a deeper way. It was also used to establish rapport with the students and make them feel at ease. In building a relationship with the participants, the intention was that they would feel more comfortable about the process and open up more. Responses were grouped into student responses and teacher/facilitator responses. It was hoped that recurring or similar themes would emerge from both sets of participants.

\section{Student Responses}

Ten questionnaires were handed out and nine students completed questionnaires and their responses were grouped and collated below. 


\section{School engagement}

Q1. Using the scale below, how would you rate school?

\begin{tabular}{|l|l|l|l|l|}
\hline 1 Like it a lot & 2 Like it a bit & $\begin{array}{l}\text { 3 Neither like } \\
\text { nor dislike }\end{array}$ & $\begin{array}{l}\text { 4 don't like it at } \\
\text { times }\end{array}$ & $\begin{array}{l}\text { Really don't } \\
\text { like it }\end{array}$ \\
\hline 3 & 5 & 0 & 1 & 0 \\
\hline
\end{tabular}

\section{Table 4.1: Responses to question 1}

Table 4.1 shows that the majority of the students $(89 \%)$ either liked school a bit $(55 \%)$ or liked it a lot (34\%). Only 1 respondent (11\%) expressed a dislike for school and even then it was at times

\section{Q2. Tick the box which best describes how you feel about school?}

The word engagement means to occupy your attention or your efforts

On a scale of $1-5$ how engaged do you feel at school

\begin{tabular}{|c|c|c|c|c|}
\hline $\begin{array}{l}\text { 1- Very } \\
\text { engaged }\end{array}$ & $\begin{array}{l}\text { 2- Engaged } \\
\text { most of the } \\
\text { time }\end{array}$ & $\begin{array}{l}\text { 3- } \text { Neither } \\
\text { engaged, nor } \\
\text { disengaged }\end{array}$ & $\begin{array}{l}4 \text { not engaged } \\
\text { most of the } \\
\text { time }\end{array}$ & $\begin{array}{l}5-\quad \text { very } \\
\text { disengaged }\end{array}$ \\
\hline 2 & 5 & 1 & 1 & 0 \\
\hline
\end{tabular}

Table 4.2 Responses to question 2

Table 4.2 looked at school engagement and the results were encouraging. Students were either engaged most of the time or very engaged. Blum \& Libbey (2004) have argued that school engagement in a significant factor when addressing student achievement. Only one respondent identified a lack of engagement. This was backed up by comments made as part of their interviews. Students were asked about their connection with the school and one 
student replied "Yeah, hard out". Another respondent when asked the same question replied "yeah, much more a part than I was before". A third respondent when asked the same question replied "Yeah, because I've done stuff participating in the school".

\section{Q3. What do most enjoy about school?}

Question three in the questionnaire delved into student motivation and looked at the factors influencing student enjoyment of school. Responses to this question were identified as having a affective, behavioural and cognitive aspect to them (Jimerson, et al., 2003).

Meeting and mixing with their peers featured strongly with student respondents with at least 3 responses mentioning friends (Friends, the Bro's, and Friends). This provided evidence of the cognitive dimension of school engagement. The importance that students place upon their relationships with their peers affects whether they enjoy school or not. This was highlighted in the interviews with brotherhood featuring highly in their responses to questioning.

Another significant factor was the importance of relationships with the teachers contributing to their enjoyment of school. Teachers were mentioned by two of the respondents and this was explored deeper as part of the audio interviews. Bishop, et al.,(2007, p. 167) argue that good relationships between teachers and students are an important factor in whether as student thrives at school or not.

Finally learning featured highly in the student's response to this question with three students identifying learning as a factor influencing their enjoyment of school. This is evidence of behavioural dimension of (Jimerson, et al., 2003) mode of school engagement. One student identified future prospects as a factor in his school enjoyment and the comment "Learning new things, so I can have a good future" was made

\section{Q4. What do you dislike about school?}

When the questionnaire changed its focus to look at the factors that students disliked about schools, it is not surprising to see that the boys mentioned rules and boundaries as a factor. This was identified by two of the respondents, Lashlie (2004, p. 15) mentions how boys need clear and firm boundaries in their adolescent years. The argument being that they will 
push up and test these boundaries for elasticity. If they are kept in place she argues, the boys will push up and against them but not through them. The need for these boundaries is a way in which the idea of outer containment can be re-enforced. Using the students responses as an example of Reckless's (1961) outer containment in action. In the context of this questionnaire, rules surrounding uniform and attendance were identified as placing the individual student in a position to view themselves as part of a wider whole e.g. school and societies perception of the school.

Other responses related to work (one respondent), Specific subjects (two respondents), Tests (one respondent) Teachers and their style - talking too fast (two respondents) and finally one respondent replied "nothing, I like school".

From these responses the way in which lessons are conducted is important in the students like or dislike of the school. Finn $(1989$, p. 122) in his examination of the factors influencing student withdrawal from school, identified unsuccessful school outcomes as a contributing factor in a frustration-self esteem model. The argument being that if a student experiences a lack of success in the classroom, this will lead to reduced self esteem and then problem behaviour. From the responses of the participants, the use of tests and of teacher style could be seen as evidence of a lack of success for the boys. This study did not look at this in and this is an area that is in need of further research.

\section{Q5. How important are the teachers at school?}

\begin{tabular}{|l|l|l|l|l|}
\hline $\begin{array}{l}\text { Very } \\
\text { unimportant }\end{array}$ & $\begin{array}{l}\text { A little bit } \\
\text { important }\end{array}$ & $\begin{array}{l}\text { Neither } \\
\text { important nor } \\
\text { unimportant. }\end{array}$ & $\begin{array}{l}\text { A little bit } \\
\text { unimportant }\end{array}$ & $\begin{array}{l}\text { Very } \\
\text { Important }\end{array}$ \\
\hline 4 & 0 & 2 & 0 & 3 \\
\hline
\end{tabular}

Table 4.3 responses to question 5

Student responses to question five were interesting with four students (44\%) identifying the teacher as un-important at school. Equally surprising was the fact that two students (22\%) identified the teacher as being of neither important nor unimportant. When a version of this 
question was posed as part of the interview the response was significantly different with the relationship between the teacher/facilitator in the Rock and Water programme being very important. From this response we can make an assumption that context is important. The shift in the importance of the teacher dependent on the setting seemed to suggest that in the traditional classroom environment, the level of engagement with the teacher by the boys was low or marginal. When viewed as part of the mainstream school community, for these respondents, the role of the teacher in their schooling was marginally less important. However further research would need to be carried out into students interpretation of the word important. Any further research might choose to look at the role of teachers in students lives. This is an area for further investigation by other researchers.

However when placed in the Rock and Water context, the role of the teacher facilitator was very important. (R. Bishop, et al., 2007, p. 18) argue that students need to be identified and recognised as "culturally located individuals". Indeed a translation of the term Te Kōtahitanga means 'all in this together' or 'unity'. Within the Rock and Water forum roles are fluid and the teacher can become the student and vice versa. The challenge for the school is to translate the strong sense of unity from Rock and Water into mainstream classrooms for our Māori and Pasifika boys.

\section{Q6. What qualities make a good school day for you?}

Question six looked at what qualities made a good day for the boys. The student's response to this question contradicted their responses to the question five. Teacher relationships were high up being mentioned on five occasions ("Teachers are relaxed, "a nice teacher", "briefly talking to the teachers about what we're gonna do", "positive towards the teachers" and "FUN teachers".) Of equal importance was the work ethic within the classroom ("Hard working kid"s, "everyone doing their work, so I can do my work as a group with friends".) The respondents also mentioned relationships with their peers and the teachers as having an impact on their enjoyment of the school day ("Teachers are relaxed", "FUN Teachers", A Nice teacher, good food and a game of touch", "My friends, girls", "The Bro's and friends. do my work as a group with friends".) The last comment is important for the engagement of Pasifika boys as (Evans, 2011, p. 71) in his research into the 
achievement of Pasifika students argued that "Pacific boys at De La Salle College clearly preferred group work as opposed to individual reading and writing" .

\section{Participation in School}

\section{Q7. Do you take part in any after school/extra-curricular activities?}

\begin{tabular}{|l|l|}
\hline Yes & No \\
\hline 7 & 2 \\
\hline
\end{tabular}

\section{Table 4.4:Responses to question seven}

Table 4.4 shows that the majority of respondents took part in school or extracurricular activities. This question was posed without reference to the rock and water programme. All of the respondents took part in rock and water so it was interesting to see that for some (2) of the students, they did not view rock and water activities as extracurricular. Rock and water has woven within it EOTC (Education outside of the classroom) activities such as kayaking, tramping, rock climbing, mountain biking. In terms of the impact that this has on improving engagement; when defining engagement as a value, OECD/PISA (2006, p. 7) suggest that the extent to which students participate in non-academic activities is significant.

\section{Q8. Which ones (in terms of extracurricular activities)?}

Question eight looked at the type of after school/extra-curricular activities undertaken by students and sport featured highly. Of the sports identified rugby (both union and league) were mentioned by five respondents. Other team sports volleyball and badminton were mentioned as was martial arts (Kempo Karate).

Of significance for this study was the mention of cultural groups, Rock and Water and a boys achievement group. In identifying a key component of Te Kōtahitanga, (R. Bishop, et al., 2007) suggest that recognising and valuing a student's culture is a way towards caring for them as culturally located individuals. That is to say that this can be used as a challenge to the deficit theory approach that has been used to explain some aspects of disengagement of 
Māori and Pasifika students. Rock and Water featured highly and the boys' achievement group from which Rock and Water grew and is still woven was also mentioned.

\begin{tabular}{|c|c|c|c|c|c|}
\hline Sports (name) & $\begin{array}{l}\text { Achievement } \\
\text { centre }\end{array}$ & $\begin{array}{l}\text { Cultural group } \\
\text { (Name) }\end{array}$ & $\begin{array}{l}\text { Boys } \\
\text { Achievement } \\
\text { group }\end{array}$ & $\begin{array}{l}\text { Rock } \\
\text { and } \\
\text { Water }\end{array}$ & Other \\
\hline $\begin{array}{ll}\text { - Kempo } \\
\text { - Rugby league } \\
\text { - }(2) \\
\text { - Union(3) } \\
\text { - Volley } \\
\text { - Badminton }\end{array}$ & 0 & $\begin{array}{l}\text { - Kapa } \\
\text { haka (3) }\end{array}$ & 1 & 7 & 1 \\
\hline
\end{tabular}

Table 4.5: Responses to question eight

\section{Q9. Why do you choose to take part?}

Question nine was in some instances misinterpreted by the boys. Some chose to answer it in response to extra- curricular activities and others used it to respond to the question why did you get involved in rock and water? Most students mentioned that extra-curricular activities gave them an opportunity to have fun ("Fun and friends", "because it's fun", "because it's what I most enjoy", "because I find it fun".) One boy mentioned that taking part built his self confidence, this was supported by another student who had a high sense of self worth gained from the activity "it keeps me fit and I'm the man".. One boy mentioned that it "keeps me out of trouble". A student made reference of the fact that the activity "gives me a chance to be myself'. From these responses after school and extra-curricular activities fulfil an important function in the lives of the boys questioned. As an outlet for their energy on one level but looking deeper, they also play a part as a form of social control. Like the spaces created by rock and water, boys have a forum in which they can grow as individuals. 
The boundaries or containments outlined by Reckless are provided by the rules of the activity and by the membership of the team be it rugby or as part of a Karate club.

Q10. Why did you get involved in Rock and water?

\begin{tabular}{|l|l|l|l|l|}
\hline $\begin{array}{l}\text { Heard from } \\
\text { friends }\end{array}$ & $\begin{array}{l}\text { Referred by } \\
\text { staff }\end{array}$ & $\begin{array}{l}\text { Tried it before } \\
\text { (e.g. } \\
\text { Intermediate })\end{array}$ & $\begin{array}{l}\text { Time out of } \\
\text { class }\end{array}$ & Other \\
\hline 2 & 3 & 1 & 1 & Anger \\
management
\end{tabular}

Table 4.6: Response to question ten

In question ten students were asked how they had got involved in the Rock and Water programme. The largest group was made up of students who had been referred by staff. (four of the nine). Of the remainder one student had tried the programme before at intermediate school and two had heard about it from friends. The group operates on a number of levels. Students can be referred as a part of the school pastoral programme by senior management or teaching staff, or they can self refer to try it. They can be placed upon it as part of the school restorative behaviour management process

\section{Q11. Do you like being part of this group?}

In question 11, students were asked if they enjoyed being part of the group. The majority of those questioned (66\%) replied that they did enjoy the group. The remainder of respondents did not answer the question.

Q12. Can you describe the things you enjoy about the Rock and Water programme? 
Question twelve looked at the specific aspects of rock and water that the students enjoyed. Interaction between the students and between students and teachers was mentioned "Good teachers and fun" "Coming closer to the boys and teachers", talking to teachers as friends". Using the strategies of rock and water to deal with issues of anger and learning what it means to be a man also featured "It's calming down my mental side", I really enjoy learning how to control my breathing and learning how to make decisions", learning to use my rock only when needed to and keeping calm at all times", "the teachers teach you how to stay tall, grow to be a better man and say no to trouble", and "learn to be responsible". Games were mentioned as were the EOTC trips.

From this evidence, the activities undertaken as part of the programme were having an impact on the boys. They could remember them and then they could apply them in contexts of their choosing.

\section{Q13. Has Rock and Water had an effect on you around school?}

\begin{tabular}{|l|l|l|}
\hline Yes & No & $\begin{array}{l}\text { Not } \\
\text { Sure }\end{array}$ \\
\hline 4 & 1 & 4 \\
\hline
\end{tabular}

\section{Table 4.7: response to question 13}

Question thirteen looked at the impact that Rock and Water had had on the students around the school. The responses in the questionnaire were inconclusive with four students replying yes, one student stating that it hadn't and four students unsure. This theme was picked up and explored in more depth in the interviews with the students.

\section{Q14. If Rock and Water has had an effect on you around school, how have you used it?}

The final question in the student questionnaire asked students to think of examples of how rock and water had been used around school. The responses from the boys were enlightening. The responses from those students who replied that rock and water had had an effect on them around the school environment were revealing. Not only were students vocalising how Rock and Water had affected them but also they were engaging with the 
specific language of the programme. For example one boy answered "By using my water and walking away from encounters". Other students replied that "I have been able to talk confidently to others, stand up in front of many people", another replied "I don't swear as much and I'm very polite", A third "A calm person instead of an angry chap". One student replied that he did not know if it had had an effect and one student replied that rock and water hadn't had an effect on him around school.

\section{Teacher/Facilitator Responses}

The teachers and facilitators were asked a range of questions relating to their involvement and motivation in participating in Rock and Water. The rationale for the questions was to explore why they chose to become involved, what did they get from the programme and how did they influence what took place in sessions. Only two facilitators are currently involved in the programme at the college. Previous teacher facilitators had moved overseas and were unable to be contacted. This explains the small sample size. The results are shown below.

\section{Q1. How did you get involved in the Rock and Water programme?}

For both respondents, they mentioned the training programme that that they had attended. Recruitment initially was by word of mouth and shoulder tapping. One mentioned "it was mentioned to me be a staff member and after training, we introduced a course to students'. The other spoke of the impact that taking part in the group had and also being given an opportunity to be trained by Freek Ykema (the author of the programme). "I took part on the group for a year, and then I was given an opportunity to train with the guru himself." From this evidence, both respondents demonstrated a commitment to the philosophy of the course.

\section{Q2. Are there any benefits to students participating in $\mathbf{R} \& \mathrm{~W}$ ? Can you name them?}

Both respondents were positive in their responses. One respondent spoke of the impact that the programme had in improving the relationships the students had around school. "It helps them (the students)to find better ways of dealing with conflict situations, whether it be with a 
teacher or with their peers". This may be evidence of the programme playing a role as a form of social control and supporting Reckless's ideas of outer containment. In that students are given a chance to see their role and response to a situation in the context of a wider societal expectation. This is supported by the second respondents response that explicitly mentions 'containers' through which males are expected to conform or fit in. " $A$ development of positive male role modelling. The development of 'connectedness' amongst male students and the promotion of a rite of passage”. In this comment the respondent alludes to a strategy that connects the student with the school. This was confirmed in statements made by students when asked as part of the interview if they felt more connected to the school. This is evidence that Rock and Water has had some impact in improving students engagement with the school. This respondent also mentioned the need to utilize pedagogies that used physical activity as a way to create a space in which boys could then speak about emotions and feelings "promoting males/boys to be physical and active. Enabling boys to expend energy and express/talk about feelings and emotions".

\section{Q3. What is the focus of $R \& W$ sessions?}

The responses from the participants differed in this question although there was some commonality. One participant spoke philosophically of "Celebrating being male and how to be a good man that is confident in his being”. The other spoke of a thematic approach to sessions "We always have a theme that we use to work with the boys and that theme will be the focus for a whole term". The commonality came when both respondents mentioned the topic of brotherhood. This was a theme or node that the students strongly identified in their interviews. They mentioned "to promote brotherhood. and "For example. ...Trust, brotherhood and we build exercises around that theme".

\section{Q4. How are these enacted?}

Only one respondent replied to this question and he spoke of four strategies employed in the group. "Using circles of discussion, using a rock and water salute and motto/belief system. 
Using lots of metaphor and analogy based conversation around power and strength, using high energy and fun, boisterous activity." The use of metaphor is an important component in engaging Maori and Pacific Island students. (R. Bishop, et al., 2007; Evans, 2011; TuhiwaiSmith, 1999) all mention in their research the importance of using metaphor as a medium through which important cultural messages can be portrayed.

\section{Q5. Have you seen a change in the students taking part?}

Both respondents mentioned yes.

\section{Q6. How?}

For this question only one respondent replied. He mentioned the impact the programme had on relationships and behaviours around the school. "Rapport and relationships strengthened between students and teachers (including facilitators) in everyday class situations. Increase in confidence leading to appropriate and respectful behaviours - school grounds, class language and conversations are being used and applied." This comment suggests that students are taking aspects of the programme and applying around the school environment. This is significant as the students are engaging with the programme in a different context, a positive example of how the programme influences boys' engagement with their peers and the school staff around the school.

\section{Q7. Would you say that Rock \& Water is a programme that would benefit all boys in the school?}

The response was positive from the one respondent that replied to this question. The other respondent left the answer to this question blank.

\section{Q8. If so why? If not, why not?}

The respondent that replied to this question spoke of how the programme may have an impact on the atmosphere around the school. They mentioned that "All boys (and girls) and many adults yearn for a sense of belonging and the ability to develop positive relationships. If the positive culture that comes from Rock \& Water was throughout the school, the place would be a happier, calmer and conducive to a better learning environment." 
The respondent also went on to speak about how increasing the frequency of Rock \& Water initiatives would be advantageous. "More time spent on Rock \& Water initiatives would be beneficial."

\section{Q9. What themes do you think are important within the programme?}

The respondents were spilt on this question. One participant took a holistic view to the themes looking at the impact that they had on the boys replying "As long as the theme has an effect on the boys, to help them see how they can use it in their everyday live, it doesn't matter what the theme as the exercises will help illustrate how that can be effective." The suggestion here is that the application of the strategy and how it can be demonstrated is of more consequence than the overall theme. This can be interpreted as developing one aspect of Te Kōtahitanga, that of unity. That is to suggest that exercises practiced in the Rock \& Water forum will have an impact in the boys' everyday life. That someone in the group has experience of this and can articulate it is more valid and has greater currency than over arching themes. The second respondent differed from this stance in that he identified particular themes such as "Brotherhood - celebration of being male." "Solidarity, connectedness and belonging." "Being in control of self-harnessing and directing positive energy and transfer of skills and making learning real/appropriate." For this respondent, the themes were providing a portal for the strategies. This was supported in his response to question 10.

\section{Q9a. Why?}

Both participants spoke of the need to connect the themes in the programme with external challenges. For one it was about "Because themes will help them (the boys) to internalize the concepts that they are taught." For the other it was about validity "without these themes, the programme would lose its importance and meaning. The themes enable facilitators to draw on life experiences and draw analogy to explain concepts and provide clarity." It is interesting to note that for one, the role of the facilitator is that of giver of knowledge; drawing on his life experiences and for the other it was about how the boys would use the theme or concept almost as a Koha or gift.

Q10. Is the teaching shared between students and facilitators in the programme? 
Both participants replied yes and one gave an example "We select tuākana to lead part of the session, we also get individuals to talk to the group about how they use Rock \& Water in their lives.. This provides some evidence of 'Ako' or shared learning. The use of tuākana to direct or initiate activities show that within the programme learning is given over to the boys and not dispensed in a top/down binary position. This is explained in more detail in question 11.

\section{Q11. How?}

In this question the respondents talk about how boys are selected or self select to deliver aspects of the programme. For one the issue of sharing the learning was controlled by the teachers/facilitators for the other it was a case of opportunistic. "We select them (tuākana/student contributors) according to their commitment to the programme and their ability to communicate with others." For the other respondent it was more a process of evolution "Predominately facilitators plan lessons, however as the programme has progressed/developed tuākana within the group have been identified and been brought to help with the planning \& facilitation. Sometimes students have brought activities or exercises that have been welcomed by the facilitators."

These viewpoint provide some evidence of a shared learning experience but the decision making process of who becomes tuākana is still held by the facilitators. For an improvement in this more discussion may need to take place.

\section{Q12. Is there a measurable outcome to the programme?}

This produced a mixed response with one person answering yes and no. He went on to justify each response by saying "That he had noticed a reduction in fights, although he had seen nothing directly measured". The other respondent replied yes but did not provide an example.

\section{Q13. How are the cultures of the participants valued in the programme?}

One respondent related Rock and Water to his own culture whilst the other made mention of the fact that all cultures and ethnicities were welcomed in the programme and that it was not so much a case of the importance of culture but that it was more an issue of gender. " $A$ 
theme of neutrality around culture exists as the themes/concepts spoken about are more entered on being a boy/man and human regardless of culture." For the other it was about recognising the cultural background of the participants "For myself as Māori, a haka has been composed particularly for Rock \& Water - the majority of boys this year are Māori". The first respondent spoke about how Māori culture had been embraced and woven into the programme to reflect the ethnicity of the participants. "Particular Mãori Tikanga(ways of knowing and doing) and culture have been incorporated into the programme as many themes and activities are akin to Māori tikanga, Māori games, haka, whakatauke and korero Māori are intertwined within each lesson."

\section{Q14. How is Rock \& Water viewed in the wider school community?}

The participants had mixed views on this question. They were positive but mentioned that the perception amongst staff could sometimes be negative. One mentioned "Being going 3 years plus, since its inception in the school. The proof is the way the boys hold themselves with great pride. The school definitely values this programme due to positive results with

students." As mentioned earlier the other participant spoke of "Some who are informed and involved place great value on the programme and are wanting to expand with girls being involved, others who are ignorant thinks it's just a place for boys to go on outdoor trips."

\section{Q15. Do you think R \& $\mathrm{W}$ is becoming part of the schools kaupapa (collective vision)?}

In response to this question both participants replied yes.

\section{Q16. How and in your opinion why?}

Both respondents spoke positively, one mentioning the impact that the programme had on the individuals and the other speaking about how the programme was gaining recognition within the wider school and its projected expansion. "Because it helps boys see a better way of dealing with conflict, they get to practice in their everyday lives. They deal with a bad 
situation in a positive way through utilising these concepts." There was mention of how the programme had been mentioned in a recent Education Review Office (ERO) visit "the principal making mention of the programme as a successful initiative in the 2011 ERO report." "SMT wanting to create a girls Rock and Water group."

Mention was also made of how recruitment of boys had been maintained for over three years by word of mouth between students "Boys attend of their own free will and has been maintained for 3 years without active recruitment". Finally mention was made of how one practice (Haka) had moved out of the Rock and Water forum and into expected school kaupapa "A Rock and Water haka has been established that honours the top year 10 academic student at junior prize giving."

\section{Interview Findings}

After the participants had completed the questionnaire, the results were collated. Participants were then asked to take part in a semi structured interview. The interviews varied in length from 30 minutes to one hour and the intention of the interviews was to delve a little deeper into participants' attitudes and opinions regarding the Rock and Water programme and their role or participation within it.

The student participants were asked questions based around the activities used in rock and water. They were asked about why they chose to participate and to describe whether Rock and water made them connect and engage with the school (see appendix 2). The results of these interviews were encoded using NVIVO 9 and collated using the report facility and are displayed in the form of a table and tree map within this program. (See appendix 3 and $3 a$ )

Themes were identified that were common to both groups and encoded from participants responses.

The themes are reported on below:- 


\section{Engagement}

As one of the key aims of this research is to look at whether Rock and Water improves the engagement of Māori and Pasifika boys. Students and teacher facilitators were asked the question "Do you feel more engaged with the school? ". The response was $100 \%$ in favour of feeling more engaged with the school. All students replied yes with one student responding "Yeah it's made me realize what school is worth, like learning is not an optional thing but you have to learn to get a job, so that's what I'm focusing on this year'. Student A

Another student responded "yeah cause you get involved, some people go to school to learn instead of going to school to learn and do stuff." Student F

Thus it can be argued that this is evidence of a behavioural component in defining student engagement with school (Jimerson, et al., 2003). The students quoted above have decided to get more involved in school and now see the school as more than a place that they attend for the day. They have invested more time and effort in their involvement with the process.

When asked to expand upon this and speak about their connection with the school. Students were asked the question “Do you feel more a part of Mana?” They all answered positively and credited the programme for that connection.

"Yeah, cause... I can't explain it but I feel way more connected with the school because of Rock and Water." Student A

“Oh yeah, because I've done stuff participating in the school.” Student E

"Yeah I do mister, cause with Rock and Water it makes you so confident to walk around the school, say hello to anybody, usually I'd walk straight past." Student C

These comments reflect only a few of the opinions expressed. When most students were asked the question, their response was predominately yes with little expansion.

One student when asked how replied "yeah course, Rock and Water makes you more talkative, more leadership roles, gives you that and I just branched off that." Student D 
His response was interesting as he had related the learning that takes place in the sessions to his role in the school and then applied it.

\section{Relationships}

The role of relationships in improving the engagement of Māori and Pasifika students cannot be over stated. One of the challenges for this research is to see how Rock and Water as an intervention fulfils some of the criteria of the Te Kōtahitanga initiative. The relationship between students and between teachers and facilitators is central to this. When asked about the role that relationships play in the programme one facilitator replied "Emm I think a lot of boys come along to the session because they've got a good relationship with the teacher or facilitator to begin with and emm i could say that of all three of us and one of our ex facilitators as well, they come along because of who's leading it and those positive relationships that we've formed but also because the relationships they've got with their peers the age that they are, wanting to belong, that teenage wanting to go because their mates say it's cool, those relationships are pulling the kids in." Facilitator A

From this quote the facilitator believes that the relationship the student has with their peers and with the facilitator/teacher in the wider school has currency. This would very much resonate with the work of Hattie (2003) in that the greatest influence of raising Māori achievement is the relationship between teacher and student. This is supported by (R. Bishop, Berryman, M., \& Richardson, C., 2001) who argue that we should be relating to and working with students without maintaining the power relationship. In a later reflection on the impact of Te Kōtahitanga (phase 3), they suggest that this approach is about

"Teachers sharing the power with others (students), they will better understand the world of 'others' and those 'othered' by power differentials". (R. Bishop, et al., 2007, p. 17)

This is a challenge for teachers and facilitators and will be explored further in the discussion of these findings.

When asked how the relationships unfold in the sessions the students responses were interesting. 
"It's very important cause like us; our relationships with you guys are like mean. Well it's kind of hard to explain, I cannot put it into words.... Different to the classroom, completely, rock and water brings you closer as a group. " Student D

"How they work is you can hate one another outside this classroom, but in this classroom its peace, it's all about peace, friendship. It feels like, like my family, the group, they're so close." Student A.

"Pretty important, cannot get angry with each other and then we should be alright." Student $G$.

“Oh everyone's good; no one argues all get treated like friends. " Student E “Ahh, getting along with each other." Student F

“Relationships are good ay, pretty good.” Student $C$.

Within the theme of relationships, the students comment on the environment and how there is an expectation of behaviour. This could be seen as evidence of Reckless (1961) ideas of outer containment being enacted. The groups' expectation of conduct and behaviour is enforced and modelled by the participants and played out in the social space of the rock and water forum. The negotiation and agreement of what constitutes acceptable behaviour between all participants, including the power relations between adults and the boys, produces a set of values that are in some way the same as the school but also more fluid. The impact is that some students feel more connected and by definition more engaged. A good illustration of how this is enacted is described below.

“There's no desks or chairs, it's all circles....you know Knights of the Round Table. Everybody is equal and you have to keep the circle balanced. There's power I suppose, because there's facilitators and tuakana that are facilitating. I suppose that could be deemed as authoritarian, but it's a more respectful relationship that are there."

\section{Facilitator B}

"Yeah, most definitely, because... just the conversations that we have across the circle. You're dealing with boys that, a lot of those boys cannot sit still in a classroom environment 
and they're rowdy and cause lots of trouble. Yet they're sitting in a circle with 20 other boys of a similar nature and they're fully engaged, fully asking questions about the stories being told and the analogies that are put forward. I mean that just speaks for itself and they're not being quiet because they're being told to, they're being quiet because they're listening to what is being said, processing it and the fact that they're coming back with questions is just more evidence that they're taking it in ... yeah."

\section{Facilitator A}

\section{Connectedness}

Connectedness is a key concept in this research, how connected to the school the boys feel is a key tool in improving their engagement with the education process. How Rock and Water connects the students to the school is described through participant responses. When asked,

\section{Do you feel more connected with the school?}

The participants replied overwhelmingly that they did. Their responses are below

"Yeah, much more a part than I was before, I was lonely - nothing to do really. Rock and water helps me meet others, meet new people that come in." Student $B$.

"Yeah, it feels like I belong here....it (rock and water) should be another subject." Student A

"Yeah I guess ' $m$ a role model now, have to teach them what to do, a bit like a tuākana." Student $E$

Yeah hard out, you feel because the majority of the school is boys and your bond is there, you've got a mean as bond and yeah it's just a good buzz." Student C

"Before I was only - nothing to do really. Rock and water helps me meet others, meet new people that come in." Student B.

The questioning then went on to ask how the connection is gained or maintained. In the interviews the participants were asked questions around the activities carried out in the programme and the values or lessons gained as a consequence. These were encoded around themes of 
- Fun,

- Trust,

- Ako (reciprocal or shared learning),

- Te Kōtahitanga (unity, belonging ),

- Respect,

- Manaakitanaga (caring for the group or individual),

- Contextual learning,

- Brotherhood,

- Manhood or Role modelling.

\section{Fun}

When asked what they enjoyed most about the programme, participants consistently indicated that fun was a significant factor in their lives. In the questionnaire the theme of fun was identified when asked what made a good school day and what made a good teacher. Rock and Water has high energy, collaborative and competitive activities woven through it. Sessions normally start with a high tempo activity, move into a formal salute and then transition between activities that are physical and competitive as a vehicle for demonstrating or practicing facets of the programme (breathing, balance, centering and grounding use of rock or water attitudes) and episodes that involve discussion and instruction. Students were asked two questions.

\section{Q1. What is the coolest thing you've done in Rock and Water?}

\section{Q2. Why?}

In response, their participants mentioned fun many times. Their responses are below

"Yeah you pretty much learn to have fun. Ah it's like a different environment Rock and water, you're like having fun. Like you're having good fun and you're playing. You're...it's like a team and when you're in class ..(laughs) its quiet." Student D 
"Just easier and fun lessons with all the boys with me. It's work but in a different way. Like no work and activities, I like doing activities. "Student F

"Yeah they're fun, keeps me entertained, Yeah keeps me entertained". Student B

"cause you don't really do it all the time. The first time we rock climbed was in Rock and Water and it was good as, it was good fun." Student $F$

"If I had to pick it, our trips that we go on, awesome, our activities, all we learn." Student C

\section{Trust}

From this question many students mentioned EOTC (Education outside of the classroom) activities that were undertaken as part of the group. The participants were asked questions related to trust and respect such as do you feel respected in the group, how and can you give me and example of how Rock and Water has worked for you. In their responses, the word trust appeared on numerous occasions relating to both physical and discussion activities. For one of the participants (a facilitator) the issue of trust was about exploring it as a theme within the programme.

"Whether you're talking about breathing or you're talking about themes of trust or anything like that, analogies are really good to help the kids to understand in layman's terms what you're really talking about." Facilitator $B$

“yeah, definitely there's trust there, there's gotta like have a lot of trust, lotta help, lotta

courage...Yeah cause as boys, we like talking to boys, but if it was a boys and a girl they'd be quiet." Student D

"Argh yeah, when you was climbing the rocks, someone at the bottom had to hold your string (safety rope) and you had to trust in them, that they wouldn't let you fall and might die. So they controlled whether you live or die. Yeah you had to trust them." Student F

"In our activities, you know how we do the four man bridge, so you have to trust all the boys, cause if one of you goes down, you all go down - like a bridge is only as good as it's parts." Student $C$ 


\section{Ako: Shared or Reciprocal Learning}

This theme was mentioned on many occasions. The question was first asked: Have you heard of the word Ako? If participants had then its meaning was negotiated and clarified. In the context of this research it was explained as shared or reciprocal learning. The participants were then asked how it was enacted within the programme. The respondents were also asked if they could think of an example when they had seen it happening. One event that was identified was the group discussion activities; another was the haka that had been written for the group.

"We all take turns usually, you, Facilitator B or Facilitator A, all the boys, we give our opinion too. "Student C

"Yeah when I do the salute, they all like listen." Student F

"The whole, many people allowed to talk, but it's good to hear from an elders perspective on ...I reckon... so we know what like... So we know what is going on." Student $D$

"Yeah hard out everyone gets a share talking, everyone gets a share learning." Student E

"Yah I think sharing is a key component where because we're working with young boys - a lot of them maybe at home there's not a lot of that type of culture in the family. It's helping bring out the ability to share their own experiences....you know relating it to actual life experiences that have happened to yourself. What I've found is in rock and water, the sharing has really been .... What's the word... a key in building relationships, because eventually from you sharing what you've done in your life; these young fellas start to unravel what they can offer; what they can share to the group." Facilitator $B$

"yeah most of the time, when we're having our talks cause the students say stuff as well and then the teachers learn." Student F

"Yes they do, cause one day they may have to say something that's on their mind with someone else; just a place where you can share your troubles or your ideas." Student A

The shared or reciprocal learning that is taking place in the programme does not stand alone. It had been created in an environment that is co-constructed with all the participants. It has 
grown from the building and strengthening of relationship within the group and it has been fostered by recognising that the individuals involved are culturally located. This is a key factor in the development of Te Kōtahitanga and is illustrated in a number of ways. One significant addition has been the inclusion of a haka in the programme. The haka does not sit alone as a gimmick; rolled out to engage and entertain the students and the wider school, but has been written and practiced by the participants as their own. This gives ownership of the practice to the group as a taonga (gift or treasure) and is valued accordingly.

\section{Te Kōtahitanga}

Unity or a sense of belonging through collective experience is a value that has been encouraged and developed in rock and water. The participants identified strongly with this value in their interviews. They were asked to Describe what happens in a session and then How important is the haka? From this the participants were asked if their culture was valued in the programme?

"I think it's hugely important. er... not only because of what Mana brought to Rock and Water, cause when we went through the training; Màori tradition, Māori tikanga wasn't necessarily part of the programme or Freek's (author of rock and water programme) ideas. But the haka and the solidarity, the unity, the power, the strength, the control ....all just gels beautifully with the philosophies of rock and water." Facilitator A

"It's to... Māori it's pretty important cause in the haka it symbolizes everything we do, like our salute; everything we run for. Yep it is cause Maori culture is slowly dying, got to keep it flowing." Student $C$.

"Well emm... the haka, basically is when you look at rock and water, you do the salute, you get in your castle and the haka is about grounding yourself to paptuanuku, to the land and it's about, a lot of it is about balance and control with the haka. You know obviously you're not always putting your voiced out full volume, sometimes you have to control it using your water, sometimes you have to give it heaps and bounce it out using your rock. It's about 
knowing how to use those two to get the haka out for the haka to illustrate the message you're putting out. Yeah so the haka is really important. If I was to relate it to Te Awa Māori ... a Māori world view, perspective; it's about personifying the ancestral house, you're standing there in the stance. I think for rock and water, when you align it with that, your teaching the boys to be solid in that stance." Facilitator B

\section{Contextual Learning}

In describing what happened in sessions, participants had an opportunity to link the activities undertaken with the wider themes of the programme. This provided evidence of contextual learning for the participants. The importance of contextual learning for students has been discussed and explored by Joselowsky (2007), this infers that schools must provide opportunities for student to learn the skills and strategies that will assist them in a wider societal context.

The tools for this contextual learning included activities to develop these skills but also make use of metaphors, stories and analogies. These tools were able to incorporate pedagogies relating to the values of Ako. The learning was valued and shared with and between the participants. Ako as a pedagogy is important in the development of Te Kōtahitanga. As an overall philosophy, oral tradition, metaphor, analogies and the value of Whakatauke (or respect) are powerful learning strategies in both Māori and Pasifika cultures. In positioning this style of teaching and learning, recognition of a practice located within the participants' culture is important as a way of valuing the participants as culturally located individuals and a challenge to and a move away from a mono cultural teaching tradition.

"Before you start, you have to come in with a salute to show respect, so em you have your left hand and you put it over your heart to show all the things that are close to you. Your right hand, like your friendship hand, you mingle around with it and you put it over the rock, just to start off the day." The respondent then goes on to describe how he uses this "What I get out is mainly breathing for me, learning how to focus before games (rugby). Like games for me, I learn how to control my breathing. Usually before a game it's pumping hard. Yeah I learned new strategies, strategies as I was going up, thinking and how to stop and think." Student $D$ 
"Yeah I would, they're given ... if its real, they're in it and are given an analogy or a context to imagine. They can relate back to it and directly to what they're doing at the time. It's powerful as." Facilitator A

"It's helping them bring out that ability to share their own experiences; you know relating it to actual life experiences that have happened to yourself. What I've found is in $R \& W$ the sharing has been... what's the word... a key in building the relationships because eventually from you sharing what you've done in your life, these young fellas start to unravel what they can offer, what they can share with the group." Facilitator B

"Some people say their life experiences and you learn stuff like what they have done, so if you're in that situation that they've been through; you can do what they've done". Student F "I remember something about talking, about walking away instead of fighting. Communication, eh what else, respect." Student C

\section{Manhood}

The theme of manhood or role modelling what it means to be a good man is extremely topical and an area that is not without controversy. Who decides the attributes of a good man and is it a universal construct? These are all questions that are for discussion in other research.

Rock and Water as a programme has activities and discussion points where the issue of manhood can be negotiated and discussed with the participants. In the context of this study, the theme was adapted to the skills of the facilitators and to the characters of the participants. In interviews the theme arose but with less frequency than expected. This was something of a surprise. The language used in the programme emphasises and celebrates masculinity. Participants replied that they felt that the programme was helping them in their journey towards manhood but not as the prime focus of the programme.

Participants were asked the question One of the themes of Rock and Water is learning how to be a man. Do you think the rock and water group is helping on that?

"Yeah hard out, I'm becoming more of a man in this group." Student $E$ 
"It represents our rock side, our manliness, you know our pride." Student C

"Because it's treating every kid, every boy that comes in as a man and them wanting to be a good man, a strong man regardless of what cultures, or backgrounds or boundaries or whatever influences they've had." Facilitator A

"For those reasons to become a better man." Student B

\section{Role Modelling}

Aligned to this was the issue of role modelling. Only three respondents mentioned the significance of role modelling in the programme. Of these two were facilitators. This might be some indication of the power relations in the programme or of the perception of their role by the facilitators.

"Ah staff... taking part like tutoring us, showing us the ways; showing us what they've already learnt, what they've experienced." Student D

"Yeah definitely, you know I think what we've experienced ... a lot of these boys lack a male (role) model in their lives. That nurturing hasn't happened for them, so the control they need, which comes for you know the male side is in rock and water being nurtured." Facilitator $B$.

"There was a mixture of different cultures, not only ourselves as leaders. There's you and me as Pakeha- you with your British heritage-Scottish culture in particular and Todd modelling Māori culture....I suppose we were role modelling for you and I in particular ... the white boys I suppose, the Caucasian kids that are involved. I think us working together as three different cultures, as leaders; as the adults was awesome role modelling for the boys." Facilitator A.

In summary, a number of themes emerged from these results. The importance of relationships within the programme is mentioned on a number of occasions. Students were open about the relationships between themselves and their peers and between themselves and the teacher facilitators. 
For many of the respondents, the opportunity to reflectively think about the programme was new. In terms of developments for the programme, the introduction of a reflect journal might be a way of incorporating this into the programme. Reflection takes place in sessions during the discussion activity and there was evidence from the results to suggest that the boys took the ideas and strategies shared in the discussion and applied them. 


\section{Chapter Six: Discussion of Findings}

In this chapter the findings from the interviews and questionnaires are discussed. These relate to the research questions and this discussion will examine whether they provide an insight into the reasons behind the engagement of Māori and Pasifika boys at school. The discussion will look to see how closely the activities utilised in Rock and Water align themselves to the values of Te Kōtahitanga. This chapter will also see how the programme fits within the parameters of social control theory. As mentioned earlier, the initial focus for this research was to look at how the Rock and Water programme improved the engagement of Māori and Pasifika boys with school. As this research progressed, themes and values of unity, togetherness, brotherhood and shared learning surfaced in student and teacher facilitator responses to questionnaires and interviews. Having read about the Te Kōtahitanga initiative I could see some similarity. The activities undertaken in Rock and Water have some similarity with this initiative but are not a perfect fit. What is being suggested as part of this research is that an opportunity presents itself to weave the values of Te Kōtahitanga through Rock and Water.

From the student questionnaire responses, the majority of students identified themselves as feeling engaged with the school. Only two respondents suggested that they were not. The extent to which Rock and Water played a part in this process was explored in the interviews. Participants were asked if they felt as a consequence of participating in Rock and Water, the extent to which they felt more engaged with the school. The response was $100 \%$ in favour of being engaged with the school.

When asked how? Involvement appeared to play a significant part. The boys identified their participation in the programme and their contribution as evidence. These findings provide evidence to support the psychological and behavioural component in the engagement debate (Finn, 1989). This meant that the boys had an increased sense of belonging with the school and had an acceptance of the schools values system. To expand on this, accepting or buying into a values system is one way in which Reckless (1961) suggests boundaries are maintained. An acceptance of school values around attendance, achievement and participation would provide an example of a pull factor as a part of wider outer 
containment. This was illustrated by the following quotes pertaining to the value of education generally and how the boys conducted themselves around the school environment.

"Yeah, it's made me realise what school is worth, like learning is not an optional thing but you have to learn to get a job, so that's what I'm focusing on this year” Student A “Just made me like friendlier and focused on my work and in class." Student B

"Yeah, I do mister... cause with our rock and water it makes you so confident to walk around the school, say hello to anybody, usually I'd walk straight past." Student C.

The behavioural component is illustrated in their participation in more of the school activities. The psychological component was triangulated with the question in the interview do you feel more a part of Mana College? To which all of the boys replied positively. Most replied yes with no elaboration but some spoke of increased confidence, more talkative and participation as themes.

The link between confidence and engagement is important as an intrinsic motivator Yonezawa (2009, p. 5) suggest that

"Learning cannot take place if students are in schools where they are anonymous". Citing (Pittman, Irby, Tolman, Yohalem, \& Ferber, 2003)

She makes the point that

“Improving young people's academic achievement in high schools requires greater attention to the engagement of young people themselves". (Yonezawa, et al., 2009, p. $5)$.

This is important for the boys in the programme as they are participating in school life to a greater extent. The boys have suggested that participating to a greater degree, being more confident and more communicative are factors that relate to their felling of belonging. It could be argued that as a consequence of their participation in the programme, they have found a voice and it is being heard. The knock on effect of this is they are less anonymous within the school. 
As argued earlier in the thesis, engagement as a value has a number of factors contributing to its success or failure. The affective dimension generally relates to students connectedness to the school. Yonezawa et al (2009) in their study of high school students' engagement in the US argued that this dimension covers aspect such as boredom, happiness, sadness and anxiety to name four. The students in this study were asked in the interview to define or describe a good school day. Fun was a choice for many of the boys, fun in relation to the activities undertaken and also to describe the teacher.

When asked to explore this theme a little deeper in the interview, many respondents spoke about the fun activities that were undertaken in Rock and Water. A telling quote being

"Just easier and fun lessons with all the boys with me its work but in a different way. Like no work and activities... I like doing activities."

The perception of what constituted work to the respondent here was telling. He had not made the connection between the activity undertaken and the learning taking place.

A strong component of Rock and Water is the delivery of material through experiential experiences. This strategy has its roots in adventure based learning and involves such strategies as challenge by choice, competition and problem solving.

Aligned to these strategies is the sharing of experiences thorough participant experience. All respondents spoke of having a voice and being heard in the Rock and Water sessions. This fulfils a number of roles. Ako or shared learning as a value is based around the sharing of information or knowledge. The co-construction of knowledge about how to deal with specific situations is woven through Rock and Water. This maybe through role plays or group conversation. The opportunity to practice these new skills is aimed at making boys better decision makers. A specific theme is that of conflict.

When questioned about the impact of the discussion, the response from the boys was subtly different from that of the facilitators. The boys emphasised that they felt their voices were heard and that people listened to them in sessions. This suggests that the boys voices were lost in mainstream schooling. There also appeared to be a suggestion that they are unheard in society. This could be evidence of 'othering' Bishop, et al (2007). To support this, one of 
the facilitators spoke of a gap in the boys' experience of discussion in the home; this was based upon his experience as a conduit between home and school. He suggested that the boys voices were either unheard or they were not given the space to make their opinions known. This could be a suggestion of the way in which family dynamics have changed within some of the families of the participants.

The assertion here is that the boundaries of inner and outer containment have shifted. This would represent a challenge to Reckless's (1961) ideas of social control. This may be due to the fact that there is some elasticity within these boundaries. For example, the participants (the boys involved in the programme) have multiple identities and multiple roles depending on the context. This is to suggest that the borders between inner and outer containment are not exclusive but may in fact overlap. Students may transition through differing roles at differing times of the day. For example, the student who might be incompliant in the classroom environment due to the effect of the relationship with their peers may become more receptive with that same classroom teacher in the Rock and Water environment. This area would need further exploration and the views of this particular respondent have at their root a deficit perspective. As an educator, I am not convinced of this, although I know the role of the respondent to this question is to liaise with families around issues of attendance and school engagement.

Using a shared sense of learning or Ako within Rock and Water is a significant move towards raising the achievement of Māori students. This form of pedagogy is one form of evidence that perceptions between students and teachers are changing, Bishop, et al (2003). Indeed the collective membership of the group could be interpreted as whānau. As McMurchy-Pilkington (2011, p. 4) argue

"Members of such a group are expected to fulfil responsibilities and mutual obligations to other members of the group such that reciprocity operates."

In the context of Rock and Water and with the engagement of the boys, this reciprocity encourages individuals to invest in the group on one level (with shared teaching and learning being an example of this within the group) and at a deeper level of engagement with the 
wider school community/environment (reducing the incidents of aggression and conflict at flash points around the school for example).

These responsibilities involve playing a role as tuākana tena within the group, leading activities, and role modelling to new members. As one boy mentions "Yeah, I guess I'm a role model now, I have to teach them what to do, a bit like a tuākana."

One way in which Rock and Water has evolved or been adapted to improve the engagement of the boys participating has been to locate it with the students' culture. This has predominately been from a Māori perspective. The decision about using aspects of Māori culture happened partly by accident and partly by design. The accident component was opportune in that one of the original developers of the programme in the school was Cook Island Māori. He felt comfortable in choosing and using analogies relating to his own experiences. He was therefore able to incorporate and weave Māori tikanga through it.

The design component came about as the first groups of students were approaching the end of the academic year. They would transition into the senior school in the following year. The facilitators at the time believed that some form of graduation or performance was needed. The need for a rite of passage ceremony signified to the students that they had made a transition from boy to young man. This happened in the wider school with the graduation from junior college to senior college at the end of year 10. For the Rock and Water group, their participation was coming to an end. In line with a number of other similar programmes the ceremony signified a reintegration into the wider school society. This was very similar to Van Gennep 's (1908) ideas of rite of passage. The students had been withdrawn from the school society for a time each week, they had been immersed into the ways of the programme and now it was time for re-integration.

To that end the idea of a haka (See appendix 4), written specifically for Rock and Water and performed at the end of the school year might be appropriate. All members of the group were consulted and allowed (as per protocol in the group) to have a say. I have to say that as a relatively recent European migrant this was a journey into the unknown for me. It was unknown from a teaching perspective; in that I was the novice for this activity. It was unknown linguistically, as I had to embrace Te Reo at a level and complexity previously 
untried. After all the boys and teacher /facilitators reached a consensus, it was incorporated into Rock and Water sessions. The haka has been developed and built up with an increase in complexity during sessions and then a performance given to a school senior manager. After the performance had been judged to be of an acceptable standard by the head of Māori and a senior member of the school leadership team, the performance was scheduled to be included in the junior college graduation ceremony. It established a new ceremony within the junior graduation and also marked a significant milestone for the boys.

The significance of this first performance cannot be overstated. For all involved it marked a major point in the evolution of Rock and Water. For all participants it has become a point of reference, the collective experience shared between the boys and the men in the programme was profound.

In terms of relationships, bonds developed in the Rock and Water sessions were forged. In terms of improving the engagement of Māori and Pacific Island boys, this became a major point of reference. Yonezawa (2009, p. 17) argues that we should

"Ask ourselves what ways and with what tools can we re-engage students in learning?"

I would argue that the use of the haka and the bonds forged as part of its performance are evidence of a way and a tool to re-engage Māori and Pacific Island boys. In this example the haka was used as the skills to develop it were within the group but this does not have to be a Māori form of performance, it could have equally been a cultural performance from another group represented - a Samoan slap dance for example. Indeed the bond created within the group addresses the flow within the frustration-self esteem model explored by Finn (1989, p. 122). The boys in the group experienced positive peer influence within the group and within the wider school community as a consequence of the performance. This in turn raised their self esteem and provided a successful school outcome in that the performance became part of the junior graduation programme.

Since the introduction of the haka in 2009, we have had a taiaha carved to recognise the achievement of the boys and this is presented to the boy deemed to have made the most progress during their time in Rock and Water. The significance of the haka and other aspects 
of Māori tikanga have been to affirm the boys' identity as being an integral part of the teaching and learning process (Gay, 2000). This also identifies student as culturally located individuals (R. Bishop, et al., 2007). As it happened there was a lot within Rock and Water that could be associated with Māori tikanga and vice versa.

As stated earlier in the literature review, issues of togetherness; a shared group identity and working together in context to share knowledge addresses issues of identity amongst Pasifika boys. Evans (2011, p. 72) identifies this as an important factor in improving the engagement and achievement of Pasifika boys working in one New Zealand school. It is not unreasonable to assume that this is also happening in Rock and Water.

The important thing here being that in travelling on this journey the purpose of Rock and Water has not been to challenge or dislodge traditional cultural ways of behaving or practice but more to celebrate and support custom and practices. The inclusion of cultural practice into Rock and Water has been about shared ownership.

Linda Tuhiwai- Smith (1999) in her work decolonising methodologies, talks of research being something that happens to indigenous communities and not with them. This argument could be extended to education. That is to suggest that the Euro-centric focus of education in New Zealand means that for Māori and Pacific Island students, education is something that happens to them. They are placed within a system that has as its criteria for success or failure the acquisition of educational capital in the form of NCEA credits. This could be one potential reason why the achievement of Māori and Pasifika students is lower than their peers of other ethnicities.

In the case of Rock and Water, the learning is with them. The performance of the haka illustrates this in that the development of the practice is shared by all of the performers. The students bring more skills and knowledge to the activity, thereby meaning that power shifts from teacher/adult as the owner and producer of the knowledge to the boys.

The development of the performance represents a journey for the all, but especially so for the adults. The load on the journey is one of shared experiences and success. This mirrors the journey within Rock and Water in which aspects of mentoring or role modelling are used with the boys to improve issues of anger management, engagement and manhood. Although 
in this instance the roles are reversed. Finally the success and mana gained from the graduation performance is received equally by all the participants and is not something that is bestowed upon the boys from their teacher.

Woven through this and integral to the principal of Ako is the value of Manaakitanga (caring for the individual or group). The students identified being cared for or looked out for as one way in which their engagement had improved. They equated this in a number of forms, as being respected; as belonging; as being connected.

When exploring the impact that this has on student engagement McMurchy-Pilkington (2011) in their study of Māori success in foundation programmes at university argue that it is important to make the connection between the concept of whānau and the school. That the educational establishment reflects or represents the family background of the learners and is not isolated from it.

It seems glib to suggest that for some Māori and Pasifika boys, school is an environment into which they are immersed and submerged within but this maybe the case. Rock and Water creates an island within the school week. The use of a specific time slot and a different location is an important factor on two levels. Firstly, to develop relationships between the participants and the facilitators and secondly to provide a forum in which issues of masculinity can be negotiated and explored. When ERO (2008) carried out a review of good practice in secondary schools around boys education they noted that one approach that was working with boys were:-

"Programmes or approaches that encouraged boys to consider matters of male identity and the quality of their own relationships and decision making. Some of the boys and teachers also reported the importance of letting boys make decisions for themselves about their learning and having some choice about how to approach some of their objectives".

Education Review Office (2008, p. 26)

This approach is utilised in Rock and Water, the boys can feel valued as individuals; as boys becoming men and where they can explore new ways of dealing with the situations and 
hazards they will encounter back in the turbulent waters of the school week. This is an example of what Alton-Lee \& Praat (2000) would call a 'rich experience' The emphasis being to ensure that boys are given rich and interesting experiences at school.

There were many instances where the boys spoke of this sense of being cared for and it was also evident in the responses given by one of the facilitators.

"Because one of the big things for me leaving... one of the most difficult things was leaving Rock \& Water group because of the people in it, you know. the facilitators, the boys, the environment we created and still I've got ambitions to do that at Aotea college that I've moved to...emm that fire won't go out, it's just a candle that's sitting there simmering at the moment... so connectedness, I'm connected to it and will be forever really. and the boys will as well $i$ hope, when boys slip up or staff move on there's still... no matter what they've done we're still connected to those boys in one way or another. Positively. A prime example is me just bumping into one of our main boys at the Shell station just the other day and one of our facilitators leaving and me having a massive urge to go around there and talk to him about it... yeah and another boy who got into trouble last year, who got our top award and all of us wanting to have him with us or at the prize giving, you've just got a connection with these other guys cause they understand what it's about." Facilitator A

"I feel like, it feels like my family, the group, they're so close. I'm personally in the group cause I love it, I love being a tuākana, I love telling people, to help with their troubles."

\section{Student A}

"Yeah I think all of that is about helping the students to relax, first and foremost. When they go into class, some of them might be a bit anxious when they see how seats are set and who they have to sit by, whereas in $R \& W$ it doesn't matter who you're by in that circle, it seems to be creating a type of unifying spirit within them. and then what you find unravels from that is you start seeing these boys becoming family, cause when they come in that circle, straight away they're personifying unity and all those things and it just seems to naturally resonate, permeate among them all and they naturally work like that."

\section{Facilitator B}


To summarise this chapter, the results of the questionnaires and the responses from the participants all indicate that student engagement has been influenced by their participation in Rock and Water. When asked, participants spoke of the extent to which Rock and Water had made them feel more connected and more a part of the school. These responses were not restricted to the student participants, facilitators who have since moved away from the programme and the school also spoke of the impact that the programme had had on them.

The responses reported here indicate that the way in which engagement has been improved is related to the pedagogies employed within the programme. Caring for the individual and caring for the group (Manaakitanga) was important in this process. Recognizing and valuing the individuals in the group was a factor in addressing the behavioural component of engagement (OECD/PISA, 2006).

Of equal importance was the practice of valuing and acknowledging the many voices within the group, sharing and collaborating (ako) was also seen by the respondents as important. The boys in the programme spoke of fun as a significant factor in their enjoyment of learning but also of their engagement with the school. Rock and Water was identified as tapping into this value through the use of ABL (adventure based learning) and experiential activities. This is a skill that could be transferred and applied to the classroom to improve the engagement of Māori and Pasifika boys.

The use of collaboration in the classroom with the boys to achieve educational outcomes could be one way in which the lessons of Rock and Water could be transferred to improve student engagement. The challenge is to look at a workable model for this. In other schools in the region, Rock and Water has been used as part of the social studies programme and is delivered to all junior college students (Year 9) on entry to the school. It is not for this study to suggest this as a strategy for all school, but it has some merit.

Of equal importance in this study is the role that relationships play within the programme. The relationships in this context were strengthened by all participants embracing the values of manaakitanga and ako. This was a challenge. Perceptions of the power relationships 
within a school and what constituted as student and what constituted a teacher were challenged.

For the facilitators, a commitment to hand over ownership of the learning was important. Both of the facilitator respondents spoke of the bond that had developed within the group as a consequence of this sharing of roles. Teaching and learning shifted from a 'master and student' approach; towards a group working moving a common goal based upon shared experiences and skills. This is can be argued is evidence of the cognitive dimension of engagement at play (Jimerson, et al., 2003).

The assertion here being that in the same way that teacher/facilitator roles were being challenged through collaborative or reciprocal learning, student perceptions of self, school, teachers and peers were being changed. Students were being given opportunities to construct new avenues of meaning based upon the themes explored in the programme. How to manage conflict, how to solve problems, how to overcome fear, what it means to be a man are all themes that were illustrated in one form of another from interviews. This is difficult to employ and Cook-Sather (2006) argues this point suggesting that the structuralist nature of schools; founded on traditional euro-centric notions of power and control make any 'repositioning' of students as active agents difficult. It could be that through the use of programmes such as Rock and Water a space for this to be explored is now available.

This negotiated space, which was created within the Rock and Water programme is still a space of social control. The boundaries of inner and of outer containment are still in play. Indeed within the programme themes of self worth are built into the programme valuing oneself and valuing the contribution of others has been mentioned in participants responses. Reckless's (1961, p. 44) suggestion that for inner containment to work an individual should have strong morals and ethics is reinforced within Rock and Water.

The use of a salute symbolizing both the two components Rock (power, strength, staying the course) and Water (flexibility, friendship, mobility, adaptability and conciliation) is employed at the start and end of each session. The Rock component of the salute (a clenched fist) is placed above the heart and is used to represent the protection of an individual's values. This has meaning for the students and in one of the earliest or beginning sessions 
participants are asked to identify those things that matter, the things worth fighting for. Without exception, family is identified by all boys- regardless of ethnicity.

This illustrates I believe, that improving student engagement is as much about realigning our ideas around social control as it is about using deficit theory as an apology for the lack of engagement by some boys in our society. Rather than focusing on the factors that lie outside of the control of schools, the focus can shift towards recognizing and supporting the common shared values of the students.

Embracing these values and discussing the ways in which they can inform a student's actions has potential. School, and in this case Rock and Water; is providing a context for the boys to see themselves as part of a wider society. As mentioned earlier in this research, this is an opportunity for teachers and facilitators to adopt a wider role and responsibility.

Overall, the finding from the interviews and questionnaires presented opportunities in which the engagement of Māori and Pasifika boys could be improved via their participation and contribution in the Rock and Water programme. 


\section{Chapter Seven: Conclusion}

The aim of this chapter is to reflect upon the findings of this research. In some ways for the researcher and the reader, this study represents a journey. This journey had a course to navigate, the examination into the impact that Rock and Water had in improving the engagement of Māori and Pasifika boys. As with all journeys there have been deviations and changes. In carrying out this research new and interesting directions have been explored. In keeping with the navigational metaphor, the final destination has been reached and new educational frontiers beckon.

This research chose to look at how a programme (Rock and Water) influences Māori and Pasifika boys' engagement with school. From the start, I defined what constitutes engagement and how schools can work to improve the engagement of students with the education process became a challenge.

There were many interlocking and interwoven factors that influence a student's engagement with school. In the context of this study addressing issues of belonging and connection have been important. Disengagement from school and education is a real issue for Māori and Pasifika boys in New Zealand. The data presented earlier in this study suggest that they are more likely to leave school at an earlier stage than non-Māori and non-Pasifika students, have a higher chance of being stood down or suspended and are not achieving at a comparable level.

The reasons for this disparity in engagement, achievement and school completion are complex and cannot be adequately explained away using deficit theory. The challenge for this study was to see how Rock and Water could improve the engagement of Māori and Pasifika boys. Could the intervention of this programme decrease the chances of them leaving education earlier, becoming a negative statistic in behaviour management strategies and through an increased engagement with school improve the likelihood of them achieving at a higher level?

From the findings of this study and in the context of this school, the engagement of Māori boys had improved as a consequence of their participation in Rock and Water. This was achieved through the use of pedagogies that embraced some of the values of Te Kōtahitanga. 
This has been achieved by embracing and adapting the programme to recognize the contribution that Māori culture and identity makes to New Zealand society. That is to say that within the programme, the pedagogy has been adapted or changed to be more culturally responsive.

The driving force for this has been from the participants, it has been at the inclusion of a philosophy that has recognized that the participants are culturally located individuals (R. Bishop, et al., 2003). As Graham, Meyer, McKenzie, McClure \& Weir (2010, p. 132) argue

"Personal history, accomplishments and behaviour can enhance or complicate learning'.

The challenge for Rock and Water staff was that of embracing the cultures of the participants whilst at the same time operating within an existing mono-cultural education system.

This led to an adaptation of the values and philosophy of the programme. Similarly Andreissen, Phalet, \& Lens(2006, p. 843) found in their study of minority groups in Netherlands schools were student perspectives of the educational experience were about a cultural mismatch between the dominant culture and the non dominant cultures. They suggest that one avenue is to

"Focus on future progress in spite of present failures'.

Andreissen, et al (2006, p. 828).

In New Zealand and in the context of this study, the boundaries are more blurred and have flexibility. That is to suggest that in the context of this study, working in a school where the dominant culture is Māori, it is a case of finding an approach in which Māori and Pacific island culture are recognized and utilized in a predominately western education system. Evidence of this is found in the incorporation of the values of Manaakitanga (caring for the individual or group), Ako (shared or reciprocal learning) and Te Kōtahitanga (unity or togetherness). This has been through the creation of tikanga (or practice) and the value of whanau (or family). 
It would be easy to say that in the context of this study, Rock and Water has embraced the concepts and ideas of Te Kōtahitanga (R. Bishop, et al., 2007). This would however, suggest that this was a deliberate and planned approach. The aims of Te Kōtahitanga were based around teacher professional practice and were introduced as a deliberate strategy of changing a culture within a school. In the context of Rock and Water, the adoption of the values outlined above was more a part of a negotiated space between students and teachers in this study. The purpose of Rock and Water was to assist in school behaviour management models.

In this study it was used as part of a restorative management model. It could be argued that Rock and Water and the restorative process have been used to reduce student stand downs and suspensions. Māori and Pasifika boys were represented disproportionately in these figures.

Within the programme itself issues of masculinity, anger management and conflict resolution are explored. In extending the discussion and debate to include cultural expectations and attitudes to these issues within the Rock and Water forum, a new hybrid space of collaboration and negotiated values has been created. In this space new forms of learning are taking place.

Based upon the findings of this study, Rock and Water is creating a space in which new forms of learning are being developed. It has suggested that one of the challenges for practioners is to reposition themselves within a "culturally responsive pedagogy" Hynds, et al (2011, p. 340).

The ways in which Rock and water does this, is to take a programme that was initially aimed at challenging stereotypes of masculinity and as Martino \& Berrill (2003) suggests

"A stronger role that men need to play in interrogating the social practices of masculinity in boys' lives as well as their own"

(Martino \& Berrill, 2003, p. 100).

This was undertaken with males role modelling the attributes of a 'good man' (Lashlie, 2004) and then into this weave through collaborative learning and pedagogies. In doing this, it 
hands over some of the responsibility for teaching and learning to the students. Using and embracing the values of Ako, activities are negotiated and then enacted with the boys.

This approach is not without its challenges and one of the critiques of this approach is the extent to which the learning is truly collaborative. The power relationships still exist; the teacher will still be the teacher outside of the Rock and Water forum. The planning and overall direction of the programme will still remain in the hands of the teacher facilitators. Student attendance is still monitored and in some cases initiated by the school. The factor that works as a force to even out this power relationship is the embracing of Manaakitanga (caring for the individual, caring for the group). Evidence presented as part of this study illustrates the strength of this value. The boys and teacher facilitators questioned and interviewed all mentioned it in one form or another.

Indeed it could be suggested that social control theory is at play in that all that is really happening in Rock and Water is an attempt to control troublesome teens and position them within an existing power structure as part of a behaviour management plan. That the ring of outer containment is being used to bring the boys back within the confines of society (Reckless, 1961). This is illustrated by the referral of students to the programme by teachers and by the school board as part of stand down and suspension conditions. This is the very challenge that (Cook-Sather, 2006) speak of when discussing how to reposition students in a structuralist and still predominately colonised system.

The hybrid space is created by those students who self select to join the group or who come as a consequence of word of mouth. This creates a momentum in the group that moves it to the boundary between inner and outer containment. For some the outer boundary is maintained and reinforced by the programme as an attempt to stop delinquency and disengagement. For others the issue is inner containment in which attitudes and values are explored, negotiated and enacted.

From the findings of this study, the Rock and Water programme is one of constant evolution, incorporating activities and values that embrace the cultures of the participants is evidence of a genuine attempt to engage the boys. To identify the students as located within their culture and then to develop skills which have relevance in a real world situation. As Yonezawa, et al 
(2009, p. 6) argue; this embraces a psychosocial approach. Rather than focusing purely on their academic needs Rock and Water looks at developing skills that will enhance their life chances. That is not to dismiss the need to develop academic achievement. The boys taking part in the programme will need to live and prosper within a society based around qualifications and attainment.

One challenge for this study has been to look at how Rock and Water can be improved is with the engagement of Pasifika boys. From the finding of this study there has been lots of evidence to suggest that the engagement of Māori students has improved as a consequence of their participation but less to suggest that Pasifika boys' engagement is improving also. This is an area for further research. The reasons for the lack of evidence relate to the demographic within the group. Only three of the respondents identified themselves as Pasifika out of a total of twelve participating. This is an area for further study. The programme has not been set up as a response to Māori and Pasifika boys disengagement. It just happens that in the context of this study the demographic of the school has a high proportion of students that identify themselves with being Māori (70\%), a smaller proportion who identify as being Pasifika (20\%) and a smaller group identifying themselves as Pakeha or other (10\%). In relation to the ethnicity of the school, the number of Pacific island respondents represented in the programme is in proportion to the population of the school. Ethnicity is not a factor when deciding which boys will participate each year, nor is it a barrier when boys self refer.

When describing the impact of the programme on student engagement, the issue of engagement with an E versus engagement with an e has to be examined. From the responses of the participants, hauora (overall well being, incorporating a physical, emotional and spiritual component) is being addressed in the programme. This points to the wider question of the purpose of education is it about achievement and results? Could it be that engagement in this context is about the growth and development of the boys into socially competent, caring men of the future?

This is an ambitious claim however and one advantage of the programme as illustrated by the responses of the teacher facilitators and the boys was that they had time and space to explore what it meant to be a man. 
This opens up the debate as to where engagement fits within the educational system, Munns et al (2005, p. 12) suggest that 'e' ngagement with a small 'e' is

"To bring into play classroom learning experiences that are purposefully designed to encourage deep understanding and expertise, and genuine enjoyment. They also aim to promote the valuing of what students are doing and active involvement in what is being learned"

This 'e'ngagement perspective has a whole-class focus that also takes up a social justice position. This means that classrooms working towards 'e'ngagement will enhance social and academic outcomes for targeted boys".

This works alongside 'E'ngagement with a big 'E' which targets specific boys with interventions such as curricular and extra-curricular activities (mentoring, role modelling, school ethos).

In Rock and Water both are at play, social justice (or 'e'ngagement) is explored through the use of role play and ('E'ngagement) experiences in the Rock and Water 'classroom' are based around enjoyable experiences specifically targeted at boys in general and Māori and Pasifika boys in particular. The respondents in this study mentioned the word fun and identified new experiences such as rock climbing and kayaking in their questionnaires and interviews,

From the discussion so far, the overall findings point to Rock and Water improving the engagement of Māori and Pasifika boys with school. There are however, a number of critiques that need to be identified.

In this school, Rock and Water is having some success in improving the engagement of Māori and Pasifika boys. Can there be a generalisation about the successes of the programme these be applied elsewhere? The short answer is in a limited way. The programme has grown within the school, from one class it has now grown to two. The focus is still with the junior college and aimed at boys in year's 9, 10 and 11. As Alton-Lee \& Praat (2000, p. 15) suggests the issue of 'which boys' is pertinent. 
To classify all boys as being in need of the programme is to suggest that being a boy is a unifying and homogenising condition. The discussion and findings in this study suggest that is not so, that some boys need to be involved in the programme for differing reasons and their involvement is for differing lengths of time. Another challenge (or it could be argued, a strength) is that the programme is now being offered to a targeted group of girls in the school. This maybe because of issues identity, it maybe because of issues of anger management. This would suggest that Rock and Water is a behaviour management strategy and fits within Reckless's (1961) ideas of social control.

Another critique is the level to which Rock and Water fits within the ideas and philosophies of Te Kōtahitanga. From the findings of this study, the programme has affinity with Te Kōtahitanga but is not an attempt to implement it in its entirety. An alternative reading may suggest that aspects of Te Kōtahitanga have been woven through Rock and Water to produce a way of teaching and learning (pedagogy) that is culturally responsive. This may also fit within the ideas of Te Kōtahitanga as an attempt at a form of teaching and learning that is self deterministic. This in turn challenges some of the ideas reasons behind deficit theory.

On a wider scale, utilising Rock and Water as a space for negotiated, co-constructed learning might be a move from a mono-cultural style of learning towards a post colonial one. One in which the coloniser moves towards the colonised to mediate and construct new notions of learning - 'e'ngagement based around notions of social justice.

\section{In summary}

This study looked at how a specific programme improved the engagement of Māori and Pasifika boys with school. In the literature review chapter of this research, many researchers (Martino, Alton-Lee and Praat, Gill) suggested that the issue was not generic, that it was not a question of all boys' engagement and achievement at school but more an issue of which boys? 
In the context of this study the specific group of boys at risk of disengaging with school and therefore leaving at an earlier age or with a lack of formal qualifications were boys from Māori or Pasifika cultures. To delve into the factors surrounding this, an exploration of what was meant by engagement had to take place.

The term is a contested one. The term chosen and utilised for this study looked at the level of engagement Māori and Pasifika boys had with school. The evidence nationally suggests that Māori and Pacific boys are less likely to be engaged with school. This is illustrated in retention data, stand down and suspension rates and attainment (see chapter 2). This study found that as a consequence of participation in the programme Māori and Pasifika boys' engagement with school improved.

The factors influencing this improvement are varied, but an attempt to identify the boys as culturally located individuals, a willingness to embrace some of the values of Te Kôtahitanga and to move away from a mono-cultural form of pedagogy are evident in the findings.

Engagement by the participants was improved in a number of ways, the development of positive and respectful relationships within the Rock and Water programme were important. This was achieved through the recognition of connections based upon life outside of the classroom.

The use of this form of pedagogy has been identified by the Education Review Office as a form of best practice. They observed that

" better classroom relationships were developed when a teacher understood the wider interests of the boys, and where they had also worked with the boys in situations other than the classroom, such as involvement in a project" (Education Review Office, 2008, p. 26).

This was backed up by evidence from overseas where the link is made between improved engagement with school and academic achievement (Younger et al., 2006, p. 11). The term used there was 'key befrienders', the aim of these individuals was to develop relationships to 
"work with disengaged and challenging individual students, and who are credible, able to establish rapport, use persuasion and model non-stereotyping attitudes and behaviours" (OFSTED, 2008, p. 13).

How this is achieved is through the use of role models and a culturally responsive pedagogy. This embraces the values of Te Kōtahitanga and creates a ripple effect in the boys' lives. They are forced to confront their own values and stereotypes. Rock and Water uses activity and discussion to achieve this. In doing so it provides 'rich and interesting' experiences for the boys such as incorporating physical activity into their learning, the use of outdoor education programmes, and mentoring and peer support.

There are challenges to the use of this programme and one of the findings of this study is to look at how this programme could be expanded to other contexts (to other schools and other groups within schools). The data produced in this study is encouraging in terms of the impact of the programme on Pasifika boys but more research would have to be carried out, focussing up them as a discrete group. As ERO themselves report

"There are complex issues of male identity and role modelling connected to educational issues for Māori and Pacific Island boys."

Education Review Office(2008, p. 30).

The complexity comes from articulating

"What similarities and differences there are in becoming a young Māori of Pacific Island man and becoming a European/Pakeha Man?"

Education Review Office(2008, p. 30).

One way in which this is being approached in this study is to use capable Māori and Pasifika students as peer leaders (tuākana tēina) and role roles in the programme.

This research has focussed upon how engagement with school can be improved from participation in the Rock and Water programme for Māori and Pasifika boys. The implications from this study are that if engagement improves, achievement will also. This is 
an area for further study. There are some encouraging signs but the jury is still out. As ERO themselves report

“The diverse range of factors influencing boys' underachievement has resulted in a range of different perspectives and approaches and the ways to respond. Many are based on anecdotal or observational data and while they may be effective in a particular setting, the collection of evidence has not yet reached a point where teachers can be confident what will work in their class".

Education Review Office(2008, p. 6)

This study has not examined the challenge that is presented to the programme when personnel change or move on. The sustainability of the programme is currently being challenged as the teacher/facilitator participants in this study have since left the school. For the programme to have currency and increased validity within the school, new facilitators are being recruited and inducted into the programme. This shows a commitment by the school management to have the programme as part of the schools curriculum or kaupapa.

Finally, this research has contributed to the debate around the engagement of Māori and Pasifika boys in schools in New Zealand. More research has to be carried out to improve the life chances of these boys. It is too easy to dismiss the factors surrounding their disengagement and place it into the 'too hard' basket based around deficit theorising. It is not enough to pass the problem on. Educators and schools have to play their part in shaping a society that gives equal opportunities and expectations to all regardless of background, gender and ethnicity. 


\section{References}

Alton- Lee, A. (2003). Quality Teaching for Diverse Students in Schooling: Best Evidence Synthesis. In M. o. Education (Ed.). Wellington: Ministry Of Education.

Alton-Lee, A., \& Praat, A. (2000). Questionning Gender: Snapshots from Explaining and Addressing Gender Differences in the New Zealand Compulsory School Sector.

Andreissen, I., Phalet, K., \& Lens, W. (2006). Future goal setting, task motivation and learning of minority and non- minority students in Dutch schools. British journal of Educational Psychology, 76, 827-850.

Astin, A. W. (1993). What Matters in College: Four Critical Years Revisited. San Francisco: Jossey-Bass,.

Biddulph, S. (2003). Raising Boys; Why boys are different and how to help them become happy and well balanced men. Sydney: Finch publishing.

Bishop, R., Berryman, M., Cavanagh, T., \& Teddy, L. (2007). Te Kohaitanga Phase 3 (pp. 252). Wellington: Ministry of education.

Bishop, R., Berryman, M., Tiakiwai, S., \& Richardson, C. (2003). Te Kotahitanga: The experiences of year 9 and 10 Māori students in mainstream classrooms. Wellington: Ministry of Education.

Bishop, R., Berryman, M., \& Richardson, C. (2001). Te Toi Huarewa. Wellington.

Blum, R. W., \& Libbey, H. P. (2004). School Connectedness:Strenghthening health and educational outcomes for teenagers. Journal of School Health, 74(7), 229-299. 
Browne, R., \& Fletcher, R. (Eds.). (1995). Boys in Schools: Addressing the real issues. Behaviour, Values and Relationships (1st ed.). Sydney: Finch Publishing Pty Limited.

Cohen, L., Manion, L., \& Morrison, K. (2000). Research methods in education. London: RoutledgeFalmer.

Collins, C., Kenway, J., \& McLeod, J. (2000). Factors Influencing the Educational Performance of Males and Females in School and their Initial Destinations after School. . Adelaide: Deakin University Press.

Cook-Sather, A. (2006). Sound, presence and voice: 'Student voice' in ecucational research and reform. Curriculum Inquiry, 36, 361-390. doi: 10.1111/j.1467873X.2006.00363.X

Cottrell, M. (2010). Indigenous Education in Comparative Perspective: Global Opportunities for Reimagining Schools. International Journal for Cross-Disciplinary Subjects in Education (IJCDSE),, 1(4), 223-227.

Education, M. o. (Aug 2011). Retention of students in senior secondary schools. Wellington.

Education Review Office. (2008). Boys' Education:Good Practice in Secondary Schools (pp. 41). Wellington: Education Review Office.

Education Review Office. (2012). Improving Education Outcomes for Pacific Learners (pp. 20). Wellington: New Zealand Government.

Evans, B. F. (2011). Teaching practices that support high achievement in the education of pacific boys. Master of Education, Unitec Institute if technology. Retrieved from http://unitec.researchbank.ac.nz/handle/10652/1734

Fetterman, D. M. (Ed.). (1998). Handbook of applied social research methods. Thousand Oaks. C.A: Sage. 
Finn, J. D. (1989). Withdrawing from School. Review of Educational Research, 59(No 2), $117-142$.

Firestone, W. A. R., S. (1987). First year project: A study of alienation and commitment in five urban districts. American Educational research Association.

Fredericks, J. A., Blumenfeld, P., \& Paris, A. H. (2004). School Engagement : Potential of the concept, state of the evidence. Review of Educational Research, 74(1), 59-109.

Gay, G. (2000). Culturally responsive teaching. New York: Teachers College Press.

Gibbs, R., \& Poskitt, J. (2010). Student Engagement in the Middle Years of Schooling (Years 7-10), A Literature Review. Wellington: Education Counts.

Gill, Z. (2005). Boys: Getting it Right: The 'New' Disadvantaged or 'Disadvantage' Redefined? The Australian Educational Researcher, Volume 32(2), 105-124.

Graham, J., Meyer, L. H., McKenzie, L., McClure, J., \& Weir, K. F. (2010). Maori and Pacific secondary student and parent perspectives on achievement, motivation and NCEA. Assessment Matters, 2, 132-157.

Guba, E. G., \& Lincoln, Y. S. (1989). Fourth Generation Evaluation. Newbury Park, C.A: Sage Publications Ltd.

Gurian, M. (1998). A Fine young man: what parents, mentors and educators can do to shape adolescent boys into exceptional men. New York: Jeremy Tarcher/Putnam Publishing.

Hall, P. (1991). Forward to the Past: Africentric Rites of Passage. Paper presented at the 21st Conference on African American Males, Washington, DC. 
Hart, C. (2010). Doing a Literature Review:Releasing the Social Science Research Imagination. London: Sage Publications Ltd, 1 Olivers Yard, 55 City Road.

Hattie, J. (2003). Teachers make a Difference: What is the research evidence? Paper presented at the Australian Council for Educational Research Annual Conference.

Hawk, K., \& Hill, J. (2000). Towards making achieving cool: Achievement in Multi-cultural High Schools. In M. o. Education (Ed.). Albany: Massey University,.

House of Representatives. (2002). Boys: Getting it right. Canberra: Standing Committee for Education and Training

Husen, T. (Ed.). (1997). Research paradigms in education. Oxford: Pergamon.

Hynds, A., Sleeter, C., Hindle, R., Savage, C., Penetiro, W., \& Meyer, L. H. (2011). Te Kotahitanga:a case study of a repositioning approach to teacher professional development for culturally responsive pedagogies. Asia-Pacific Journal of Teacher Education, 39(4), 339-351. doi: http://dx.doi.org/10.1080/1359866X.2011.614684

Jimerson, S. R., Campos, E., \& Greif J, L. (2003). Towards an Understanding of Definitions and measures of School Engagement and Related Terms. Californian School Psychologist, 8, 7-27.

Johnson, B., \& Christensen, L. (2008). Educational Research:Quantitative, Qualitative and Mixed Approaches (Third ed.). London: Sage Publications Ltd.

Joselowsky, F. (2007). Youth engagement, high school reform and improved learning outcomes:building systemic approaches for youth engagement. National Association of Secondary school Principals Bulletin 91(3), 257-276.

Kaplan, A. (Ed.). (1973). The conduct of inquiry. Oxford: Pergamon. 
Lashlie, C. (2004). It's About Boys: The Good Man Project.

Loveridge, J. (2010). Involving Children and Young People in Research in Educational Settings. In M. o. Education (Ed.), (pp. 172). Wellington: Victoria University of Wellington, Jessie Hetherington Centre for Educational Research.

Martino, W. (2003). We just get really fired up:Indigenous boys, masculinites and schooling. Discourse:Studies in the Cultural Politics of education, 24(2), 159-174.

Martino, W., \& Berrill, D. (2003). Boys, Schooling and Masculinities: interrogating the 'Right' way to educate boys. Educational Review, 55(2), 99-117.

McMurchy-Pilkington, C. (2011). We are family:Maori success in foundation programmes. Higher Education Research \& Development, iFirst(2011), 1-14. doi: 10.1080/07294360.2011.643294

Ministry of Education. (2007a). Boys' Achievement. A Synthesis of the Data In Ministry Of Education (Ed.), (pp. 52). Wellington,: Learning policy frameworks, .

Ministry of Education. (2007b). A Report to Schools on New Zealand Student Engagement 2007. In K. Phillips (Ed.). Wellington.

Ministry Of Education. (2009a). Ka Hikitia: Managing for success: The maori education strategy, 2008-2012. Wellington: Ministry of Education.

Ministry Of Education. (2009b). Stand-downs from school, from http://www.educationcounts.govt.nz/indicators/data/student-engagementparticipation $/ 3720$

Ministry Of Education. (2011). Stand-downs, suspensions, exclusions and expulsions from school, from http://www.educationcounts.govt.nz/indicators/main/studentengagement-participation/80346 
Ministry Of Education. (2012). Decile ratings. NZ Education, from

http://www.minedu.govt.nz/NZEducation/EducationPolicies/Schools/SchoolOperatio ns/Resourcing/ResourcingHandbook/Chapter1/DecileRatings.aspx

Ministry of Education. (Aug 2011). Retention of students in senior secondary schools.

Retrieved from http://www.educationcounts.govt.nz/indicators/main/studentengagement-participation/1955

Ministry of Education. (Nov 2010a). Participation and Attainment of Pasifika students in National Certificate of Educational Achievement. 11. Retrieved from Schooling Analysis Pasifika Senior Secondary Students' Achievement, 2007-2009 website: http://www.educationcounts.govt.nz/_data/assets/pdf_file/0005/88592/FactsheetPasifika-2009_v2.pdf

Ministry Of Education. (Nov 2010b). Schooling Analysis Maori Senior Secondary Students' Achievement, 2007 -2009. 7. Retrieved from Participation and Attainment of Māori students in National

Certificate of Educational Achievement website: http://www.educationcounts.govt.nz/_data/assets/pdf_file/0006/88593/MaoriFactsheet.pdf

Munns, G., Arthur, L., Downes, T., Gregson, R., Power, A., Sawyer, W., . . Steele, F. (2005). Motivation and engagement of boys: Evidence-based teaching practise. In A. G. Q. T. Programme (Ed.), (pp. 110). Sydney: Australian Government Department of Education, Science and Training.

Munns, G., \& Parente, A. (2003). "Because I stayed": Australian Indegenous Secondary School Students who remain at High School. Paper presented at the NZARE AARE, Auckland. 
Newmann, F. M., \& Wehlage, G. (1993). Five standards of authentic instruction. Educational Leadership, 50(7), 8-12.

OECD/PISA. (2006). Equally prepared for life? How 15 year old boys and girls perform in schook (pp. 76): OECD.

OFSTED. (2003). Boys' achievement in secondary schools (pp. 58). London: Office for Standards in Education.

OFSTED. (2008). White boys from low-income backgrounds: good practice in schools (pp. 17). London: Office for Standards in Education.

Pascarella, E. T., \& Terenzini, P. T. (1991). How College Affects Students. San Francisco: Jossey-Bass,.

Pittman, K., Irby, M., Tolman, J., Yohalem, N., \& Ferber, T. (2003). Preventing problems, promoting development, encouraging engagement: Competing priorities of inseperable goals. Washington DC: Forum for Youth Investment.

Pratt, M., L. (1991). Arts of Contact Zone. Profession, 33-40.

Reckless, W. C. (1961). A new theory of delinquency and crime. Federal Probation, 25(December), 42-46.

Suaalii, T. M., \& Mavoa, H. (2001). Who says yes? Collective and individual framing of Pacific children's consent to, and participation in, research in New Zealand. Childrenz Issues - Journal of the Children's Issues Centre, 5(1), 39-42.

Te Awekotuku, N., \& Maori, M. (1991). He Tikanaga Whakaro, Research Ethics in the Maori Community. Wellington: Manatu Maori. 
Tuhiwai-Smith, L. (1999). Decolonizing methodologies: Research and indigenous people. Dunedin: University of Otago Press.

Tupouniua, S., Crocombe, R. G., \& Slatter, C. (1975). The Pacific way : social issues in national development. Suva: South Pacific Social Sciences Association.

Van Gennep, A. (1908). Les rites de passage. London E.C 4: Routledge and kegan paul.

Weber, M. (1968). Economy and society. New York: Bedminster.

Ykema, F. (2000). Rock and Water, Skills for physical-social teaching with boys. Schagen, Netherlands: Gaduku Institute.

Yonezawa, S., Jones, M., \& Joselowsky, F. (2009). Youth Engagement in High Schools:Developing a multidimensional, critical approach to improving engagement for all students. Journal for Educational Change.

Younger, M., \& Warrington, M. (2005). Raising boys' achievement in secondary schools. Issues, Dilemmas and Opportunities Shoppenhangers rd, Maidenhead, Berkshire SL6 2QL: Open University Press.

Younger, M., Warrington, M., Gray, J., Ruddock, J., McLellan, R., Bearne, E., . . Bricheno, P. (2006). Raising boys' achievment: University of Cambridge Faculty of Education. 
Appendix Contents

Appendix 2: Interview questions (students).

Pg. 125

Appendix 2a: Facilitator A, semi structured interview questions .

Pg.126

Appendix 2b: Facilitator B, semi structured interview questions .

Pg.129

Appendix 3: Questionnaire

Pg.131

Appendix 4: NVIVO tree map showing frequency of Nodes encoded .

$\operatorname{Pg} .134$

Appendix 4a: Table of encoded Nodes with frequency of reference .

Pg.135

Appendix 5: Rock and Water Haka.

Pg.136 
Appendix 2: Interview questions

Interview questions (students)

1. Describe a rock and water session? (what happens)

2. Why is the salute important (what does it represent)?

3. Who takes part?

4. What do you get out of the sessions?

5. What is the coolest thing you've done in rock and water?

6. Why?

7. Can you give me an example of how rock and water has worked for you?

8. Do you feel more connected with the school?

9. Do you think R \& W makes you more a part of Mana?

10. Describe a discussion session

What are the themes?

Who speaks?

What do you learn?

11. Does R \& W help you around school?

12. Do you look forward to sessions?

13. What is the importance of relationships in $\mathrm{R} \& \mathrm{~W}$ ?

14. How do they work (Student/student teacher/student)

15. Do you feel respected in Rock and water?

16. What does respect mean to you?

17. Are you opinions heard in the group?

18. Can you give me an example when you have expressed your opinion in the group?

19. Can you give me an example when you have used rock and water?

20. How did it help you?

21. Do you feel part of the group?

22. What do you think rock and water is for?

23. Why are you in the group? 
Appendix 2A: Facilitator A, Semi-structured Interview Questions

- You mentioned in your questionnaire the haka, How important is the Haka in R \& W?

- there is a term that has been put forward by Prof Bishop and the term is culturally responsive pedagogy and basically what that means is you recognise and celebrate the cultures of the students that you've got in front of you, em so we've spoken a little about the haka, so how are the cultures embraced and recognised in R \& W?

- You mentioned in your questionnaire about brotherhood. Why do you think this is significant in R \& W?

- Maybe I can prompt you a little bit, Brotherhood between who?

- So some people think that or suggest that programmes such as R \& W exert a form of social control on the students, so put boundaries around them and allow them to push up against those boundaries. How much influence do you think schools in general can exert on students?

- So what about the relationships in $\mathrm{r} \& \mathrm{w}$, How are they constructed, how do they play out?

- How important are the metaphors, the analogies in the sessions that you have in R \& W sessions?

- Do you think that they are more important to Maori and Pacific students?

- So in your experience of working with the rock and water group, would you agree that boys are contextual learners? That they learn concepts in context?

- So how do you think the skills being learnt or taught in $\mathrm{R} \& \mathrm{w}$ are being transferred?

- So Te Kotahitanga which means the idea of unity, we're all in this together, has the concept of Ako- shared or reciprocal learning woven through it, that's one of the cornerstones of the initiative and what i'm trying to say is that in $\mathrm{R} \& \mathrm{~W}$, first of all does that process take place and secondly do you think using analogy and metaphor and contextual learning ....are these vehicles through which the Ako takes place?

- In the questionnaire, you speak of connectedness, connectedness to what?

- In your questionnaire you talk of a change in the boys from when they started R \& W to the current point, can you give me an example of that?

- You mention about positive and supportive language, what specifically do you mean? 
- One of the questions asks about how the teaching is shared between students and facilitators and you mention how Tuakana had been identified and brought in to help in the planning of sessions. So my question refers to that, how much influence do students have in the planning process?

- So my next series of questions are to do with outcomes from R \& W, and also to do with the sections. so would you like to see a more measurable outcome from the programme say a granting of credits, some award given to students?

- So when you talk about the essence of it, how do you think the culture of it or of the $\mathrm{R} \& \mathrm{~W}$ group has been used to improve student engagement with school?

- So why do you think some people see R \& W as an outdoor activity club?

- Do you think the model that's been followed at Mana, do you think this a model for other schools to buy into or to tap into?

- I suppose the question I'm asking is where do you see R \& W sitting in the curriculum? Do you see it in PE, Do you see it in Guidance? Do you see it in mainstream? Where do you see it?

- Do you think the way in which students are recruited into it, do you think that should be tightened up? when you was at Mana, what was the process?

- Are you familiar with the idea of defecit theory?

- Do you think this is unique to Maori and PI students

- Is Rock and Water a vehicle for breaking down those barriers?

- So how is the layout of the R \& W group different to the traditional classroom?

- So do you think the students come into the R \& W Forum/area do they feel welcomed? Do you think this represents the Fale or the Marae?

- So a culturally responsive pedagogy then? 
Appendix 2B: Facilitator B Semi-structured interview questions

- How important is the haka in $\mathrm{R} \& \mathrm{~W}$ ?

- So would it be fair to say the haka is recognising the culture of the students in the group and relating it to the philosophy of $\mathrm{R} \& \mathrm{~W}$ ?

- Now in R \& W stories and metaphors and analogies are used quite a lot. How important are they?

- So in R \& W sharing or Ako is a big component, whether that's sharing time, sharing resources, sharing stories. How do you think that improves the relationships between student to student, student to teacher, teacher to teacher?

- Is that a move away from what I'd call a traditional, European or Pakeha view of education? The relationship the teacher has with the student. So in the European context, the teacher is the one with the knowledge, the one with the authority and some societies the one with the power? In front of the class, whereas in R \& W - a different relationship is developing

- So there's more fluidity to the role?

- So what do you think has been the impact that R \& W has had on our student's engagement with the school?

- Is it just purely about the relationships or have you seen a change or improvement in engagement i.e. getting to classes, getting to school, you know attitude around the school, attitude to learning?

- In your questionnaire, you mention that the tuākana bring some activities to the sessions, can you think of activities that students have brought, that we've used?

- In the sessions, the space that we use in $\mathrm{R} \& \mathrm{~W}$ is different to the traditional classrooms em for example the traditional classroom has the tables and chairs laid out in a particular way, the white board in a particular place, in $\mathrm{R} \mathrm{\&} \mathrm{W}$ we make use of a circle and we don't use chairs and the shoes and socks are off. How important is the environment or the setting is to $\mathrm{R} \& \mathrm{~W}$ ?

- Is it too much for me to say that it might be or reflect the layout or structure inside the Marae or inside the Fale? 
- And the shoes off in the Marae and the shoes and socks of in R \& W, what's the significance of shoes off in the Marae?

- Discussion is a big part of $\mathrm{R} \& \mathrm{~W}$, activities are very strong, but discussion and talking through a situation, that's quite a big part of $\mathrm{R} \& \mathrm{~W}$ isn't it?

- You mentioned about control a few times in your questionnaire, do you think the purpose of $\mathrm{R} \& \mathrm{~W}$ is about teaching control to the boys?

- So there's an argument that boys learn in context, so they learn things when they need them to get them over a particular hurdle, contextual learning. How is that done in $\mathrm{R}$ $\& \mathrm{~W}$ ? How do we go about that?

- You mentioned quite a lot about the Maori tikanga that goes on in the sessions, do you think that the things that we do are the same for Pacific island students?

- So do you think for boys in general, $\mathrm{R} \& \mathrm{~W}$ is creating a space where the boys can celebrate and they can identify with, articulate and talk about their culture

- My next question talks about how R \& W could be part of the schools Kaupapa, do you think because we only have the boys for $1-2 \mathrm{hrs}$ a week. There's a space for R \& W within the whole school? Say within the wider curriculum?

- Do you think R \& W should have a measurable outcome, emm. Should the students get a ... some credits for completing a terms worth of work, could there be an award, em.. or should there be some performance maybe, a graduation ceremony, that students should get involved in?

- So the journey the student has been on?

- Facilitator A was talking about the impact that R \& W had upon him, particularly when he left the school and when the poroporoaki was taking place and the acknowledgement that was given to him from the boys, he said that was really powerful, so how do you feel about your experience within R \& W? Is it something you're going to take on with you?

- So it's a bit like 'walking the talk' eh? 
Appendix 3: Questionnaire

\section{Rock and Water Programme Questionnaire}

\section{School engagement}

Q1. Using the scale below, how would you rate school?

\begin{tabular}{|l|l|l|l|l|}
\hline 1 Like it a lot & 2 Like it a bit & $\begin{array}{l}\text { 3 Neither like nor } \\
\text { dislike }\end{array}$ & $\begin{array}{l}\text { 4 don't like it at } \\
\text { times }\end{array}$ & $\begin{array}{l}\text { 5 Really don't } \\
\text { like it }\end{array}$ \\
\hline & & & & \\
\hline
\end{tabular}

Q2. Tick the box which best describes how you feel about school?

The word engagement means to occupy your attention or your efforts

On a scale of $1-5$ how engaged do you feel at school

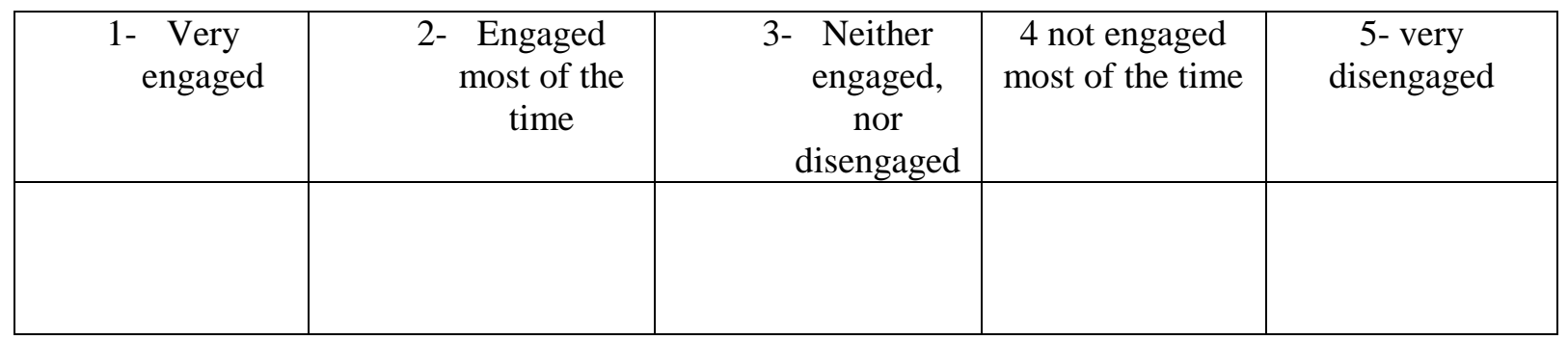

Q3. What do most enjoy abut school?

Q4. What do you dislike about school?

Q5. How important are the teachers at school?

\begin{tabular}{|l|l|l|l|l|}
\hline Very unimportant & $\begin{array}{l}\text { A little bit } \\
\text { important }\end{array}$ & $\begin{array}{l}\text { Neither important } \\
\text { nor unimportant. }\end{array}$ & $\begin{array}{l}\text { A little bit } \\
\text { unimportant }\end{array}$ & Very Important \\
\hline & & & & \\
\hline
\end{tabular}

Q6. What qualities make a good school day for you? 


\section{Participation in school}

Q7. Do you take part in any after school/extra-curricular activities?

\begin{tabular}{|l|l|}
\hline Yes & No \\
\hline & \\
& \\
\hline
\end{tabular}

Q8. Which ones?

\begin{tabular}{|l|l|l|l|l|l|}
\hline Sports (name) & $\begin{array}{l}\text { Achievement } \\
\text { centre }\end{array}$ & $\begin{array}{l}\text { Cultural group } \\
\text { (Name) }\end{array}$ & $\begin{array}{l}\text { Boys } \\
\text { Achievement } \\
\text { group }\end{array}$ & $\begin{array}{l}\text { Rock and } \\
\text { Water }\end{array}$ & Other \\
\hline & & & & & \\
\hline
\end{tabular}

Q9. Why do you choose to take part?

Q10. Why did you get involved in Rock and water?

\begin{tabular}{|l|l|l|l|l|}
\hline $\begin{array}{l}\text { Heard from } \\
\text { friends }\end{array}$ & Referred by staff & $\begin{array}{l}\text { Tried it before } \\
\text { (e.g. Intermediate) }\end{array}$ & Time out of class & Other \\
\hline & & & & \\
& & & & \\
\hline
\end{tabular}

Q11. Do you like being part of this group?

\begin{tabular}{|l|l|l|}
\hline Yes & No & Not bothered \\
\hline & & \\
\hline
\end{tabular}


Q12. Can you describe the things you enjoy about the Rock and Water Programme?

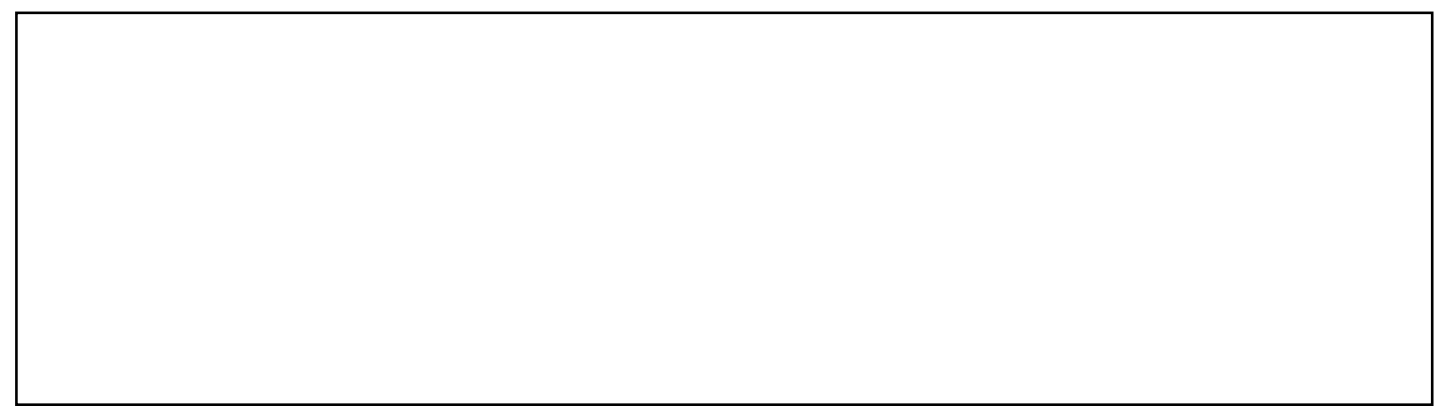

Q13. Has Rock and water had an effect on you around school?

\begin{tabular}{|l|l|l|}
\hline Yes & No & Not Sure \\
\hline & & \\
& & \\
\hline
\end{tabular}

Q14. If Rock and Water has had an effect on you around school, how have you used it? 
Appendix 4: NVIVO 9 Tree map showing frequency of themes (nodes) in interviews

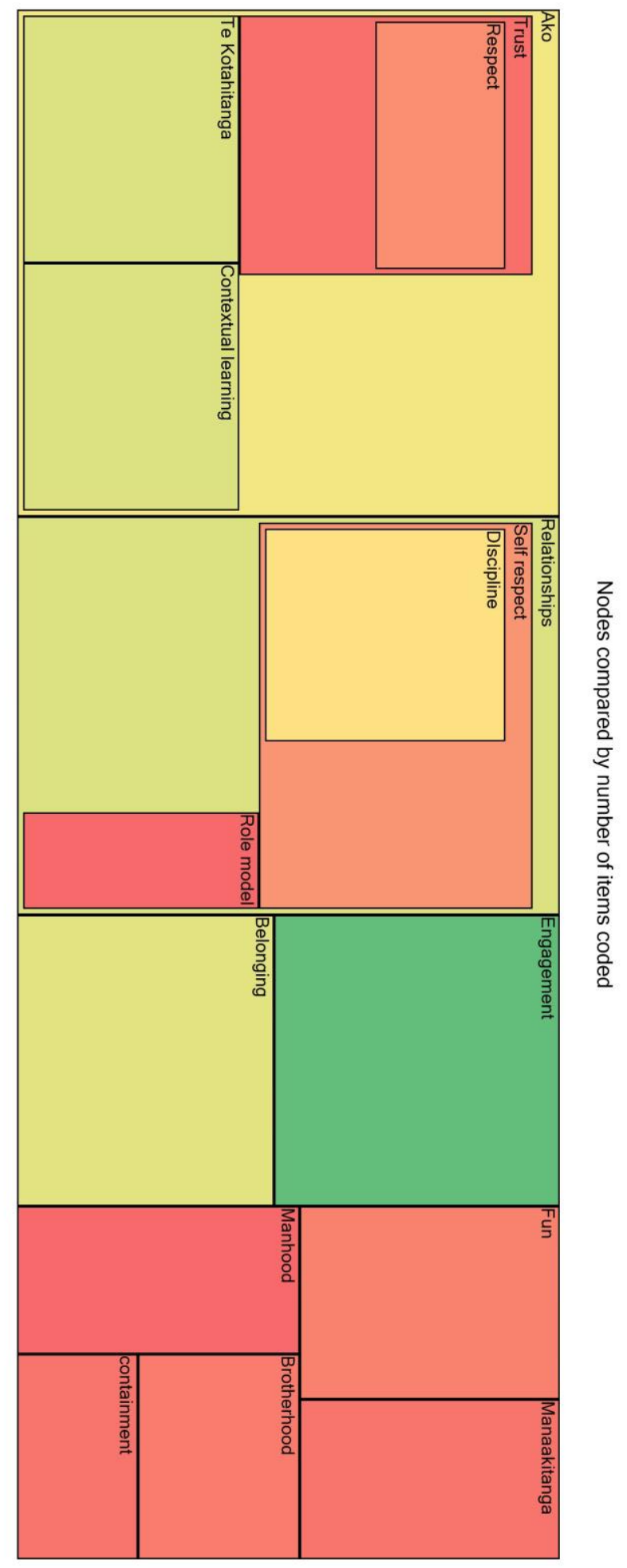


Appendix 4a table showing nodes compared by number of references

\begin{tabular}{|c|c|c|}
\hline Nodes & $\begin{array}{l}\text { Number of coding } \\
\text { references }\end{array}$ & $\begin{array}{l}\text { Number of items } \\
\text { coded }\end{array}$ \\
\hline NodesIVAko & (2) & 9 \\
\hline NodesIVAkolContextual learning & 30 & 7 \\
\hline NodesI\AkolTe Kōtahitanga & 30 & 7 \\
\hline NodesI\AkolTrust & 6 & 5 \\
\hline NodesIVAkolTrustlRespect & 11 & 5 \\
\hline Nodes|lBelonging & 29 & 9 \\
\hline Nodes IIBrotherhood & 8 & 4 \\
\hline Nodes Ilcontainment & 7 & 3 \\
\hline Nodes|lEngagement & 46 & 10 \\
\hline NodesIIEngagementlConnectedness & 8 & 5 \\
\hline NodesIIFun & 9 & 6 \\
\hline Nodes|lManaakitanga & 7 & 5 \\
\hline NodesIIManhood & 5 & 5 \\
\hline Nodes|lRelationships & 30 & 9 \\
\hline Nodes|IRelationships\Role model & 5 & 3 \\
\hline NodesIIRelationshipsISelf respect & 12 & 6 \\
\hline Nodes IIRelationships ISelf respect|Discipline & 24 & 8 \\
\hline
\end{tabular}

Source: Nivio 9: G:\study2011\Datacollection\Rockandwaterprogrammeandboys engagementmaster.nvp 
Appendix 5: Rock and Water Haka

Kia whakanga hoki au I ahau hi aue hi (Go into the body of my warrior ancestor)

Ringa Maui motomoto (Left hand clenched fist)

Kia Tata mai ki te Manawa ( Bring it close to the heart)

He tohu whakakaha wahakpingore (Sign of strength and inflexibility)

He tikaro atu e to maia (To defend and stand up for myself)

E anga anga ki whea (show I know which way to go)

Ringa matau wherawherahia ringa hariru (The right hand is an open hand which you use to handshake)

Ringa matau tuku atu tuku mai (You receive and give with this hand)

Ringa matau he tohu marie, whakarata, manamotuhake, me te whakapaapaatanga (The right hand represents peace, friendship, solidarity and communication)

Hipohipokina ringa motomoto kohatu (Cover the rock fist)

Ko te mea nui manamotuhake whakahoatanga (Main intention being solidarity and friendship)

Ko enei nga mataapono a te roopu kohatu me te wai whakaute e hi (These are the principles of the rock and water, respect)

Source: Todd Parata (Kaitito), (Ngati Wai, Ngati Hine, Te Waiariki, Ngati Marutuahu, Ngati Koroki, Ngai te rangi, Ngati Pukenga, Ngati Ranginui)

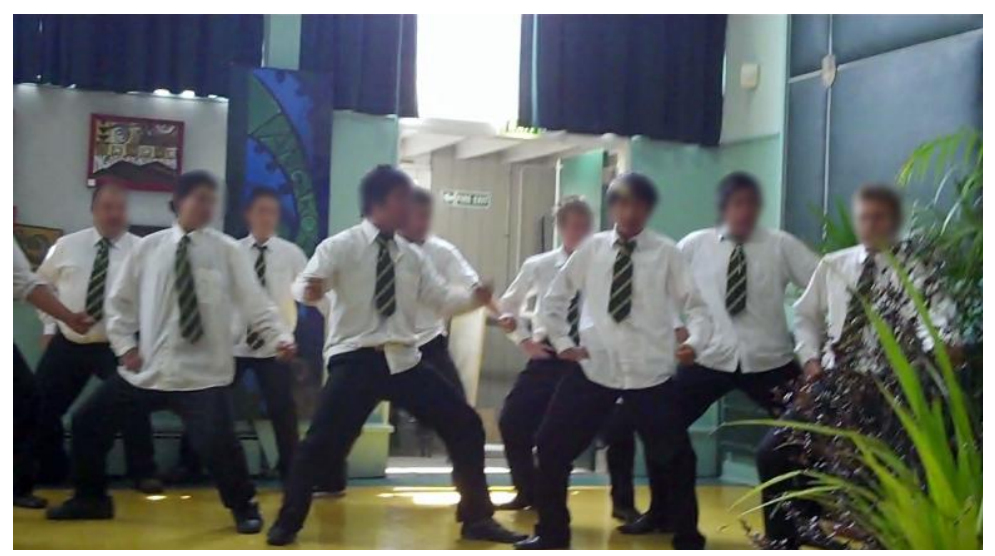

